UNIVERSIDADE DE SÃO PAULO

ESCOLA DE ENFERMAGEM

BERNARDETE WEBER

TRADUÇÃO, ADAPTAÇÃO TRANSCULTURAL E VALIDAÇÃO DO MÉTODO INTERMED PARA A LÍNGUA PORTUGUESA: ESTUDO EM PACIENTES HOSPITALIZADOS 


\section{TRADUÇÃO, ADAPTAÇÃO TRANSCULTURAL E VALIDAÇÃO DO MÉTODO INTERMED PARA A LÍNGUA PORTUGUESA: ESTUDO EM PACIENTES HOSPITALIZADOS}

Tese apresentada ao Programa de Pós-Graduação em Gerenciamento em Enfermagem da Escola de Enfermagem da Universidade de São Paulo para obtenção do título de Doutor em Ciências.

Área de concentração:

Fundamentos e Práticas de Gerenciamento em Enfermagem e em Saúde

Orientadora:

Prof ${ }^{a}$. Dra ${ }^{a}$. Maria Helena Trench Ciampone 
AUTORIZO A REPRODUÇÃO E DIVULGAÇÃO TOTAL OU PARCIAL DESTE TRABALHO, POR QUALQUER MEIO CONVENCIONAL OU ELETRÔNICO, PARA FINS DE ESTUDO E PESQUISA, DESDE QUE CITADA A FONTE.

Assinatura:

Data:

Catalogação na Publicação (CIP)

Biblioteca "Wanda de Aguiar Horta"

Escola de Enfermagem da Universidade de São Paulo

Weber, Bernardete

Tradução, adaptação transcultural e validação do método INTERMED para a língua portuguesa: estudo em pacientes hospitalizados / Bernadete Weber. --

São Paulo, 2012.

$175 \mathrm{p}$.

Tese (Doutorado) - Escola de Enfermagem da Universidade de São Paulo.

Orientadora: $\operatorname{Prof}^{\mathrm{a}} \mathrm{Dr}^{\mathrm{a}}$ Maria Helena Trench Ciampone

Área de concentração: Fundamentos e práticas de gerenciamento em enfermagem e em saúde

1. Hospitalização 2. Pacientes internados 3. Administração dos cuidados ao paciente 4. Qualidade dos cuidados de saúde I. Título. 


\section{FOLHA DE APROVAÇÃO}

Nome: Bernardete Weber

Titulo: Tradução, adaptação transcultural e validação do método INTERMED para a língua portuguesa: estudo em pacientes hospitalizados.

Tese apresentada ao Programa de Pós-Graduação em Gerenciamento em Enfermagem da Escola de Enfermagem da Universidade de São Paulo para obtenção do título de Doutor em Ciências.

Aprovado em:

\section{Banca Examinadora}

Prof. Dr.

Julgamento:

Prof. Dr.

Julgamento:

Prof. Dr.

Julgamento:

Prof. Dr.

Julgamento:

Prof. Dr.

Julgamento:
Instituição:

Assinatura:

Instituição:

Assinatura:

Instituição:

Assinatura:

Instituição:

Assinatura:

Instituição:

Assinatura: 
Llos meus pais, que me ensinaram o valor do estudo.

Alos meus filhos Daula e CKauro, meu bem maior. 


\section{AGRADECIMENTOS}

À Profa Dr $^{a}$ Maria Helena Trench Ciampone, que com toda sabedoria me orientou com a propriedade de uma grande mestra,

À Profa $\operatorname{Dr}^{a}$ Beatriz Aparecida Ozello Gutierrez, através de quem conheci o INTERMED,

À Profa. Dra Marina Peduzzi pela pertinência das sugestões no exame de qualificação,

À $\mathcal{D r}^{a}$ Adriana Carvalhal, pelo apoio e atenção,

A Flávia Renata Fratezi, incansável colaboradora,

A Alexandre Biasi, Ana Paula Curi, Armando De Negri Filho, Enilda Maria de Souza Lara, Fumico Sonoda, Maria Bernadete Tanganelli Piotto, Renério Fraguas Junior, Silvia Maria Curi Ismael e Simone Kelly $\mathcal{N} i k$ lis pelas importantes contribuições,

A Jeane Roza Quintans, Kátia Cristina Leite, Leonel de Ramos, Lucélia Ferreira Lima, Juliana Soraya Zanelato, Graziele Garcia Pires de Campos e Clézio Souto de Oliveira pela colaboração na coleta de dados,

A Ana Cristina Rossetti, Elivane Silva Victor, Erica Aranha Suzumura, Juliana Trench Ciampone e Mabel Fernandes Figueiró pelo apoio,

Ao Instituto de Ensino e Pesquisa do Hospital do Coração, aos gerentes de enfermagem è à equipe de enfermagem pela colaboração,

Ao Hospital Universitário da Universidade de São Paulo e Hospital Municipal Dr. Moysés Deutsch pela possibilidade de desenvolvimento dessa pesquisa,

Ao Ministério da Saúde, pela contribuição e financiamento a essa pesquisa,

Aos pacientes, que tornaram possivvel a realização desse trabalho,

À minha família, pelo estímulo e confiança. 
Weber B. Tradução, adaptação transcultural e validação do método INTERMED para a língua portuguesa: estudo em pacientes hospitalizados [tese]. São Paulo: Escola de Enfermagem, Universidade de São Paulo; 2012.

\section{RESUMO}

O método INTERMED é um instrumento que classifica a complexidade biopsicossocial de pacientes em diversos níveis de assistência, qualifica o cuidado e melhora a comunicação interprofissional. Ele permite avaliar a complexidade do paciente através da investigação de quatro domínios: biológico, psicológico, social e sistema de saúde. Promove o cuidado integrado com foco no paciente e viabiliza práticas de gestão da clínica e de leitos hospitalares. O objetivo principal desta pesquisa foi realizar a tradução, adaptação transcultural e validação do método INTERMED para realidade hospitalar brasileira. Os objetivos secundários foram avaliar a consistência interna do método, estudar a interface dos resultados do INTERMED com dados sociodemográficos e verificar sua contribuição no gerenciamento de leitos hospitalares e gestão da clínica. $O$ instrumento foi aplicado a um total de 300 pacientes, com mais de 5 dias de internação hospitalar, com idade $\geq$ a 21 anos e média de idade de 57,8 anos, sendo que $58,3 \%$ eram do sexo masculino. Esta amostra foi coletada entre setembro e dezembro de 2011 em três hospitais da cidade de São Paulo, a saber, um privado (A), um de ensino (B) e um público (C). A validação e adaptação transcultural ocorreram em cinco fases: tradução, síntese, retrotradução, avaliação e validação por um comitê de juízes e pré-teste. A validação da tradução pelo comitê de juízes foi realizada pelo Índice de Validade de Conteúdo e a consistência interna do instrumento foi avaliada pelo coeficiente alpha de Crombach. A estrutura do documento foi estudada pelo Coeficiente de Correlação de Spearman e a validade preditiva para tempo de internação, pela relação entre a pontuação total do score do INTERMED e o tempo de hospitalização dos pacientes. A validação da tradução foi de $94,2 \%$ de equivalência semântica, $94,3 \%$ equivalência idiomática e $86,6 \%$ de equivalência cultural entre $\mathrm{o}$ instrumento original e o traduzido. No pré-teste, obteve-se acima de $90 \%$ de compreensão em todos os itens do INTERMED. Os scores médios obtidos com o INTERMED foram de 15, 20 e 21 nas instituições A, B e C respectivamente. Isto significa, pela classificação, do instrumento, que nas três instituições os pacientes não eram complexos (<21 pontos). A consistência interna e precisão do instrumento foram consideradas boas para as três instituições. As correlações entre os domínios do instrumento foram positivas e significantes em sua maioria. Em relação à validade preditiva, tempos maiores de internação foram observados em pacientes com escores maiores. Os dados encontrados sugerem que para além da gravidade biológica, o tempo de internação pode estar relacionado aos aspectos psicológicos, sociais ou do sistema de saúde, como a espera para realização de procedimentos. A versão brasileira do INTERMED possui equivalência com o instrumento original; é confiável, uma vez que os itens do instrumento relacionamse e são complementares entre si; é válida, pois é capaz de medir o objeto ao qual se propõe. Assim, recomenda-se sua incorporação como uma ferramenta de apoio a gestão de leitos e ao cuidado integral do paciente.

Palavras-chave: Gestão hospitalar. Gestão de leitos. Gestão da clínica. Gestão interprofissional da assistência. Cuidado integrado. INTERMED. 
Weber B. Translation, cross-cultural adaptation and validation of the INTERMED method to the Portuguese language: study involving inpatients [thesis]. São Paulo: São Paulo: Nursing School, São Paulo University, 2012

\begin{abstract}
The INTERMED method is an instrument that classifies the biopsychosocial complexity of patients under various levels of healthcare. It also qualifies care and improves interprofessional communication. It also allows us to evaluate patient's complexity by means of the investigation of four domains: biological, psychological, social and healthcare. Apart from that, it promotes integrated care by focusing on the patient and by enabling clinical management practices and the availability of hospital beds. The main objective of this research was to translate, transculturally adapt and validate the INTERMED method to the Brazilian health system reality. As a secondary objective, INTERMED aimed at evaluating the internal consistency of the method by studying the interface of the INTERMED results along with sociodemographic data and by verifying its contribution to the availability of hospital beds and clinical management. That instrument was applied to a total of 300 inpatients who had been at hospital for more than 5 days. All of them were 21 years old or more and the average age was 57,8 years old, being $58,3 \%$ male patients. That sample was collected between September and December 2011 at three hospitals in São Paulo, being one private (A), one university hospital (B) and one public hospital $(C)$. The validation and transcultural adaptation occurred on five stages: translation, synthesis, back-translation, evaluation and validation by a committee of judges and pre-test. The validation of the translation by the committee of judges was carried out by using the Content Validity Index and the internal consistency of the instrument was evaluated by the alpha Crombach coefficient. The structure of the document was studied by using the Spearman correlation coefficient and the predictive validity for length of stay was evaluated by the ratio between the INTERMED total score and the patients' length of stay. The validation of the translation reached $94,2 \%$ of semantic equivalence, $94,3 \%$ of language equivalence and $86,6 \%$ of cultural equivalence when the original and the translated document were compared. During pre-test phase, more than $50 \%$ of comprehension was achieved in all INTERMED items. The average scores achieved by INTERMED were 15,20 and 21 at institutions A, B and C, respectively. It means that according to the classification of the instrument at the three institutions patients were not considered complex (<21 points). The internal consistency and the accuracy of the instrument were regarded as good for the three institutions. In general, the correlation among the domains of the instrument were positive and significant. As regards the predictive validity, longer lengths of stay were observed in patients with higher scores. The data found suggest that besides the biological seriousness, the length of stay may be related to psychological or social aspects or even to the health system in which the time patients wait for procedures may be long. The Brazilian version of INTERMED is equivalent to the original; it is reliable, since its items relate to each other and are complementary among themselves; it is valid, on the grounds that it is able to measure the object it is intended to. Having said that, its use is recommendable as a tool to support the patient's integrated care management as well as the availability of hospital beds.
\end{abstract}

KEY-WORS: Hospital management. Beds management. Clinical management. Interprofessional management care. Integrated care. INTERMED. 


\section{LISTA DE ILUSTRAÇÕES}

Figura 1 - Diferenças entre condições agudas crônicas de saúde ......23

Figura 2 - $\quad$ Operacionalização do estudo, São Paulo - 2012.................51

Figura 3 - $\quad$ Instrumento para avaliação dos juízes, São Paulo 2012

Figura 4 - V Variáveis do INTERMED, São Paulo - 2012 ......................55

Figura 5 - Informações coletadas nos domínios do INTERMED, São Paulo - 2012

Figura 6 - $\quad$ Principais diferenças entre as duas traduções do INTERMED, São Paulo - 2012

Figura 7 - Equivalência semântica entre a versão traduzida e a original avaliada pelos juízes, São Paulo - 2012

Figura 8 - Equivalência idiomática entre a versão traduzida e a original avaliada pelos juízes, São Paulo - 2012

Figura 9 - $\quad$ Equivalência semântica entre a versão traduzida e a original avaliada pelos juízes, São Paulo - 2012 .68

Figura 10 - Relação entre pontuação geral no escore INTERMED e tempo de internação, São Paulo - 2012 .80

Figura 11 - Relação entre pontuação geral no escore INTERMED e tempo de internação na instituição A, São Paulo - 2012 ....81

Figura 12 - Relação entre pontuação geral no escore INTERMED e tempo de internação na instituição B, São Paulo - 2012 .....81

Figura 13 - Relação entre pontuação geral no escore INTERMED e tempo de internação na instituição C, São Paulo - 2012 .....82 


\section{LISTA DE TABELAS}

Tabela 1 - Medidas de concordância entre os Juízes, São Paulo 2012 .66

Tabela 2 - Características sociodemográficas da amostra, São Paulo - 2012 .71

Tabela 3 - Hipóteses diagnósticas e diagnósticos de alta, São Paulo - 2012 .72

Tabela 4 - Respostas obtidas no domínio biológico, São Paulo 2012 74

Tabela 5 - Respostas obtidas no domínio psicológico, São Paulo 2012. .75

Tabela 6 - Respostas obtidas no domínio social, São Paulo - 2012.....76

Tabela 7 - Respostas obtidas no domínio sistema de saúde, São Paulo - 2012 .77

Tabela 8 - Descrição dos escores obtidos e avaliação da consistência interna do INTERMED, São Paulo - 2012.......78

Tabela 9 - Correlação entre os escores dos domínios, São Paulo 2012

Tabela 10 - Relação entre pontuação geral no escore INTERMED e tempo de internação, São Paulo - 2012

Tabela 12 - Relação entre escolaridade e pontuação INTERMED, São Paulo - 2012 .84

Tabela 13 - Relação entre renda e pontuação INTERMED, São Paulo - 2012 .85

Tabela 14 - Relação entre religião e pontuação INTERMED, São 
Paulo - 2012

.86

Tabela 15 - Relação entre importância da religião e pontuação INTERMED, São Paulo - 2012

Tabela 16 - Relação entre autoavaliação do estado de saúde e pontuação INTERMED, São Paulo - 2012

Tabela 17 - Relação entre sintomas psicológicos e autoavaliação do estado de saúde, São Paulo - 2012 .88

Tabela 18 - Relação entre coordenação do cuidado e renda, São Paulo - 2012 .89

Tabela 19 - Relação entre coordenação do cuidado e escolaridade, São Paulo - 2012 .90 


\section{SUMÁRIO}

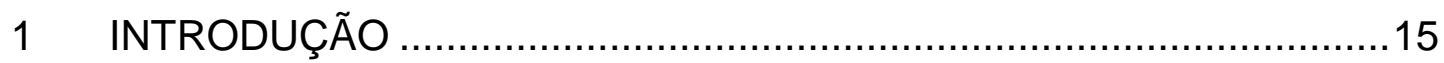

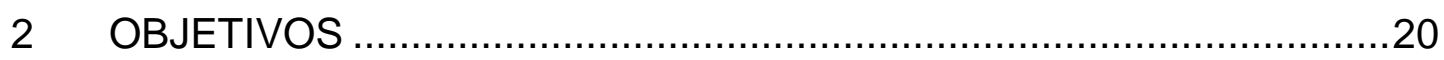

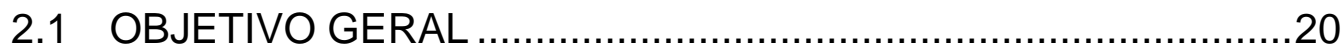

2.2 OBJETIVOS ESPECÍFICOS .....................................................20

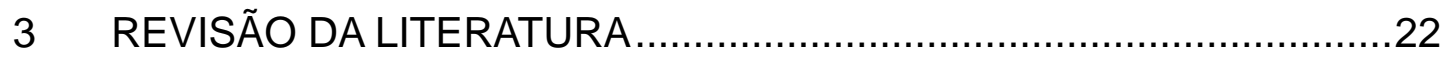

3.1 A SITUAÇÃO DE SAÚDE E OS SERVIÇOS DE SAÚDE .............22

3.2 TENDÊNCIAS AO ENVELHECIMENTO E REDUÇÃO DA

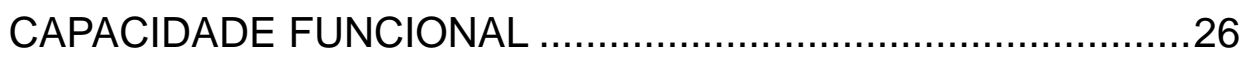

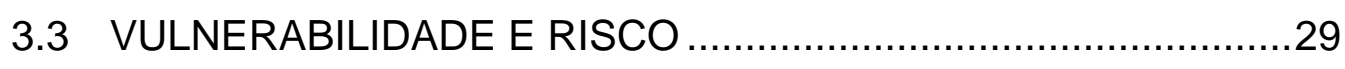

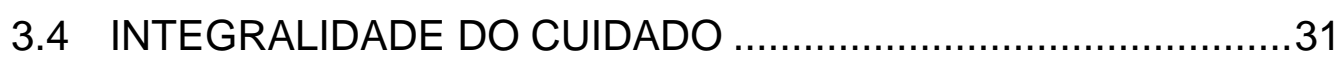

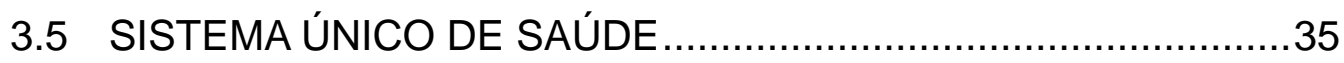

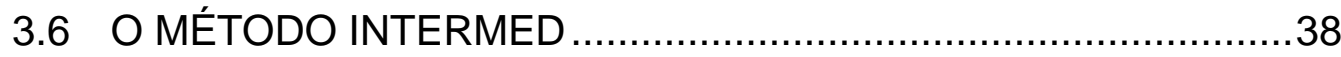

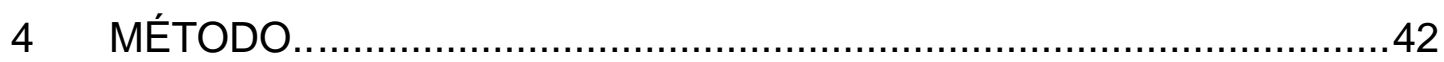

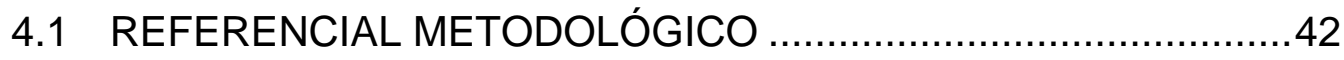

4.1.1 O processo de tradução e adaptação transcultural ..........42

4.1.2 O processo de validação ....................................................4

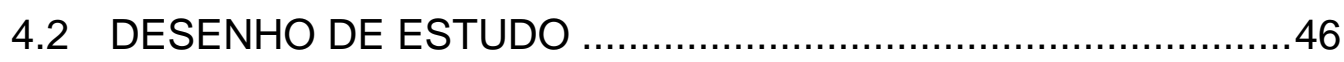

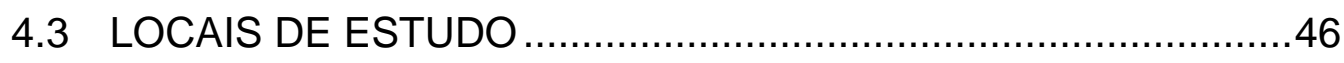

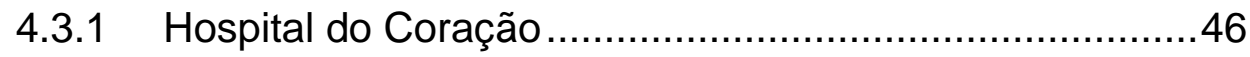

4.3.2 Hospital Universitário da Universidade de São Paulo .....48

4.3.3 Hospital Municipal Dr. Moysés Deutsch ............................49

4.4 FASES DA PESQUISA E PROCEDIMENTOS

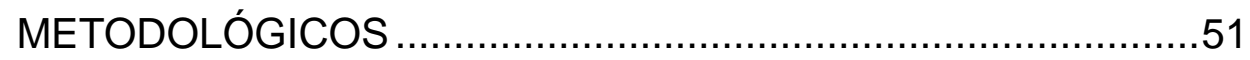

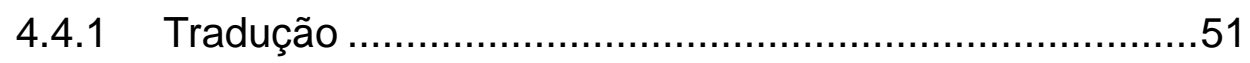

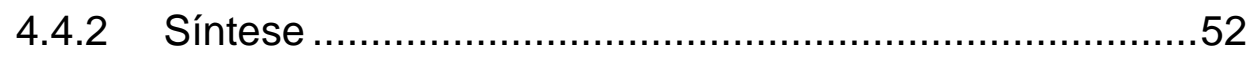

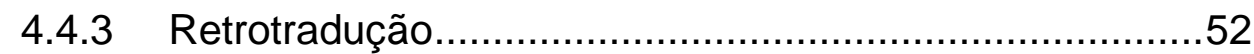

4.4.5 Avaliação por um grupo de juízes ..................................52

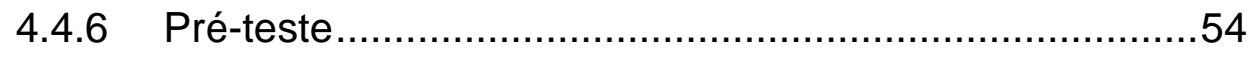


4.5 INSTRUMENTO DE COLETA DE DADOS - O MÉTODO

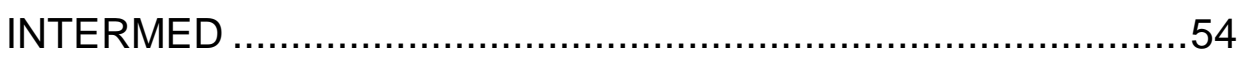

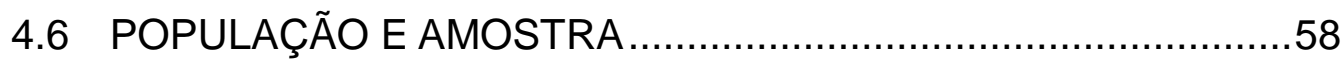

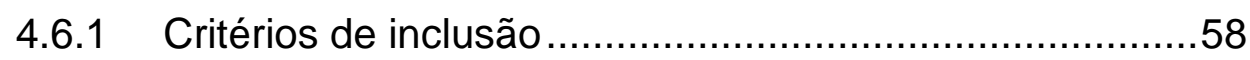

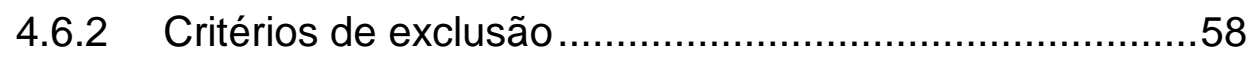

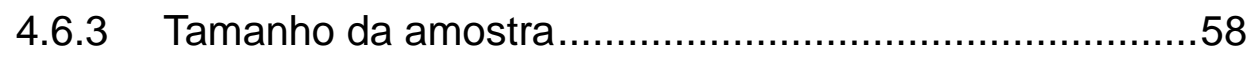

4.7 ASPECTOS ÉTICOS DA PESQUISA .........................................59

4.8 PROCEDIMENTOS DE COLETA DE DADOS ……….................59

4.9 ANÁLISE ESTATÍSTICA ............................................................

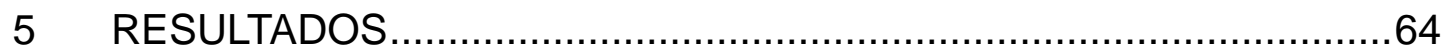

5.1 TRADUÇÃO E ADAPTAÇÃO TRANSCULTURAL DO

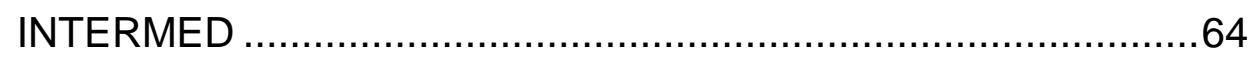

5.1.1 Tradução, síntese e retrotradução....................................64

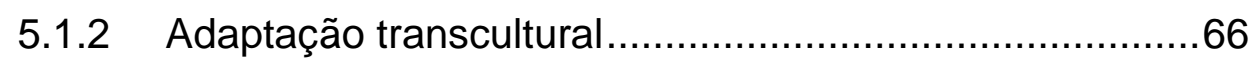

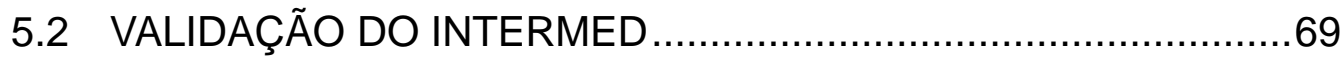

5.2.1 Caracterização dos participantes do estudo.....................69

5.2.2 Respostas obtidas com a aplicação do INTERMED ........73

5.2.3 Escores obtidos e consistência interna ...........................78

5.2.4 Validade preditiva ......................................................

5.2.5 Relação entre características sociodemográficas e escore INTERMED ................................................... 82

6 DISCUSSÃO

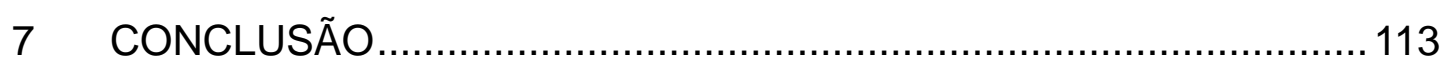

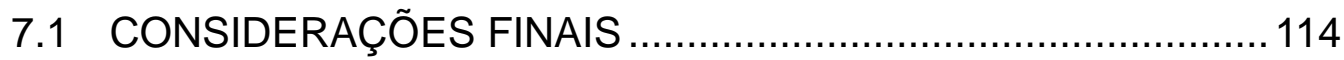

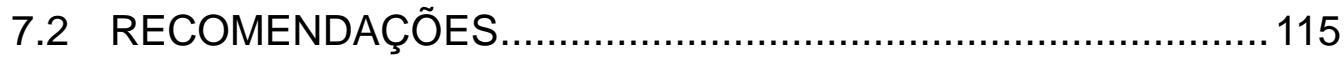

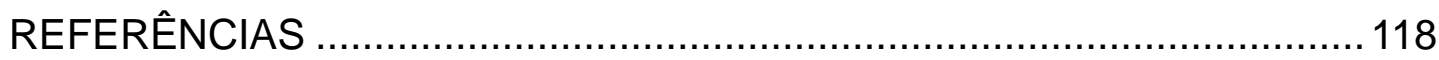

APÊNDICES

ANEXOS 


\section{Introdusãa}




\section{INTRODUÇÃO}

O Brasil é um país de dimensões continentais nas quais convivem conquistas, potencialidades e um quadro de desigualdades em sua estrutura social e econômica, seja do ponto de vista geográfico, seja do acesso a bens e serviços. Na área da saúde, o Sistema Único de Saúde (SUS) tem uma proposta avançada de atenção que se depara tanto com dificuldades específicas de consolidação de suas diretrizes como as de enfrentamento de uma situação de saúde marcada pela superposição de danos e riscos epidemiológicos de natureza aguda e condições crônicas relacionadas a um maior ou menor grau de desenvolvimento e de urbanização, condicionados por transformações demográficas e epidemiológicas.

Essa situação gera um conjunto diversificado de necessidades e demandas aos serviços de saúde que vem sendo trabalhados pelo SUS por meio de diversas iniciativas, como: descentralização de recursos fundo a fundo para estados e municípios, implantação e expansão acelerada da Estratégia da Saúde da Família (ESF) e do Piso da Atenção Básica, e uma política de regulação do acesso a tecnologias e procedimentos de alta complexidade em âmbito nacional, entre outras.

Este conjunto de iniciativas permitiu uma série de avanços na organização do SUS, ao mesmo tempo que evidenciou fragilidades significativas no que diz respeito à segmentação dos serviços e à fragmentação do cuidado aos indivíduos e populações. Neste sentido, a aprovação do Pacto pela Saúde com a publicação da Portaria no 399/GM de 22 de fevereiro de 2006, além de reafirmar o compromisso dos gestores de saúde das três esferas de governo com os princípios e diretrizes do Sistema Único de Saúde, apresenta-se como possibilidade de superação daquelas fragilidades, na medida em que coloca a regionalização da saúde como um de seus eixos centrais (Brasil, 2006a). 
Construir estratégias efetivas de regionalização implica repensar o papel dos hospitais nas diversas redes locorregionais, bem como qualificar a atenção hospitalar.

É consenso entre os atores do SUS, que atingir determinado padrão de qualidade no SUS é fundamental para a legitimação do sistema de saúde brasileiro perante a população e que são peculiares as dimensões da qualidade no complexo modelo de saúde adotado no Brasil, onde a integração e a clara definição da função específica das diversas organizações de saúde, em especial os hospitais, na constituição de redes e corredores virtuais de atenção é elemento chave no processo de qualificação (Hartz, Contandriopoulos, 2004).

O Brasil possui uma rede hospitalar importante na qual cerca de $70 \%$ dos leitos são destinados ao SUS. Em 2006, por exemplo, eram 7.644 hospitais públicos e privados, responsáveis por 11,7 milhões de internações. Contudo, sua composição é bastante heterogênea do ponto de vista da incorporação tecnológica e complexidade de serviços, com grande concentração de recursos e de pessoal em complexos hospitalares de cidades de médio e grande porte, mostrando claro desequilíbrio regional.

Os hospitais se deparam com desafios significativos em seu funcionamento, e possivelmente o maior deles seja o de oferecer cuidados com qualidade. A qualidade aqui entendida como a capacidade de prestar serviços com efetividade, eficácia, eficiência, otimização, aceitabilidade, legitimidade e equidade, o que depende tanto de uma organização interna do cuidado quanto de um comportamento coordenado e integrado às redes, em uma perspectiva sistêmica da atenção à saúde. Atingir padrões de qualidade, no caso dos hospitais, significa desenvolver estratégias de superação de um modelo ainda hegemônico, caracterizado por uma atuação centrada em procedimentos, fragmentada em especialidades médicas, pouco cuidadora e desarticulada dos demais componentes das redes de atenção à saúde.

A rede hospitalar brasileira permanece caracterizada por inúmeros estabelecimentos de saúde com grande fragilidade gerencial, 
longe de atender às exigências para constituírem verdadeiros espaços para uma atenção hospitalar resolutiva, adequada e otimizada. Focalizando a gestão de organizações e unidades produtivas na área de saúde, é importante reconhecer que os hospitais representam estruturas estratégicas colocadas no topo da pirâmide em modelos hierarquizados.

A revisão desses modelos vem atrelada a uma melhor compreensão dos conceitos de integralidade e de redes de atenção, paralelamente à constatação do esgotamento e insuficiência dos modelos hierarquizados. A organização em redes flexíveis trouxe arranjos que modificam as relações entre as unidades, de modo a colocar os resultados desejados como norteadores da organização e gestão dos processos e produtos.

A qualificação dos serviços de saúde, entendendo-se como fundamental o cuidado ao paciente, assume papel relevante, principalmente se considerarmos a atual situação dos serviços de saúde no país: a escassa utilização de planejamento; a inexistência de um sistema de informações confiável; a ausência de um sistema de gestão baseado na melhoria contínua de qualidade dos processos e centrado em resultados; o baixo uso de indicadores de desempenho e de qualidade; e a inexistência de uma cultura voltada para a qualidade e segurança do cuidado ao paciente e para a qualificação da própria estrutura organizacional.

A gestão da clínica, com diferentes nuances, tem sido utilizada por diversos países - Inglaterra, Espanha e Brasil, entre outros - como uma estratégia para a qualificação da assistência hospitalar. A gestão da clínica, no âmbito deste projeto, está concebida a partir de determinados elementos estruturantes, como a não separação entre a gestão e cuidado; a progressiva autonomia e responsabilização das equipes de cuidado; o estabelecimento de objetivos, metas e indicadores relativos ao cuidado; e o alinhamento de diretrizes clínicas, protocolos ou fluxogramas, com um modelo baseado em uma visão da clínica ampliada e centrada nas necessidades do paciente (Brasil, 2009). 
A gestão da clínica como uma área da competência profissional representa um conjunto de capacidades que possibilitam a organização do cuidado seguro e de qualidade, considerando necessidades e riscos apresentados pelos pacientes, por meio da utilização de arranjos que permitam construção de vínculo, trabalho em equipe, responsabilização e socialização de informações. Compreende, também, a utilização de diretrizes e ferramentas baseadas em evidências científicas e de indicadores que permitam monitorar o desempenho, entre outras (Brasil, 2009).

A natureza do trabalho clínico na área de saúde representa um excelente catalisador para estimular o envolvimento dos profissionais de saúde na gestão dos recursos para um melhor cuidado à saúde e, neste sentido, a integração coordenada da clínica com a gestão torna-se estratégica como disparador para a sensibilização, ampliação e articulação de novas capacidades para uma atenção à saúde que enfrente as transformações por que passam as sociedades.

Em busca de novas experiências que corroborassem para o exercício desses supostos na prática de serviços de saúde deparamo-nos na literatura internacional, com artigos científicos que divulgavam os resultados de experiências de gestão da clínica focados em uma ferramenta denominada INTERMED. Aprofundando a revisão da literatura, a abordagem mostrou-se extremamente interessante por parecer capaz de integrar a prática interprofissional na gestão de casos, oportunizando práticas de gestão da clínica e de gestão de leitos hospitalares.

Essa problemática descrita constituiu-se em fonte principal de motivação para a realização da presente pesquisa que teve como pergunta: - INTERMED é de fato uma ferramenta de gestão que pode mostrar evidências de eficácia na gestão de leitos hospitalares no contexto dos serviços de saúde brasileiros?

Para responder à pergunta investigativa, o primeiro passo consiste em um trabalho sistemático de adaptação transcultural e validação do método INTERMED. 
Objetivas 


\section{OBJETIVOS}

\subsection{OBJETIVO GERAL}

Realizar a tradução, adaptação transcultural e validação do método INTERMED para uso na realidade hospitalar brasileira.

\subsection{OBJETIVOS ESPECÍFICOS}

- Realizar a adaptação transcultural do método INTERMED, com a tradução para o idioma português falado no Brasil;

- Avaliar a validade preditiva, a validade de conteúdo e a consistência interna do método INTERMED aplicado à realidade do sistema de saúde brasileiro, abrangendo instituições hospitalares privadas, de ensino e públicas;

- Investigar a presença de associação entre características sociodemográficas e os resultados obtidos com o INTERMED, contemplando o escore total e alguns itens individuais do instrumento;

- Descrever as possibilidades de contribuição do método na redução do tempo de permanência e gerenciamento de leitos em três instituições hospitalares com características distintas. 


\section{ORevisãa da Piteratura}




\section{REVISÃO DA LITERATURA}

\subsection{A SITUAÇÃO DE SAÚDE E OS SERVIÇOS DE SAÚDE}

A situação da saúde no Brasil pode ser descrita, sinteticamente como marcada por condições concretas que apontam para: um quadro de transição demográfica acelerada; mortalidade e morbidade concentradas nas condições crônicas; prevalência de elevada morbimortalidade por condições agudas decorrentes de causas externas e de agudizações de condições crônicas; queda da mortalidade infantil, mas com elevado número de causas evitáveis; grande prevalência proporcional das doenças do aparelho circulatório e do diabetes; tripla carga das doenças, com dois terços sendo determinadas por condições crônicas; desigualdade nos níveis de saúde e no acesso aos serviços; transição demográfica acelerada; mortalidade e morbidade concentradas nas condições crônicas; e desigualdade nos níveis de saúde e no acesso aos serviços.

De acordo com estudos desenvolvidos, as principais diferenças entre as condições agudas e crônicas de saúde podem ser sintetizadas conforme Figura 1, a seguir. 
Figura 1 - Diferenças entre condições agudas crônicas de saúde

\begin{tabular}{|c|c|}
\hline Condições agudas & Condições crônicas \\
\hline Duração limitada, curta & Duração longa \\
\hline Manifestação abrupta & Manifestação gradual \\
\hline Autolimitadas & Não autolimitadas \\
\hline $\begin{array}{l}\text { Diagnóstico e prognóstico usualmente } \\
\text { precisos }\end{array}$ & $\begin{array}{l}\text { Diagnóstico e prognóstico usualmente } \\
\text { incertos }\end{array}$ \\
\hline Intervenção usualmente efetiva & $\begin{array}{l}\text { Intervenção usualmente com alguma } \\
\text { incerteza }\end{array}$ \\
\hline Resultado: a cura & Resultado: o cuidado \\
\hline Centradas no cuidado profissional & Centradas no autocuidado orientado \\
\hline Cuidado centrado no médico & Cuidado multiprofissional e interprofissional \\
\hline $\begin{array}{l}\text { Conhecimento e ação clínica concentrados } \\
\text { no profissional }\end{array}$ & $\begin{array}{l}\text { Conhecimento e ação clínica } \\
\text { compartilhados pelos profissionais e } \\
\text { usuários }\end{array}$ \\
\hline
\end{tabular}

Fonte: Mendes, 2007.

Os principais desafios para a gestão dos serviços de saúde se situam, portanto, no âmbito da gestão da clínica. A gestão da clínica consiste na aplicação de tecnologias de microgestão dos serviços de saúde com a finalidade de assegurar padrões clínicos ótimos, de aumentar a eficiência, de diminuir os riscos para os usuários e para os profissionais, de prestar serviços efetivos e de melhorar a qualidade da atenção à saúde.

Os principais desafios para a gestão dos sistemas de serviços de saúde consistem na transição da gestão das condições agudas para a gestão das condições crônicas, por exemplo: mudança de modelo de atenção à saúde para redes de atenção à saúde; passar das decisões baseadas em opiniões para a decisão baseada em evidências; alteração do modelo de gestão, com a gestão da clínica; e mudança da gestão dos recursos para a gestão dos fins.

A utilização crescente da gestão da clínica, em vários países, decorre da constatação do ganho de eficácia e eficiência nos sistemas de 
saúde, quando comparada à clássica gestão de meios, centrada apenas em recursos humanos, materiais e financeiros.

A gestão da clínica tem como pressuposto a integração vertical dos diversos pontos de atenção à saúde para conformar uma rede de atenção à saúde, que seja capaz de prestar a atenção, responder às necessidades de saúde, no lugar certo, no tempo certo, com o custo certo e a qualidade certa.

As tecnologias da gestão da clínica são: as diretrizes clínicas; a gestão das condições de saúde; a gestão de caso; a auditoria clínica e o prontuário clínico.

As diretrizes clínicas consistem em recomendações preparadas de forma sistemática, com base em evidências científicas, com o propósito de influenciar as decisões dos profissionais de saúde e dos pacientes a respeito da atenção apropriada em circunstâncias clínicas específicas. Constituem-se em diretrizes clínicas: as linhas-guias e os protocolos clínicos (Mendes, 2007).

As linhas-guias normalizam todo o processo de atenção, em todos os pontos de atenção, obedecendo à ação coordenadora da atenção primária à saúde.

O protocolo clínico é um instrumento de Gestão da Clínica que normaliza o padrão de atenção à saúde em um ponto de atenção.

Por isso, os objetivos da gestão da clínica são: fornecer elementos de apoio à decisão e manejo clínico; organizar o processo de trabalho e os fluxos; definir as competências e responsabilidades dos serviços, das equipes e dos profissionais.

Para tanto, é preciso basear-se em rigor científico, pautar-se em recomendações baseadas em evidência científica; construir corresponsabilidade (produzida por equipe multidisciplinar, com representantes de todos os grupos interessados); ter clareza e 
monitoramento dos resultados esperados (melhoria da qualidade, eficiência e efetividade clínica); favorecer a excelência no atendimento.

A gestão da clínica tem como princípios constituir-se em base para decisão de profissionais e usuários; ser instrumento de aprendizagem profissional e de educação em saúde para o usuário; constituir-se em instrumento de comunicação; pautar-se em princípios éticos e de preservação da relação profissional-usuário.

A literatura aponta para os seguintes benefícios do processo de gestão da clínica para os usuários: diminuição da assimetria de informação entre profissionais e usuários, com disponibilização de informação de boa qualidade aos usuários; padronização dos cuidados, com redução da variabilidade da prática profissional; melhoria dos resultados e da qualidade do atendimento, promovendo práticas mais eficazes e seguras.

Para os profissionais de saúde, os benefícios da gestão da clínica significam: melhora a qualidade da decisão clínica - recomendações claras; diminui a variação da prática clínica; fornecimento de informação sobre que intervenções são eficazes - em que contextos e quais evidências científicas desaconselham práticas, por serem inúteis ou danosas; constituição de base de referência para programas de qualidade em saúde; possibilidade de identificação de áreas que necessitam de investigação clínica apropriada; existência de um instrumento de educação permanente.

Para os serviços de saúde os benefícios são: racionalização dos processos de trabalho em saúde; otimização dos recursos - humanos, materiais e financeiros; melhoria da eficiência e efetividade clínica nos serviços de saúde.

A gestão da condição de saúde consiste na gestão de processos de uma condição ou doença que envolve intervenções na promoção da saúde, na prevenção da condição ou doença, no seu tratamento e reabilitação, englobando o conjunto de pontos de atenção à saúde de uma 
rede assistencial, com o objetivo de alcançar bons resultados clínicos, a custos compatíveis, com base na evidência disponível na literatura científica.

Esses supostos e conceitos explicitados que integram a proposta de gestão da clínica e, consequentemente, da gestão de leitos requerem uma mudança radical na cultura e abordagem clínica contemplando: abordagem numa população adscrita; identificação de pessoas em risco de adoecer ou adoecidas; foco nas ações de promoção e/ou preventiva, ou atenção adequada, com intervenção precoce; e visando aos melhores resultados e menores custos.

\subsection{TENDÊNCIAS AO ENVELHECIMENTO E REDUÇÃO DA CAPACIDADE FUNCIONAL}

Os países em desenvolvimento vêm apresentando, nas últimas décadas, um progressivo declínio nas suas taxas de mortalidade e, mais recentemente, também nas suas taxas de fecundidade. Estes dois fatores associados promovem a base demográfica para um envelhecimento real dessas populações, à semelhança do processo que continua ocorrendo, ainda que em escala menos acentuada, nos países desenvolvidos (Kalache, Veras, Ramos, 1987). Porém, constata-se que a mudança demográfica tem diferentes repercussões nos diversos continentes.

Nos países desenvolvidos, especialmente no continente europeu, a transição demográfica acarretou a diminuição na taxa de fecundidade no período da Revolução Industrial, período que antecede o surgimento das pílulas anticoncepcionais. O aumento da expectativa de vida ocorreu de modo insidioso e lento e foi possível graças às melhores condições sociais e de saneamento, além do uso de antibióticos e de vacinas (Kalache, Veras, Ramos, 1987). Sendo assim, a velocidade dessa transição demográfica foi paralela à promoção de novas tecnologias e ações médico-sociais que atendessem às demandas da nova configuração populacional (Born, 2005). Em contrapartida, nos países da América Latina, especificamente no Brasil, 
a transição demográfica ocorreu em outro momento histórico, marcado pelo processo de urbanização, sem mudanças significativas na distribuição de renda e condições de vida da população.

Entre os anos 1940 e 1960, o Brasil experimentou declínio significativo da mortalidade, mantendo a fecundidade em níveis bastante altos, o que gerou uma população jovem estável e com rápido crescimento. A população aumentou de 41 milhões, em 1940, para 93 milhões, em 1970 (Oliveira 2006). Entretanto, a partir da década de 1960, houve diminuição significativa da taxa de fecundidade, desencadeando um processo de transição etária no país.

No Brasil, a síntese dos indicadores sociais do IBGE (2004) revelou que a proporção de idosos é cada vez maior. Em 2000, 30\% dos brasileiros tinham de zero a 14 anos, e os maiores de 65 anos representavam 5\% da população. Em 2050, esses dois grupos etários se igualarão: cada um deles representará $18 \%$ da composição demográfica brasileira.

Esse cenário demográfico, expõe a necessidade do uso de estratégias de assistência integral ou o cuidado integral, em que as iniciativas assistenciais são de âmbito biopsicossocial, assegurando a integralidade do cuidado ao longo da vida. Apesar do processo de envelhecimento não estar, necessariamente, relacionado a doenças e incapacidades, as doenças crônico-degenerativas são mais frequentes entre os idosos e estão diretamente relacionadas com maior incapacidade funcional (Chaimowicz, 1998; Alves et al., 2007). Nesse sentido, há necessidade de cuidador que ofereça cuidados à pessoa doente ou dependente, exercendo tal atividade de forma remunerada ou não. $O$ cuidador seria alguém que realiza ações voltadas para o bem-estar, a saúde, a higiene pessoal, a alimentação, a educação, a cultura, o lazer e a recreação da pessoa assistida, buscando a melhoria da sua qualidade de vida (Duarte, 2009; Brasil, 2002). 
O comprometimento da capacidade funcional do idoso tem implicações importantes para a família, a comunidade, para o sistema de saúde e para a vida do próprio idoso, uma vez que a incapacidade ocasiona maior vulnerabilidade e dependência na velhice, contribuindo para a diminuição do bem-estar e da qualidade de vida dos idosos (Alves et al., 2007).

Assim, a capacidade funcional passa a ser compreendida como um novo componente no modelo de saúde, sendo de suma importância para o cuidado integral (Ramos, 2003).

A capacidade funcional pode ser definida como a aptidão de realizar tarefas que fazem parte da rotina diária do ser humano e que geralmente são fundamentais para uma vida independente (Brasil, 2006b). Dessa maneira, a incapacidade funcional pode ser compreendida pela presença de dificuldade na execução de certos gestos e atividades da vida diária ou até mesmo pela impossibilidade em desempenhá-las (Rosa et al., 2003).

Envelhecer mantendo íntegro o funcionamento orgânico e psicossocial não significa problema, quer para o indivíduo, quer para a família e a comunidade (Siqueira et al., 2004). Porém, quando as funções começam a deteriorar-se de modo a desafiar a reserva funcional do idoso e atingir seu limite, os problemas e as queixas quanto à saúde começam a surgir (Kalache, Veras, Ramos, 1987). A dificuldade ou ausência em desempenhar algumas das atividades está relacionada aos seus aspectos orgânicos, ou seja, à perda ou modificação de estruturas ou funções psicológicas ou fisiológicas decorrentes do envelhecimento (Carvalho Filho, 2006).

Devido a esse desequilíbrio no estado de saúde, os indivíduos passam a utilizar mais os serviços hospitalares e de maneira intensiva, isso envolve gastos elevados em decorrência da terapêutica necessária, implicando no tratamento de duração prolongada e de recuperação mais lenta e complicada (Coelho, 2000). A hospitalização é seguida, em geral, por 
uma diminuição da capacidade funcional e mudanças na qualidade de vida, muitas vezes, irreversíveis. Nesse sentido, a abordagem biopsicossocial possibilita melhoria de qualidade de vida favorecendo o envelhecimento saudável e consequente retardo das incapacidades funcionais e, por conseguinte, redução da vulnerabilidade (Creditor, 1993).

\subsection{VULNERABILIDADE E RISCO}

A abordagem biopsicossocial pressupõe uma compreensão da vulnerabilidade de forma estruturada. Assim, se quisermos chegar a algum lugar, e de algum modo minimamente racional, teremos de expressar essa racionalidade em meios e fins claramente definidos e objetivamente verificáveis. Ou seja, identificar as variáveis que possam indicar vulnerabilidade e manejá-las (Ayres, 2004).

O entendimento da vulnerabilidade no que diz respeito aos projetos de intervenção, se a avaliação não se baseia numa racionalidade particularizada nas características de cada propósito, perde sua função integradora (Ayres, 2004).

Nichiata et al. (2008) em estudo sobre revisão do conceito de vulnerabilidade, identificaram a diferença entre esta e o risco. Em epidemiologia, risco é utilizado quando

Buscam identificar nas pessoas características que as colocam sob maior ou menor exposição, com comprometimento de ordem física, psicológica e/ou social. Calcula-se a maior ou menor probabilidade e chance de grupos populacionais de adoecer e ou morrer por algum agravo de saúde (Ayres et al., 2006 apud Nichiata et al., 2008).

O risco é caracterizado a partir de um processo analítico, de um conhecimento objetivo de caráter probabilístico, enquanto a vulnerabilidade trata de elementos abstratos que, associados e associáveis, buscam a 
síntese nos processos de adoecimento (Nichiata et al., 2008). Logo, "vulnerabilidade quer expressar os potenciais de adoecimento/não adoecimento relacionados a todo e cada indivíduo que vive em certo conjunto de condições" (Ayres et al., 2006 apud Nichiata et al., 2008; Takahashi, 2009) .

A utilização do conceito de vulnerabilidade considera que, enquanto o risco indica as probabilidades, a vulnerabilidade aponta a iniquidade, a desigualdade social que no adoecimento é antecedente ao risco (Nichiata et al., 2008).

Ayres (2004) defendeu que a noção de vulnerabilidade busca identificar as dimensões sociais, político-estruturais e comportamentais relevantes. $O$ autor referido diz ainda que 0 aspecto coletivo da vulnerabilidade deve ser avaliado por meio de fatores como: o acesso à informação que tem o grupo social em questão; a porcentagem do produto nacional bruto destinado a investimentos na saúde pelas autoridades e legislação locais; o acesso a serviços de saúde nos diversos estratos sociais; e o comportamento de indicadores epidemiológicos, como o coeficiente de mortalidade infantil.

Nichiata et al. (2008) identificaram outros fatores para a análise, como idade, sexo, etnia, apoio social, escolaridade, renda, estilo de vida e fatores de risco modificáveis e não modificáveis para enfrentamento de doenças.

Assim, identificam-se diferenças na caracterização da vulnerabilidade, que pode ser entendida, segundo Goldim (2004) como: exclusão protetora; redução da voluntariedade; restrição à espontaneidade; restrição à liberdade; redução da autonomia; redução da capacidade; redução da autodeterminação; suscetibilidade; fragilidade; desigualdade; proteção adicional; compartilhamento de responsabilidades; e solidariedade.

Marandola Junior e Hogan (2005) afirmaram que a vulnerabilidade possui três componentes: a ocorrência de uma situação adversa, endógena 
ou exógena, ou seja, um evento potencialmente prejudicial; uma incapacidade de apresentar uma resposta eficaz diante do evento, por falta de recursos; e a dificuldade de adaptação ao contexto resultante.

A complexidade dos aportes às necessidades de saúde implica em ressaltar o caráter multidisciplinar quando se trata da perspectiva da vulnerabilidade (Takahashi, 2009). O alcance do conceito de vulnerabilidade possibilita conferir maior integralidade às ações de saúde, ao fortalecer propostas de intervenções que considerem três dimensões: a individual, que diz sobre a ação individual de prevenção frente a uma situação de risco; a programática, referente às políticas públicas de enfrentamento, sua organização e distribuição dos recursos de prevenção e controle; e a social, que se refere à estrutura econômica, políticas de educação e saúde, cultura e ideologia (Nichiata, 2008).

Diante deste cenário, visto que os indivíduos com doenças crônico-degenerativas são vulneráveis pela condição biológica e naturalmente mais suscetíveis a riscos e complicações no seu estado de saúde-doença, com possibilidades de agravamento, em especial se a sua permanência nos hospitais torna-se mais prolongada, em geral pelas condições psicossociais associadas, é de suma importância uma atenção especial a este assunto tendo em vista suas implicações médicas, sociais e políticas.

\subsection{INTEGRALIDADE DO CUIDADO}

Diante da realidade apresentada, a necessidade de atender integralmente o paciente, no sentido de satisfazer as suas necessidades de saúde em menor tempo e com maior eficiência, eficácia e qualidade, tornouse meta importante nas organizações de saúde. A atenção integral ao paciente no hospital compreende o esforço relativo a uma abordagem completa, holística, portanto integral, para cada pessoa portadora de 
necessidades de saúde que, por um período de sua vida, precise de cuidados hospitalares (Cecílio, Merhy, 2003).

Para alcançar a integralidade no cuidado de pessoas, grupos e coletividade torna-se necessário visualizar o usuário como sujeito histórico, social e político, articulado ao seu contexto familiar, ao meio ambiente e à sociedade na qual se insere (Mattos, 2004). Assim, o cuidado integral extrapola a estrutura organizacional hierarquizada e regionalizada da assistência à saúde, prolonga-se pela qualidade real da atenção individual e coletiva assegurada aos usuários do sistema de saúde, e requer o compromisso com o contínuo aprendizado e com a prática interprofissional. Desta forma, o cuidado integral em saúde ocorreria a partir de uma combinação generosa e flexível de tecnologias duras, leve-duras e leves (Merhy, 2002).

O cuidado, de forma idealizada, recebido/vivido pelo paciente é somatório de um grande número de pequenos cuidados parciais que vão se complementando, de maneira mais ou menos consciente e negociada, entre os vários cuidadores que circulam e produzem a vida do hospital. Assim, uma complexa trama de atos, e procedimentos, de fluxos, de rotinas, de saberes, num processo dialético de complementação, mas também de disputa, vão compondo o que entendemos como cuidado em saúde. A maior ou menor integralidade da atenção recebida resulta, em boa medida, da forma como se articulam as práticas dos trabalhadores do hospital (Merhy, Cecílio, 2003).

A integralidade do cuidado só pode ser obtida em rede. Pode haver algum grau de integralidade "focalizada" quando uma equipe, em um serviço de saúde, por meio de uma boa articulação de suas práticas, consegue escutar e atender, da melhor forma possível, as necessidades de saúde trazidas por cada um (Cecílio, 2001).

Muitos gestores da saúde têm em suas estratégias o cuidado com foco no paciente. No Brasil há um relato de experiência de sistematização da 
assistência, denominada Assistência Integral, e descrita como um modelo de cuidado preconizado na prática assistencial e definido como um sistema de atendimento hospitalar que estabelece procedimentos e cuidados ao paciente como um conjunto de ações multiprofissionais integradas em um único fluxo, cujo objetivo é suprir as necessidades múltiplas e simultaneamente acolher e engajar o paciente na sua individualidade, com resultados que se concretizam na beira de leito (Weber, Demeneghi, 1997).

Além disso, é preciso considerar o entorno de cada indivíduo, pois todo o ser humano se constitui a partir de seu meio ambiente, família e cultura; aliados aos legados biológicos, esses elementos preestabelecem a pessoa (psicoemocional) (Lidz, 1983). Portanto, conhecer a origem, a cultura e o ambiente do paciente pode orientar os profissionais da saúde na investigação do quadro clínico.

Ao refletir sobre as práticas de saúde, Ayres (2004) utiliza como referência o pensamento de Heidegger (1995) sobre o tema enquanto categoria ontológica, desafiando os profissionais de saúde a terem o foco no doente e na sua presença no espaço assistencial, numa perspectiva transdisciplinar.

Como explica o autor:

Normalmente quando se fala em cuidado de saúde, ou cuidado em saúde, atribui-se ao termo um sentido já consagrado no senso comum, qual seja, o de um conjunto de procedimentos tecnicamente orientados para o bom êxito de um certo tratamento.

Entretanto, Heidegger (1995) propôs que o ser humano, criador e criatura da existência, molda incessantemente as diversas formas de existência a partir do cuidado, como uma "compreensão existencial da condição humana como cuidado", que pode significar a parcela de corresponsabilidade do ser cuidado, portanto poder ter preservada a sua saúde, no que corresponder ao âmbito individual. 
Ayres (2004) questiona o vazio de um cuidado ("terapêutica") que parece estar "perdendo seu interesse pela vida, (...) perdendo o elo de ligação entre seus procedimentos técnicos e os contextos e finalidades práticos que os originam e justificam". Isso porque, se o cuidado molda a existência, para cuidar "há que sustentar, ao longo do tempo, uma certa relação entre a matéria e o espírito, o corpo e a mente".

Lobo (2010) justificou a importância da identificação das necessidades do paciente, de abrangência interprofissional, na medida em que há um aumento progressivo de pacientes que apresentam necessidades complexas, gerando maior dificuldade de manejo; com frequência, pessoas com idade mais avançada, crônicos com comorbidades psíquicas e/ou com uma rede social limitada.

Outro estudo de Lobo (2011) relatou a inquietude causada pela fragmentação da assistência, também numa visão da saúde pública, por não aportar uma atenção psicossocial aos pacientes. Diz ainda da crescente importância de uma atenção médica integral, em que os cuidados médicos habituais devam ser acompanhados de atenção aos problemas psicopatológicos e sociais.

Em seu estudo, Weber (2008) afirmou que a integralidade se caracteriza no modelo da Assistência Integral, ao identificar o foco na pessoa como o mais importante atributo de valor pode ser um dos elementos na cadeia de ações que promovem a adesão ao tratamento e, mais do que isso, a adesão ao ser cuidado.

Assim, sendo o hospital um dos equipamentos de saúde que compõem a rede de serviços disponíveis em que circulam vários tipos de usuários, portadores das mais diferentes necessidades, em diferentes fases de suas vidas, pode-se afirmar a importância de se manter um cuidado integral voltado aos pacientes em função das possíveis múltiplas e variadas condições crônicas que representam alto custo pessoal, familiar e social. 


\subsection{SISTEMA ÚNICO DE SAÚDE}

A atenção à saúde no Brasil pode ser observada a partir de dois enfoques (Paim, 2004). O primeiro trata-se de ser uma resposta social aos problemas e necessidades de saúde. Desta forma, a assistência à saúde está inserida no campo disciplinar da Política de Saúde, especialmente no que se refere às ações e omissões do Estado em relação à saúde do indivíduo e da coletividade. O segundo enfoque trata da assistência à saúde como serviço compreendido no interior de processos de produção, distribuição e consumo. Neste, a atenção à saúde insere-se no setor terciário da economia e depende de processos que perpassam os espaços do Estado e do mercado.

Pode-se dizer que a atenção à saúde é dinâmica, já que depende das modificações dos perfis epidemiológicos da população que depende, fundamentalmente, das condições e estilos de vida (modo de andar a vida) e se expressa em necessidades (sofrimento, doença, agravos, riscos, vulnerabilidade ou ideais de saúde) e demandas por consultas, vacinas, informações, exames, tratamentos e hospitalizações (Paim, 2004).

Nas últimas décadas do século XX, antes da década de 1980, o Estado era um instrumento de desenvolvimento social, de forma que as políticas sociais e de seguridade social eram redistributivas. O Estado tinha como função ser interventor, planejador, empreendedor, produtor e executor. Já na década de 1980, até meados da década de 1990, surgem políticas de contenção de gastos, as primeiras privatizações, a ideia de descentralização e políticas sociais locais. A lógica do mercado passa a ser de competitividade e flexibilidade administrativa, com contratações e demissões de recursos humanos. O Estado passa a exercer a função de protetor do direito ou propriedade.

Desta forma, há uma crise no Estado Provedor, no qual a assistência à saúde estava subordinada a um sistema de serviços de saúde, caracterizado pela insuficiência, descoordenação, má distribuição, 
ineficiência e ineficácia (Brasil, 1975). Porém, na década de 1990, há um Estado forte a fim de coordenar e regular os interesses públicos. Além disso, há incorporação dos mecanismos de gerenciamento privado na gestão pública.

Essa nova fase do estado é acompanhada pelo surgimento do Sistema Único de Saúde (SUS). Segundo Paim (2004), foi uma conquista da democracia, a sociedade participou ativamente da formulação de proposições políticas para a saúde durante a $8^{\text {a }}$ Conferência Nacional de Saúde, realizada em 1986, cujas recomendações foram incorporadas, em grande parte, pela Constituição de 1988. A implementação do Sistema Unificado e Descentralizado de Saúde (SUDS), como estratégia-ponte para a implantação do SUS, cujos dispositivos legais foram aprovados em 1990, dava sequência à reforma do sistema e dos serviços de saúde, inspirada nos princípios e diretrizes da integralidade, equidade, descentralização e participação (Brasil, 2003a). Com isso, de acordo com Paim (2002), buscava-se ampliar o acesso e qualidade das ações e serviços, além de se experimentar novos modelos de atenção à saúde, que contemplassem os princípios e diretrizes propostos.

Um dos princípios do SUS é a integralidade, que constitui ao mesmo tempo uma diretriz para a organização do sistema, de acordo com a constituição de 1988. Vincula-se a um movimento de ideias que gerou a proposta de Medicina Preventiva nas escolas médicas americanas na passagem da década de 1940 para a de 1950 (Arouca, 1975). Assim, o processo saúde-doença foi pensado a partir do modelo da história natural das doenças (Clark, MacMahon, 1967). Para o Conselho Nacional de Secretários de Saúde (Brasil, 2003), no momento pré-patogênico, ou seja, antes do modelo da doença, é possível desenvolver um conjunto de ações específicas e inespecíficas para evitar o aparecimento do problema. Tais medidas compõem a chamada prevenção da ocorrência ou prevenção primária, englobando as ações de promoção e de proteção da saúde. As medidas adotadas nesse momento podem ser identificadas, genericamente, como prevenção da evolução (Hilleboe, Larimore, 1965) ou como prevenção 
secundária (recuperação da saúde) e prevenção terciária (reabilitação da saúde).

Outro pressuposto importante quando nos referimos ao SUS, é a equidade, inferindo que os serviços de saúde teriam que atender a todo tipo de categoria social. Entretanto, segundo o Conselho Nacional de Secretários de Saúde (Brasil, 2003a), esses recursos apresentam uma distribuição desigual entre estratos sociais e entre regiões, estados e municípios, áreas urbanas e rurais e, nas cidades, entre periferia e centro, conforme será apresentado mais adiante. Daí a equidade constituir-se, numa sociedade extremamente desigual como a brasileira, outro grande desafio da atenção à saúde e do SUS.

Outro aspecto importante do SUS é marcado pelo acesso do usuário à atenção necessária e a qualidade das ações e serviços. Tais serviços, no Brasil, são condicionados pela distribuição desigual da infraestrutura do sistema de serviços de saúde e pelos demais elementos que estruturam um sistema de serviços. Desta forma, de acordo com o Conselho Nacional de Secretários de Saúde (Brasil, 2003a), o acesso universal e igualitário às ações e serviços de saúde representa muito mais uma imagem-objetivo para os que investem em um sistema de saúde digno e de qualidade do que, propriamente, uma evidência.

Mesmo diante dos vários problemas supracitados, na década de 1990 ocorreram fatos político-institucionais com consequências marcantes, tais como: expansão do Programa Saúde da Família (PFS) para diversos brasileiros, criação da Agência Nacional de Vigilância Sanitária (ANVISA), aprovação da Lei dos medicamentos genéricos, implantação do Sistema de Informação do Orçamento Público em Saúde (SIOPS), adoção do cartão SUS em alguns municípios, implementação do Programa de Interiorização do trabalho em Saúde (PITS), atualização da Relação Nacional de Medicamentos Essenciais (RENAME), estabelecimento da Ementa

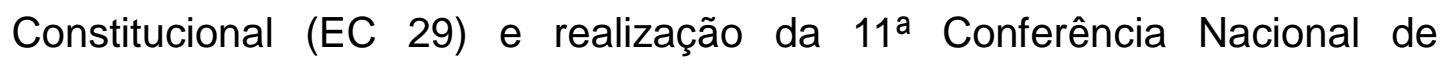
Vigilância Sanitária. 
Em suma, a partir do cenário descrito, justifica-se a necessidade de se testar na realidade brasileira novos métodos e instrumentos que favoreçam um cuidado integral. Dentre os pesquisados na literatura, um método, denominado INTERMED, foi elaborado por Huyse et al. (1999) na Holanda e vem sendo utilizado em diversos países do continente europeu, no Canadá e nos EUA, onde foi adaptado para a identificação de necessidades na gestão de casos complexos. Existem descritos na literatura científica, relatos que avaliam o método como eficiente e que favorece à equipe interprofissional o gerenciamento do cuidado.

Acredita-se que a realização da presente investigação favorecerá conhecer as demandas de cuidado apresentadas pelos indivíduos internados em diferentes instituições hospitalares da rede SUS, bem como em hospitais que atendem convênios e particulares, que buscam um cuidado integral e de qualidade, norteado pelos princípios da Humanização, que seja resolutivo e que fortaleça o trabalho da equipe multiprofissional (Brasil, 2003b).

\subsection{O MÉTODO INTERMED}

O modelo de saúde biomédico, dominante nas práticas assistenciais, não considera as dimensões psicológica, social e comportamental do indivíduo (Engel, 1977; Ramos et al., 2009). Já em 1977, Engel descreveu que para compreender os determinantes da doença e chegar a tratamentos racionais e padrões de cuidado à saúde, um modelo de cuidado requer que se considere o paciente, o contexto social em que vive e o sistema de saúde complementar elaborado pela sociedade para lidar com os efeitos perturbadores da doença, ou seja, o papel do médico e do sistema de saúde, o que demanda um modelo de cuidado biopsicossocial.

Nesse sentido, um grupo de pesquisadores holandeses (Huyse et al., 1999) desenvolveu um método operacional para integrar 
sistematicamente os aspectos biológico, psicológico e social do indivíduo e sua relação com o sistema de saúde, possibilitando a integralidade do cuidado para um ajustamento mútuo, entre os profissionais de saúde, do nível de necessidades do paciente.

O método, denominado INTERMED, é composto por um instrumento, que já foi traduzido e validado em diferentes países, idiomas e sistemas de saúde, como o inglês, alemão, francês, espanhol, italiano, japonês e norueguês (INTERMED Foundation, 2010). Ele complementa a tradicional entrevista médica e, como um sistema de documentação, pode ser utilizado em cuidados de saúde de diferentes configurações e acrescentado, como qualquer outro documento importante, ao prontuário médico, sendo uma ferramenta para apoiar decisões e gerenciamento de casos (Stiefel et al., 1999).

O método INTERMED parece ser abrangente para a classificação de necessidades de cuidado. Os resultados dos estudos publicados mostraram que o INTERMED é um método confiável para classificar o cuidado dos pacientes, segundo as suas necessidades. Nesse sentido, concluíram que o método pode ser uma ferramenta útil na avaliação dos pacientes de diferentes patologias e diagnósticos, bem como ter seu potencial para colaborar no ajuste necessário entre prestação de serviços de saúde, em geral, e de saúde mental (Stiefel et al., 1999).

O INTERMED permitiu dar a abrangência ao sistema integrado de gerenciamento de caso, quando a atenção ao domínio da saúde física (quadro médico geral) perdeu sua posição de dominância. Passou a assumir um lugar ao lado dos fatores psicológicos, sociais e do sistema de saúde como um conjunto de componentes compartilhados que influenciam a saúde e os prognósticos. Assim, por meio da metodologia INTERMED, a complexidade passou a ser definida como uma composição de interação do histórico, estado atual e vulnerabilidade dos riscos à saúde e das necessidades de saúde de cada um desses quatro domínios, nos quais barreiras à atenção poderiam surgir (Kathol, Perez, Cohen, 2010). 
Em pacientes com diabetes, a pontuação do INTERMED foi relacionada aos valores de hemoglobina glicada, avaliada seis meses antes e três e nove meses depois (Fischer, Stiefel, de Jonge, 2000). Pacientes sob diálise tiveram a pontuação do INTERMED relacionada à baixa qualidade de vida no seguimento de um ano (de Jonge et al., 2003a). Em pacientes ambulatoriais com esclerose múltipla, o escore do INTERMED foi associado a medidas de deficiência e número de profissionais propostos no plano de tratamento multidisciplinar (Hoogervorst et al., 2003). Esses dados confirmam a capacidade do método em detectar pacientes com risco e prever resultados clínicos em amostras diversas de pacientes.

Assim, justificam-se os esforços em pesquisa que realize a tradução e validação transcultural do instrumento para a língua portuguesa, com aplicação em pacientes adultos hospitalizados em diferentes contextos assistenciais.

Considera-se que o instrumento possa ser um dos motes para impulsionar a proposta de gestão da clínica e que favoreça a gestão de leitos no contexto hospitalar. 


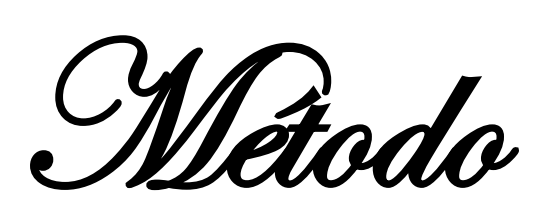




\section{MÉTODO}

\subsection{REFERENCIAL METODOLÓGICO}

\subsubsection{O processo de tradução e adaptação transcultural}

O desafio da aferição de um fenômeno pode, por um lado, ser enfrentado com a construção de um novo instrumento, o que representa um processo muito longo e dispendioso financeiramente, que resulta em ferramenta, de início, sem comparabilidade internacional. Por outro lado, pode-se proceder a adaptação de um padrão de medida existente desenvolvido em uma cultura diferente do local de estudo.

Como esses instrumentos são desenvolvidos de acordo com os formatos, normas, conceitos e expectativas prevalentes nos seus países de origem, antes de utilizá-los é preciso verificar se eles representam o mesmo significado para populações etnoculturais distintas (Jorge, 2008).

A definição de padrões de aferição de fenômenos relacionados ao processo saúde-doença, incluindo modelos de tratamento e cuidado dos indivíduos, deve considerar a cultura local que afeta sua percepção e expressão (Guillemin, 1995). A cultura é uma rede de significados construída pelo sujeito, compartilhada pelo grupo social e que orienta a conduta dos seus membros (Geertz, 1989).

A adaptação transcultural é um processo que requer 0 cumprimento de duas etapas claramente distintas: tradução e ajuste cultural do instrumento e sua validação para uso em outro cenário (Beaton et al., 2000).

O processo formal de adaptação transcultural tem a finalidade de avaliar e assegurar, com rigor, a equivalência entre o instrumento no idioma 
original e sua versão traduzida (Guillemin, 1995; Beaton et al., 2000; Reichenheim, Moraes, 2007).

Não existe um consenso sobre a melhor metodologia para traduzir e adaptar culturalmente um instrumento, no entanto, a escolha adequada da metodologia permite a inclusão de variáveis específicas próprias da cultura e a adoção de uma linguagem clara, simples e de fácil acesso à população (Bandeira, Calzavara, Varella, 2005).

Com base em uma revisão de literatura, autores propuseram um método para o processo de adaptação transcultural composto por cinco fases e que foi adotado nesse estudo (Beaton et al., 2000).

Na primeira fase, é realizada a tradução do instrumento original, com duas traduções feitas por tradutores independentes, com produção de um relatório detalhado. A literatura recomenda que o processo de tradução seja realizado por profissionais cujas língua-mãe e cultura sejam aquelas para as quais se está realizando a tradução.

A fase seguinte é a composição de uma versão síntese do instrumento a partir das duas traduções geradas. É aconselhável a produção de um relatório detalhado com a descrição de todas as discrepâncias observadas entre as duas traduções e de como foram resolvidas, de preferência pela obtenção de consenso entre o pesquisador e os dois tradutores.

A terceira fase compreende a retrotradução, com a realização de duas retrotraduções a partir da versão síntese por dois tradutores independentes que não conhecem o instrumento original e que possuem $o$ idioma pátrio igual ao do instrumento original, incluindo a produção de um relatório detalhado.

A penúltima fase é a avaliação por um grupo de juízes, fundamental para alcançar a equivalência do questionário traduzido, visto que esse grupo consolida todas as versões do instrumento e compõe a 
versão pré-final a ser testada. O comitê deve ser formado por especialistas em áreas relacionadas ao tema de estudo e deve alcançar a equivalência entre o instrumento original e a versão pré-final a ser testada em três áreas: semântica, que se refere à avaliação do significado das palavras; idiomática, relacionada ao uso de expressões coloquiais ou idiomáticas; e cultural, que consiste em verificar se os conceitos apresentados no instrumento original correspondem aos utilizados no contexto da cultura local estudada.

A quinta fase é o pré-teste, em que se realiza a aplicação da versão pré-final do instrumento a indivíduos com as mesmas características do público-alvo da pesquisa. A literatura recomendou que o pré-teste fosse realizado com um grupo de 30 a 40 indivíduos (Beaton et al., 2000). Cada um deles responde ao instrumento e, em seguida, é entrevistado para relatar sobre como entendeu cada item e respectivas respostas, suas dúvidas e sugestões de reformulação para um melhor entendimento. Essa etapa assegura que a versão adaptada do instrumento mantenha sua equivalência com o original, em sua aplicação. A distribuição das respostas é examinada para identificar a porcentagem de perdas e as dificuldades identificadas. Os itens que apresentarem dificuldades sem resolução junto ao indivíduo do pré-teste retornam para o comitê de especialistas para discussão e definição das mudanças necessárias para a produção da versão final do questionário adaptado.

Para concluir a fase de tradução e ajuste cultural do instrumento, todos os relatórios produzidos e a versão final do questionário adaptado devem ser submetidos à avaliação dos pesquisadores que elaboraram o instrumento original para sua aprovação.

\subsubsection{O processo de validação}

Para completar o processo de adaptação transcultural do instrumento é necessário testar sua validade e confiabilidade. Medidas válidas são representações precisas da característica que se pretende 
medir; e medidas confiáveis geram os mesmos resultados, sendo replicáveis e consistentes.

A validade é a capacidade do instrumento de medir o objeto ao qual se propõe, de forma reproduzível (Streiner, Norman, 1996), podendo ser de conteúdo, de critério e de constructo (Fletcher R, Fletcher S, 2006). A validade de conteúdo é o grau em que um instrumento de medição inclui todas as dimensões do conceito que se pretende medir e nada mais. Já a validade de critério é a correlação da medida com um critério externo ao fenômeno investigado. Uma variação dela é a validade preditiva, ou seja, a capacidade de a medida predizer desempenhos futuros. Finalmente, a validade de constructo refere-se à relação consistente de um instrumento de medidas com outras medições semelhantes derivadas da mesma teoria e conceitos que estão sendo medidos (Hulley, Martin, Cummings, 2003; Fletcher R, Fletcher S, 2006; Martins, 2006).

A confiabilidade é o quanto repetidas avaliações, medições ou quantificações de um mesmo sujeito ou objeto produzem resultados semelhantes (Fletcher R, Fletcher S, 2006; Martins, 2006). A confiabilidade de um instrumento pode ser verificada pela sua consistência interna, que prediz se os itens do instrumento relacionam-se ou são complementares entre si. A consistência interna pode ser testada estatisticamente com a utilização do coeficiente alpha de Cronbach, calculado a partir de correlações entre escores de itens individuais. Os valores podem variar de 0 a 1, sendo considerados aceitáveis aqueles acima de 0,70, e excelentes valores iguais ou superiores a 0,80 (Hulley, Martin, Cummings, 2003).

O processo de validação inclui a aplicação do questionário traduzido e adaptado culturalmente a uma amostra de pacientes elegíveis, conforme descrito a seguir. 


\subsection{DESENHO DE ESTUDO}

Estudo do tipo transversal para tradução de instrumento para o português falado no Brasil, adaptação transcultural e validação em população brasileira hospitalizada. Nos estudos transversais todas as medições são feitas num único momento, não existindo, portanto, período de seguimento dos indivíduos. Para levar a cabo um estudo desse tipo o investigador tem que, primeiro, definir a questão a responder, depois, definir a população a estudar e um método de escolha da amostra e, por último, definir os fenômenos a estudar e os métodos de medição das variáveis de interesse. Esses tipos de estudos são apropriados para descrever características das populações no que diz respeito a determinadas variáveis e a seus padrões de distribuição. Os estudos transversais podem, também, ser utilizados para descrever associações entre variáveis.

\subsection{LOCAIS DE ESTUDO}

Para o desenvolvimento do projeto, optou-se por validar o instrumento em três instituições hospitalares da cidade de São Paulo, com diferentes perfis de população, sendo um hospital de ensino; um privado e um público, descritos abaixo.

\subsubsection{Hospital do Coração}

O Hospital do Coração iniciou suas atividades em 1976, tendo como objetivos promover a recuperação da saúde com excelência e ética, atuar com pioneirismo em cardiologia, compartilhar recursos tecnológicos e conhecimentos com outras especialidades e associar ensino e pesquisa, valorizando a participação multiprofissional e multidisciplinar na assistência humanizada, visando à prevenção e ao bem-estar com qualidade de vida. 
O hospital é administrado pela Associação do Sanatório Sírio, fundada em 1918 por um grupo de senhoras árabes com o objetivo de ajudar crianças órfãs da I Guerra Mundial. A administração do hospital é formada por uma diretoria, composta por: Diretora Presidente, Diretor Geral, Diretor Clínico, Superintendente Corporativo, Superintendente Médico e de Relações Institucionais, Superintendente de Operações e Superintendente de Qualidade e Responsabilidade Social.

O HCor é uma instituição de caráter privado, acreditada pela Joint Commission International em 2006 e reconhecida como Hospital de Excelência pelo Ministério da Saúde, contribuindo para a melhoria da saúde pública por meio de ações sociais.

A instituição localiza-se na zona sul da cidade de São Paulo e conta com 251 leitos. Suas instalações incluem pronto-socorro, centro cirúrgico, unidade de terapia intensiva adulta, pediátrica e neonatal, unidade coronariana, unidades de internação, hemoterapia, hospital dia e consultórios.

Os pacientes admitidos são atendidos por uma equipe interprofissional composta por médicos, enfermeiros, fisioterapeutas, farmacêuticos, nutricionistas, psicólogos, fonoaudiólogos e assistentes sociais. Além disso, o hospital possui todos os serviços de apoio para alta complexidade, como laboratório clínico, serviço de imagem (tomografia, radiografia, ressonância magnética, ecocardiografia, dentre outros), banco de sangue, bem como uma estrutura para pesquisa diagnóstica laboratorial e radiológica.

Este estudo foi realizado nas unidades de internação clínica e cirúrgica não intensiva de pacientes adultos, que totalizam 134 leitos, com uma ocupação média de $90 \%$, localizadas do quarto ao décimo primeiro andar do hospital. 


\subsubsection{Hospital Universitário da Universidade de São Paulo}

O Hospital Universitário da Universidade de São Paulo (HU-USP) tem como objetivo produzir assistência, ensino e pesquisa à comunidade da Universidade de São Paulo (USP) e à população local.

Para atingir esses objetivos, ele estimula e promove o ensino e a pesquisa; desenvolve atividades assistenciais de prevenção, tratamento, proteção e recuperação da saúde; e colabora com as instituições de ensino no desenvolvimento de tecnologias assistenciais, educativas e operacionais.

O HU-USP se localiza na região oeste da cidade de São Paulo e abrange a região centro-oeste, sendo um hospital regionalizado, da rede pública estadual, e caracterizado pelo atendimento secundário, prestando um serviço diferenciado com atendimento de excelência.

A sua administração é composta por um Conselho Deliberativo e uma Superintendência. Esse Conselho é constituído pelos diretores das faculdades de Medicina, Ciências Farmacêuticas, Saúde Pública, Enfermagem, Psicologia, Odontologia, pelo Superintendente do HU-USP, por um representante discente e um representante dos usuários. Ao Conselho, cabe definir as diretrizes básicas da assistência, da pesquisa e do ensino. A Superintendência é responsável pela operacionalização do hospital.

Os recursos financeiros da instituição são provenientes da própria Universidade de São Paulo e do Sistema Único de Saúde.

O hospital é campo de ensino e pesquisa, principalmente para as seguintes faculdades: Medicina, Ciências Farmacêuticas, Odontologia, Saúde Pública, Escola de Enfermagem, Instituto de Psicologia e Escola de Artes, Ciências e Humanidades.

Os critérios para atendimento ao usuário são: pertencer à comunidade USP (docentes, discentes, funcionários e dependentes) ou 
residir na área de abrangência, o que inclui os bairros Butantã, Rio Pequeno, Morumbi, Raposo Tavares, Vila Sônia e Jaguaré.

O hospital é referência para as Unidades Básicas de Saúde da região do Butantã e contrarreferência do Hospital das Clínicas da Faculdade de Medicina da USP.

No total, conta com 247 leitos distribuídos nas unidades de: clínica médica e cirúrgica, alojamento conjunto, pediatria, terapia intensiva, semi-intensiva, neonatal e pediátrica, e hospital dia. Além disso, possui centro cirúrgico e obstétrico, serviço de imagem e diagnóstico, hemodiálise, central de material esterilizado, pronto-socorro adulto e infantil, ambulatório e programa de assistência domiciliar.

O quadro de profissionais inclui médicos, enfermeiros, auxiliares e técnicos de enfermagem, psicólogos, assistentes sociais, fisioterapeutas, terapeutas ocupacionais, fonoaudiólogos e nutricionistas.

Os dados desta pesquisa foram coletados na Clínica Médica do HU-USP, constituída de 41 leitos, com taxa de ocupação de $90 \%$. A unidade está localizada no quinto andar do hospital e recebe pacientes, na sua maioria, idosos e portadores de doenças crônico-degenerativas.

\subsubsection{Hospital Municipal Dr. Moysés Deutsch}

O Hospital Municipal Dr. Moysés Deutsch - M'Boi Mirim (HMMD) foi idealizado e construído pela Prefeitura Municipal de São Paulo, sua mantenedora, com atendimento exclusivo à rede SUS. Sua gestão é compartilha pela Organização Social de Saúde Centro de Estudos e Pesquisas Dr. João Amorim (CEJAM) em parceria com a Sociedade Beneficente Israelita Brasileira Albert Einstein.

O HMMD foi criado para integrar e fortalecer a rede básica de saúde na região do M'Boi Mirim, zona sul da cidade de São Paulo, sendo 
referência para 43 unidades de saúde e tendo como foco o atendimento de urgências, emergências e assistência ao parto.

A instituição é um hospital geral, de atenção secundária, com 240 leitos distribuídos entre pronto-socorro, unidade de terapia intensiva adulta, pediátrica e neonatal, maternidade, clínica médico-cirúrgica, pediatria e psiquiatria.

Com relação ao quadro de pessoal, a instituição conta com 1.400 funcionários diretos e 100 indiretos e tem por missão acolher a população do M'Boi Mirim, prestando assistência humanizada e eficiente, em conformidade com os princípios do SUS, e contribuir para o aprimoramento do sistema de saúde.

O hospital é o único da região, atuando como referência para cerca de 600 mil habitantes. Os moradores dessa região têm uma renda familiar mensal média de $R \$ 779,49$ e se encontram no agrupamento classificado como alta e altíssima vulnerabilidade social. A Estrada de M'Boi Mirim (principal via de acesso) está em terceiro lugar na cidade em número de atropelamentos, ficando atrás apenas das marginais Tietê e Pinheiros.

Para a realização desta pesquisa, foram entrevistados pacientes internados na Clínica Médico-Cirúrgica, composta por 190 leitos. 


\subsection{FASES DA PESQUISA E PROCEDIMENTOS METODOLÓGICOS}

A operacionalização do estudo seguiu modelo proposto na literatura (Beaton et al., 2000) e encontra-se resumida na Figura 2.

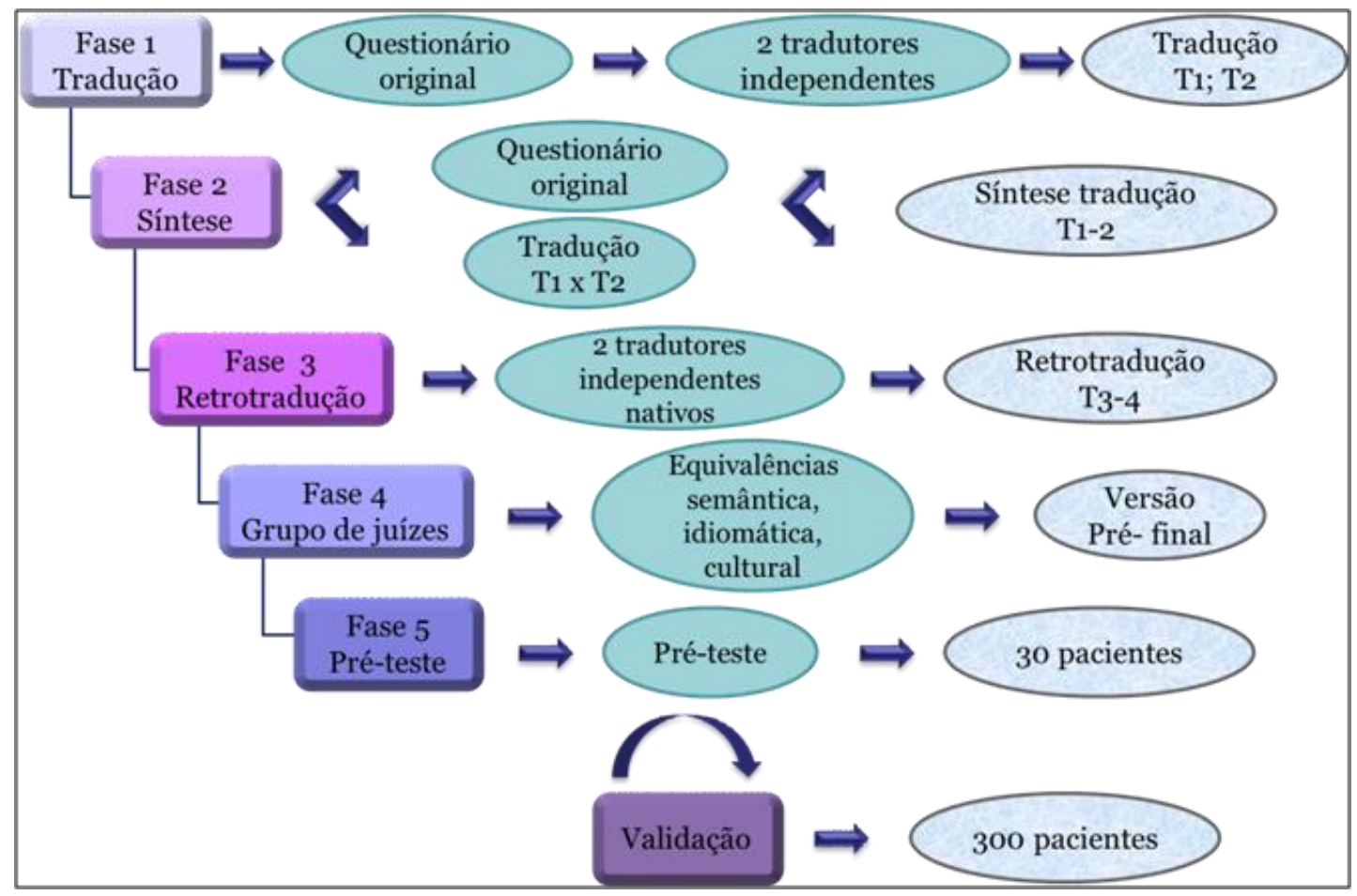

Figura 2 - $\quad$ Operacionalização do estudo, São Paulo - 2012

\subsubsection{Tradução}

Conforme recomendação da literatura, foram realizadas duas traduções por tradutores independentes, profissionais brasileiros com bom domínio do inglês, sendo uma enfermeira com conhecimento dos objetivos do estudo e uma professora de inglês, sem conhecimento prévio da pesquisa. 


\subsubsection{Síntese}

A composição de uma versão síntese do instrumento foi realizada com base no questionário original e nas duas traduções. Essa síntese foi obtida por consenso por um grupo de seis pesquisadores com formação em nutrição, enfermagem, fisioterapia e gerontologia.

\subsubsection{Retrotradução}

A partir da versão síntese, foram realizadas duas retrotraduções por tradutores independentes que não conheciam o instrumento original. Um profissional era americano e o outro inglês, ambos com bom domínio do idioma português, e um deles com experiência em ensino de inglês para profissionais da área da saúde.

\subsubsection{Avaliação por um grupo de juízes}

A avaliação das equivalências - semântica, idiomática e cultural foi verificada pelo comitê de juízes, composto por nove profissionais com experiência em gestão em saúde, assistência e metodologia de pesquisa, sendo: duas psicólogas, uma médica clínica, um psiquiatra, um epidemiologista, três enfermeiras e uma assistente social.

Os especialistas preencheram os seguintes critérios: ser profissional da área de saúde; ter domínio da língua inglesa; conhecer os processos de construção e adaptação de instrumentos; conhecer a temática de cuidado integral; e ter experiência assistencial com pacientes clínicocirúrgicos. Os dois primeiros critérios foram considerados imprescindíveis, sendo necessário que os juízes apresentassem, pelo menos, mais um dos demais critérios. 
Os membros do comitê receberam todas as versões do instrumento a ser adaptado: o original, as duas traduções, a síntese das traduções e as duas versões da retrotradução, bem como um formulário de instruções para avaliação das equivalências (Apêndice 1).

Todos os itens componentes do método foram analisados pelos juízes. Para tanto, os especialistas receberam um instrumento de avaliação em que apontaram sua concordância ou discordância quanto à forma final de cada questão, assinalando uma das seguintes opções: -1 (não equivalente); 0 (indeciso); e 1 (equivalente), incluindo um espaço para sugestões, conforme ilustrado na Figura 3, a seguir.

\begin{tabular}{|c|c|c|}
\hline \multicolumn{3}{|c|}{ Questão INTERMED } \\
\hline Semântica & Idiomática & Cultural \\
\hline$(-1) \quad(0) \quad(1)$ & $(-1) \quad(0) \quad(1)$ & $(-1) \quad(0) \quad(1)$ \\
\hline & ões para esta & \\
\hline
\end{tabular}

Figura 3 - Instrumento para avaliação dos juízes, São Paulo - 2012

Após estudo individual das versões, os juízes enviaram suas contribuições, que foram avaliadas e compiladas pela pesquisadora. A concordância entre os especialistas foi avaliada por meio do índice de Validade de Conteúdo (IVC) (Waltz, Strickland, Lenz, 1991), calculado como a razão entre o número de itens avaliados como equivalentes por dois juízes e o total de itens da escala. A avaliação de cada juiz foi comparada com as avaliações dos demais, calculando-se o IVC para cada par de juízes (juiz $1 \mathrm{X}$ juiz 2; juiz $1 \times$ juiz 3 ; juiz $2 \times$ juiz 3 ; juiz $4 \times$ juiz 5 , e, assim, sucessivamente).

Posteriormente, os especialistas reuniram-se na conferência de consenso para alcançar a equivalência entre $o$ instrumento original e a versão final a ser testada. Na reunião, foram apresentadas aos juízes todas 
as contribuições enviadas e, por consenso, ao final do comitê, o grupo consolidou todas as versões do instrumento na versão pré-final.

\subsubsection{Pré-teste}

A versão pré-final do instrumento foi aplicada em 30 indivíduos, sendo 10 por instituição. Como os resultados do pré-teste mostraram que os participantes não tiveram dúvidas quanto aos itens das questões, esses pacientes foram incluídos na amostra final. Nessa fase, cada participante foi entrevistado por um pesquisador treinado, relatando seu entendimento sobre cada item e respectivas respostas, para assegurar adequada equivalência entre $o$ instrumento original e a sua versão traduzida.

\subsection{INSTRUMENTO DE COLETA DE DADOS - O MÉTODO INTERMED}

O método INTERMED é um sistema para classificar a complexidade biopsicossocial de pacientes em diversos níveis de assistência e melhorar a comunicação interprofissional com finalidades clínicas, científicas e educativas (Stiefel et al., 1999; Lobo et al., 2003). Composto por 20 variáveis, discutidas e validadas por uma gama de pesquisadores e clínicos de diversos países, o método sintetiza informações relacionadas a quatro domínios: biológico, psicológico, social e sistema de saúde, em uma perspectiva do tempo que consiste em história, estado atual e prognóstico, conforme resumido na Figura 4 , a seguir. 


\begin{tabular}{|c|c|c|c|}
\hline Domínios & História & Estado Atual & Prognóstico \\
\hline \multirow{2}{*}{ Biológico } & Cronicidade & $\begin{array}{l}\text { Gravidade dos } \\
\text { sintomas }\end{array}$ & \multirow{2}{*}{$\begin{array}{l}\text { Complicações/ } \\
\text { ameaça à vida }\end{array}$} \\
\hline & Dilema diagnóstico & $\begin{array}{l}\text { Desafio diagnóstico/ } \\
\text { terapêutico }\end{array}$ & \\
\hline \multirow{2}{*}{ Psicológico } & $\begin{array}{l}\text { Barreiras de } \\
\text { enfrentamento }\end{array}$ & $\begin{array}{l}\text { Resistência ao } \\
\text { tratamento }\end{array}$ & \multirow{2}{*}{$\begin{array}{l}\text { Ameaça à saúde } \\
\text { mental }\end{array}$} \\
\hline & Disfunção psiquiátrica & $\begin{array}{c}\text { Sintomas } \\
\text { psiquiátricos }\end{array}$ & \\
\hline \multirow[t]{2}{*}{ Social } & $\begin{array}{l}\text { Problemas no } \\
\text { trabalho e lazer }\end{array}$ & $\begin{array}{c}\text { Condições no } \\
\text { domicílio }\end{array}$ & \multirow[t]{2}{*}{ Vulnerabilidade socia } \\
\hline & Situação social & Rede de apoio social & \\
\hline \multirow{2}{*}{$\begin{array}{l}\text { Sistema } \\
\text { de Saúde }\end{array}$} & Acesso ao cuidado & $\begin{array}{l}\text { Organização do } \\
\text { cuidado }\end{array}$ & \multirow{2}{*}{$\begin{array}{l}\text { Impedimentos do } \\
\text { sistema/plano de } \\
\text { saúde }\end{array}$} \\
\hline & $\begin{array}{l}\text { Experiência do } \\
\text { tratamento }\end{array}$ & $\begin{array}{l}\text { Coordenação do } \\
\text { cuidado }\end{array}$ & \\
\hline
\end{tabular}

Fonte: Stiefel et al., 1999.

Figura 4 - V Variáveis do INTERMED, São Paulo - 2012

O método é organizado em 12 células, sendo que 2 variáveis pertinentes foram selecionadas e reunidas de cada célula das colunas história e estado atual, e 1 variável escolhida da coluna de prognóstico.

Os escores para cada variável dos domínios do INTERMED são representados em uma escala do tipo Likert, cuja pontuação foi definida como: 0 - nenhuma vulnerabilidade/necessidade; 1 - pouca vulnerabilidade/necessidade de monitoramento ou prevenção; 2 vulnerabilidade moderada/necessidade de tratamento ou inclusão em um plano de tratamento; 3 - vulnerabilidade severa/necessidade imediata de intervenção ou tratamento intensivo. A pontuação pode variar de 0 a 60 pontos, sinalizando a vulnerabilidade ou a necessidade de cada paciente, de acordo com a seguinte classificação: <21 pontos: paciente não complexo; entre 21 e 30 pontos: complexidade limítrofe; e >30 pontos: paciente 
complexo, que necessita de gerenciamento de caso e um cuidado interprofissional (Stiefel et al., 1999).

A entrevista é composta por 17 questões abertas e um quadro a ser preenchido de acordo com as respostas do participante, gerando uma Classificação de Avaliação de Complexidade. A Figura 5 resume as informações coletadas durante a entrevista do INTERMED, por domínio. No domínio biológico, a distinção entre doença aguda e crônica vem do conceito de doenças somáticas e cuidados necessários aos pacientes, especialmente idosos. No domínio psicológico, as informações sobre estratégias de enfrentamento e histórico psiquiátrico são importantes porque aumentam a complexidade do paciente e o uso do sistema de saúde, diminuem a resposta ao tratamento e aumentam a expressão de sintomas físicos. Em relação ao domínio social, a interação social e a rede de apoio disponível influenciam no processo de adaptação à doença e à organização do cuidado. Finalmente, no domínio sistema de saúde, são coletados dados acerca da intensidade e adequação dos cuidados requeridos, incluindo a complexidade da organização do sistema (Anexo 1). 
Método

\begin{tabular}{|c|c|}
\hline HISTÓRIA & INFORMAÇÃO COLETADA \\
\hline Biológico & $\begin{array}{l}\text { Cronicidade de uma dada doença e episódios anteriores de } \\
\text { diagnósticos incertos }\end{array}$ \\
\hline Psicológico & Estratégias de enfrentamento e histórico psiquiátrico \\
\hline Social & $\begin{array}{l}\text { Integração social, em termos de emprego e atividades de lazer e a } \\
\text { capacidade do paciente em manter relações sociais }\end{array}$ \\
\hline Sistema de Saúde & Intensidade e adequação dos cuidados requeridos anteriormente \\
\hline \multicolumn{2}{|l|}{ ESTADO ATUAL } \\
\hline Biológico & $\begin{array}{l}\text { Severidade dos sintomas, relatos de perdas físicas e } \\
\text { complexidade de diagnósticos }\end{array}$ \\
\hline Psicológico & Nível de cooperação do paciente ao tratamento \\
\hline Social & $\begin{array}{l}\text { Situações atuais vividas e relações de suporte social, como } \\
\text { família, amigos ou colegas }\end{array}$ \\
\hline Sistema de Saúde & $\begin{array}{l}\text { Complexidade organizacional em termos de números e tipos de } \\
\text { condições do cuidado à saúde, antes e depois de uma doença }\end{array}$ \\
\hline \multicolumn{2}{|l|}{ PROGNÓSTICO } \\
\hline Biológico & $\begin{array}{l}\text { Resultados esperados da doença, como deficiências, } \\
\text { complicações ou recorrência da doença ou ameaça à vida }\end{array}$ \\
\hline Psicológico & $\begin{array}{l}\text { Declínio mental esperado e necessidades psicológicas relatadas } \\
\text { que podem resultar de doenças atuais ou antecedentes } \\
\text { psiquiátricos }\end{array}$ \\
\hline Social & $\begin{array}{l}\text { Necessidades sociais esperadas a respeito da integração social do } \\
\text { paciente }\end{array}$ \\
\hline Sistema de Saúde & $\begin{array}{l}\text { Cuidados à saúde que são esperados em termos de intensidade e } \\
\text { de complexidade da organização do sistema }\end{array}$ \\
\hline
\end{tabular}

Fonte: Stiefel et al., 1999.

Figura 5 - Informações coletadas nos domínios do INTERMED, São Paulo - 2012

Destaca-se que o INTERMED possui vantagens em relação a outros instrumentos por: a) ser de rápida aplicação, com duração média entre 15 e 20 minutos; b) explorar muitas informações do paciente, possibilitando o conhecimento e avaliação histórica, atual e futura de quatro aspectos - biológico, psicológico, social e sistema de saúde; e c) possibilitar a coleta de informações por outras pessoas envolvidas no cuidado com o paciente, como familiares e cuidadores, nos casos em que o paciente esteja 
impossibilitado de responder às questões por prejuízo cognitivo grave ou por outras disfunções (Stiefel et al., 1999; Latour, 2006, Wild et al., 2011).

\subsection{POPULAÇÃO E AMOSTRA}

Para atingir os objetivos propostos, optou-se pela aplicação do instrumento em pacientes de três instituições hospitalares, conforme descrito no item 4.3 e de acordo com os critérios abaixo mencionados.

\subsubsection{Critérios de inclusão}

- Ter idade igual ou superior a 21 anos;

- Estar hospitalizado há cinco ou mais dias por patologias clínico-cirúrgicas;

- Concordar em participar do estudo por meio da assinatura do Termo de Consentimento Livre e Esclarecido (TCLE).

\subsubsection{Critérios de exclusão}

Foram excluídos todos os pacientes que não apresentaram condições de responderem às questões do INTERMED devido a alterações do estado mental ou cognitivo e/ou não terem condições de se comunicar verbalmente.

\subsubsection{Tamanho da amostra}

Durante a fase pré-teste, o instrumento foi aplicado a um grupo de 30 indivíduos, de acordo com as recomendações da literatura (Beaton et al., 
2000), sendo 10 de cada um dos três locais de estudo, com o objetivo de representar minimamente os perfis das instituições participantes.

Para a adequada validação do instrumento após a sua tradução e adaptação transcultural, a literatura que versa sobre aspectos metodológicos (Sapnas, Zeller, 2002) sugeriu a avaliação de, no mínimo, 100 instrumentos. Por se tratar de um estudo com três centros para verificar a adequação do instrumento em realidades distintas, foram observados 100 instrumentos por instituição.

\subsection{ASPECTOS ÉTICOS DA PESQUISA}

Inicialmente, foi solicitada autorização dos autores para utilização do método (Anexo 2).

O estudo foi conduzido em conformidade com todas as exigências éticas que envolvem as pesquisas com seres humanos, de acordo com a Resolução n 196/96 do Conselho Nacional de Saúde (CNS/MS).

Além disso, a pesquisa foi aprovada pelos Comitês de Ética em Pesquisa de cada instituição participante (Anexos 3, 4, e 5) e todos os pacientes entrevistados assinaram o Termo de Consentimento Livre e Esclarecido (TCLE) (Apêndice 2).

\subsection{PROCEDIMENTOS DE COLETA DE DADOS}

Inicialmente, foi ministrado treinamento formal aos profissionais envolvidos na coleta de dados. O pesquisador que realizou o treinamento acumula ampla experiência na utilização do método em uma universidade canadense, no âmbito do ensino, pesquisa e assistência utilizando o método INTERMED, na sua prática clínica cotidiana (Carvalhal, 2010). Vale ressaltar que esse pesquisador foi indicado pela equipe da Fundação INTERMED 
(INTERMED Foundation, 2010), em Amsterdã, Holanda, que idealizou e desenvolveu o método.

O treinamento foi dividido em duas etapas: um grupo focal e uma oficina de capacitação, atividades das quais participaram doze enfermeiros, dois gerontólogos, um fisioterapeuta, um psicólogo, um nutricionista e um psiquiatra, todos com experiência em pesquisa e/ou assistência. Destes, alguns fizeram parte do grupo de coleta de dados.

O grupo focal objetivou a discussão inicial sobre a equivalência cultural do instrumento traduzido. Sob a coordenação do pesquisador indicado, seguiu-se a criteriosa leitura do INTERMED, com sugestões dos presentes para melhor adequação cultural do método. No grupo focal, todos os participantes puderam expressar suas opiniões e enriquecer as discussões - devido às diferentes experiências profissionais -, permitindo, assim, uma avaliação criteriosa do INTERMED e das hipóteses do estudo, o que favoreceu a apropriação do método pelos membros do grupo e um melhor desenvolvimento da pesquisa.

A oficina de capacitação para utilização do INTERMED visou à padronização dos procedimentos de coleta. Os pesquisadores tiveram contato com 0 instrumento traduzido. Para o desenvolvimento das habilidades necessárias para a realização adequada da coleta de dados, foi utilizada a técnica de simulação.

Para tanto, foram realizadas duas simulações, sendo que cada uma contou com a participação de dois integrantes da oficina, em uma sala de simulação. Os casos simulados foram baseados na experiência assistencial dos profissionais presentes e, posteriormente, foram transcritos e utilizados para treinamento da equipe na aplicação do método.

Os dados foram coletados entre os meses de setembro e dezembro de 2011. Antes de abordar o paciente, o entrevistador identificava no censo diário os pacientes que poderiam ser elegíveis para a pesquisa, conforme critérios de idade e tempo de internação. Em seguida, reunia-se 
com integrantes da equipe assistencial da unidade para confirmar se o paciente era elegível. Posteriormente, seguia-se a análise do prontuário e, finalmente, o contato com o paciente. Para fazer a entrevista, o pesquisador entrava no quarto, explicava os objetivos do estudo e solicitava a participação. Após a entrevista, o pesquisador realizava o escore de acordo com os critérios do método INTERMED.

Além das questões do INTERMED, os pacientes responderam a um questionário sociodemográfico para caracterização do seu perfil (Apêndice 3). Os dados coletados incluíram: sexo, idade, estado civil, raça, ocupação, renda familiar, escolaridade, hipótese diagnóstica e diagnóstico de alta, data de internação e de alta, religião e autoavaliação do estado de saúde.

\subsection{ANÁLISE ESTATÍSTICA}

Uma amostra de conveniência foi utilizada, incluindo todos os pacientes admitidos nas três instituições que preenchessem os critérios de inclusão, até obter amostra de 100 pacientes por instituição. Os dados foram descritos por frequências absolutas e porcentagens no caso das variáveis qualitativas e por médias e desvios padrão ou medianas e intervalos interquartis no caso das variáveis numéricas.

A concordância entre especialistas na avaliação do instrumento traduzido foi estudada por meio do Índice de Validade de Conteúdo (IVC).

A consistência interna do instrumento foi avaliada pelo coeficiente alpha de Cronbach (Cronbach, 1951). Como todos os pacientes entrevistados estavam hospitalizados, o item sistema de saúde organização do cuidado (estado atual) foi excluído, já que não contribuiu para a estratificação de risco, por ser constante neste estudo.

A estrutura do instrumento foi estudada calculando-se o coeficiente de correlação de Spearman entre os domínios (Lobo et al., 2011). 
A validade preditiva foi investigada, avaliando a relação entre a pontuação total obtida no escore INTERMED e o tempo de hospitalização, por meio de modelos de regressão linear simples aplicados aos valores de tempo transformados logaritmicamente (Magalhães, Lima, 2000). Os resultados foram apresentados por razões de médias e intervalos de confiança de $95 \%$.

Comparações entre os valores do escore em diferentes grupos foram feitas por meio de Análise de Variância com um Fator (ANOVA), avaliando-se a homogeneidade da variância pelo teste de Levene e aplicando a correção de Brown-Forsythe quando necessário. A presença de associação entre variáveis sociodemográficas e os resultados obtidos com o INTERMED foi avaliada por meio de coeficientes de correlação de Spearman, no caso das variáveis numéricas, ou por testes de associação de Qui-Quadrado de Pearson, para as variáveis qualitativas. As análises foram realizadas com o auxílio do programa estatístico SPSS para Windows versão 16.0 e consideraram-se estatisticamente significantes valores de $p$ menores que 0,05 . 
Resultados 


\section{RESULTADOS}

Para a apresentação dos resultados optou-se por iniciar com a tradução e a adaptação transcultural do método INTERMED. Em seguida, serão mostrados os resultados referentes à validação, o que inclui a caracterização da amostra. Finalmente, serão apresentados os dados relacionados à percepção do estado de saúde dos pacientes e a correlação entre as variáveis sociodemográficas e os domínios do INTERMED.

\subsection{TRADUÇÃO E ADAPTAÇÃO TRANSCULTURAL DO INTERMED}

\subsubsection{Tradução, síntese e retrotradução}

$\mathrm{Na}$ tradução do INTERMED, do inglês para o português, houve pequenas diferenças entre as duas traduções realizadas, as quais foram resolvidas por consenso pelo grupo de pesquisadores para gerar a versão síntese. A Figura 6, a seguir, ilustra as principais diferenças entre as duas traduções e como foram resolvidas: 
Resultados

\begin{tabular}{|c|c|c|c|}
\hline Original & Tradução 1 & Tradução 2 & Consenso \\
\hline $\begin{array}{l}\text { Symptom Severity/ } \\
\text { Impairment }\end{array}$ & $\begin{array}{l}\text { Severidade/ Insuficiência } \\
\text { dos sintomas }\end{array}$ & $\begin{array}{l}\text { Gravidade dos sintomas/ } \\
\text { Comprometimento }\end{array}$ & $\begin{array}{l}\text { Gravidade dos Sintomas/ } \\
\text { Comprometimento }\end{array}$ \\
\hline $\begin{array}{l}\text { Mild but notable } \\
\text { symptoms }\end{array}$ & $\begin{array}{c}\text { Sintomas leves, porém } \\
\text { notáveis }\end{array}$ & $\begin{array}{c}\text { Sintomas leves, mas } \\
\text { significativos }\end{array}$ & $\begin{array}{c}\text { Sintomas leves, mas } \\
\text { significativos }\end{array}$ \\
\hline Severe & Graves & Severos & Graves \\
\hline Inability & Inabilidade & Incapacidade & Incapacidade \\
\hline No & Sem & Nenhum & Nenhum \\
\hline Substantial & Substanciais & Significativas & Significativas \\
\hline Illness & Enfermidade & Doença & Doença \\
\hline Medical & Médica & Clínica & Clínica \\
\hline Admission & Admissão & Hospitalização & Hospitalização \\
\hline Problems & Problemas & Dificuldade & Dificuldade \\
\hline Cognitive impairment & Insuficiência cognitiva & $\begin{array}{c}\text { Comprometimento } \\
\text { cognitivo }\end{array}$ & $\begin{array}{l}\text { Comprometimento } \\
\text { cognitivo }\end{array}$ \\
\hline Disturbances & Perturbações & Distúrbios & Distúrbios \\
\hline Now & Agora & Atualmente & Atualmente \\
\hline For & Por & Durante & Durante \\
\hline Disruptive social relations & $\begin{array}{l}\text { Relações sociais } \\
\text { rompentes }\end{array}$ & $\begin{array}{c}\text { Relações sociais } \\
\text { tumultuadas }\end{array}$ & $\begin{array}{c}\text { Relações sociais } \\
\text { tumultuadas }\end{array}$ \\
\hline Residential Instability & $\begin{array}{l}\text { Instabilidade de } \\
\text { residência }\end{array}$ & Instabilidade residencial & Instabilidade residencial \\
\hline Institutional setting & $\begin{array}{c}\text { Assentamento } \\
\text { institucional }\end{array}$ & Instituição & Instituição \\
\hline But possible delays & Com atrasos & Com possíveis demoras & Com possíveis demoras \\
\hline Increased integration & Integração aumentada & Maior integração & Maior integração \\
\hline $\begin{array}{c}\text { Trouble keeping } \\
\text { consistent }\end{array}$ & Em manter consistência & $\begin{array}{c}\text { Em manter profissional } \\
\text { estável e/ou de } \\
\text { preferência }\end{array}$ & $\begin{array}{c}\text { Em manter profissional } \\
\text { estável e/ou de } \\
\text { preferência }\end{array}$ \\
\hline Primary ER & Pronto-socorro primário & Serviço de emergência & Serviço de emergência \\
\hline Provider communication & $\begin{array}{c}\text { Comunicação com o } \\
\text { prestador }\end{array}$ & $\begin{array}{c}\text { Comunicação com os } \\
\text { profissionais }\end{array}$ & $\begin{array}{c}\text { Comunicação com os } \\
\text { profissionais }\end{array}$ \\
\hline $\begin{array}{l}\text { Referral/ } \\
\text { admission }\end{array}$ & $\begin{array}{l}\text { Referência/ } \\
\text { admissão }\end{array}$ & $\begin{array}{l}\text { Encaminhamento/ } \\
\text { admissão }\end{array}$ & $\begin{array}{l}\text { Encaminhamento/ } \\
\text { admissão }\end{array}$ \\
\hline Resolved & Resolvidas & Solucionadas & Solucionadas \\
\hline $\begin{array}{l}\text { Are currently diagnostic } \\
\text { investigations in process } \\
\text { for these complaints? }\end{array}$ & $\begin{array}{c}\text { Investigações } \\
\text { diagnósticas atuais estão } \\
\text { em processo para estas } \\
\text { queixas? }\end{array}$ & $\begin{array}{l}\text { Atualmente, essas } \\
\text { queixas estão sendo } \\
\text { investigadas? }\end{array}$ & $\begin{array}{l}\text { Atualmente, essas } \\
\text { queixas estão sendo } \\
\text { investigadas? }\end{array}$ \\
\hline Caretaker & Cuidadores & Profissionais & Profissionais \\
\hline Is there communication & Há comunicação & Existe comunicação & Existe comunicação \\
\hline You are well insured & $\begin{array}{l}\text { Você está bem } \\
\text { assegurado }\end{array}$ & $\begin{array}{l}\text { Você tem um bom seguro- } \\
\text { saúde }\end{array}$ & $\begin{array}{l}\text { Você tem um bom seguro- } \\
\text { saúde }\end{array}$ \\
\hline As far as I can see & Até onde eu posso ver & $\begin{array}{c}\text { Até onde é de meu } \\
\text { conhecimento }\end{array}$ & $\begin{array}{l}\text { Até onde é de meu } \\
\text { conhecimento }\end{array}$ \\
\hline Cultural background & Experiência cultural & Formação cultural & Formação cultural \\
\hline $\begin{array}{c}\text { Are there } \\
\text { communicational } \\
\text { problems due to impeded } \\
\text { understanding of your } \\
\text { language? }\end{array}$ & $\begin{array}{c}\text { Há problemas de } \\
\text { comunicação devido a } \\
\text { entendimento impedido de } \\
\text { sua linguagem? }\end{array}$ & $\begin{array}{c}\text { Há problemas de } \\
\text { comunicação devido a } \\
\text { problemas de linguagem? }\end{array}$ & $\begin{array}{c}\text { Há problemas de } \\
\text { comunicação devido a } \\
\text { problemas de linguagem? }\end{array}$ \\
\hline Job & Emprego & Trabalho & Trabalho \\
\hline Is able to leisure & É capaz de ter lazer & Consegue ter lazer & Consegue ter lazer \\
\hline $\begin{array}{l}\text { Can get along well with } \\
\text { other persons }\end{array}$ & $\begin{array}{c}\text { Consegue viver bem com } \\
\text { outras pessoas }\end{array}$ & $\begin{array}{l}\text { Consegue ter um bom } \\
\text { relacionamento com } \\
\text { outras pessoas }\end{array}$ & $\begin{array}{l}\text { Consegue ter um bom } \\
\text { relacionamento com } \\
\text { outras pessoas }\end{array}$ \\
\hline To become talkative & Se tornar falador & Falar demais & Falar demais \\
\hline Or silent & Ficar quieto & Ficar em silêncio & Ficar em silêncio \\
\hline What doctors say & O que os médicos dizem & $\begin{array}{l}\text { O que os médicos } \\
\text { recomendam }\end{array}$ & $\begin{array}{l}\text { O que os médicos } \\
\text { recomendam }\end{array}$ \\
\hline
\end{tabular}

\section{Figura 6 - Principais diferenças entre as duas traduções do} INTERMED, São Paulo - 2012 
Com relação às duas retrotraduções, não houve diferenças significativas entre elas e o instrumento original, demonstrando semelhança de significado e conceito. Dessa forma, originou-se a primeira versão traduzida do método INTERMED (Apêndice 4), que foi submetida ao comitê de juízes.

\subsubsection{Adaptação transcultural}

Para realizar a adaptação transcultural, foi necessário analisar as equivalências semântica, idiomática e cultural do instrumento traduzido, tarefa outorgada ao comitê de juízes. Dos nove juízes participantes, todos devolveram o material de avaliação com suas sugestões, no entanto, três deles não assinalaram a nota correspondente às equivalências.

Os valores obtidos das medidas de concordância entre os juízes são apresentados na Tabela 1, em que a intersecção de cada linha e coluna representa a porcentagem de respostas equivalentes entre cada um dos pares de juízes. Os menores índices de concordância foram observados no aspecto cultural, em que o valor mínimo de IVC foi 0,7. Contudo, este valor é considerado satisfatório para avaliação de concordância.

Tabela 1 - Medidas de concordância entre os Juízes, São Paulo - 2012

\begin{tabular}{c|cccccc|cccccc|cccccc}
\hline & \multicolumn{9}{|c|}{ Semântica } & \multicolumn{4}{c|}{ Idiomática } & \multicolumn{7}{c}{ Cultural } \\
\hline Juiz & $\mathbf{1}$ & $\mathbf{2}$ & $\mathbf{4}$ & $\mathbf{5}$ & $\mathbf{6}$ & $\mathbf{9}$ & $\mathbf{1}$ & $\mathbf{2}$ & $\mathbf{4}$ & $\mathbf{5}$ & $\mathbf{6}$ & $\mathbf{9}$ & $\mathbf{1}$ & $\mathbf{2}$ & $\mathbf{4}$ & $\mathbf{5}$ & $\mathbf{6}$ & $\mathbf{9}$ \\
\hline $\mathbf{1}$ & $*$ & 0,9 & 0,9 & 1,0 & 0,8 & 1,0 & $*$ & 0,9 & 0,9 & 0,9 & 0,8 & 0,9 & $*$ & 0,8 & 0,7 & 0,7 & 0,7 & 0,7 \\
$\mathbf{2}$ & & $*$ & 0,9 & 0,9 & 0,8 & 0,9 & & $*$ & 0,9 & 0,9 & 0,8 & 0,9 & & $*$ & 0,7 & 0,7 & 0,7 & 0,7 \\
$\mathbf{4}$ & & & $*$ & 0,9 & 0,8 & 0,9 & & & $*$ & 1,0 & 0,9 & 1,0 & & & $*$ & 0,9 & 0,9 & 0,9 \\
$\mathbf{5}$ & & & & $*$ & 0,9 & 1,0 & & & & $*$ & 0,9 & 1,0 & & & & $*$ & 0,9 & 1,0 \\
$\mathbf{6}$ & & & & $*$ & 0,9 & & & & & $*$ & 0,9 & & & & & $*$ & 0,9 \\
$\mathbf{9}$ & & & & & $*$ & & & & & & $*$ & & & & & & $*$ \\
\hline
\end{tabular}

As avaliações de equivalência obtidas são ilustradas nas Figuras 7, 8 e 9, que demonstram equivalência semântica em $94,2 \%$ das questões, equivalência idiomática em $94,3 \%$ das questões e $86,6 \%$ de equivalência 
cultural. Destaca-se a proporção de itens em que os juízes ficaram indecisos no aspecto cultural, 9,7\%. Estes resultados indicaram que a versão traduzida do instrumento INTERMED apresentou equivalência satisfatória à versão original.

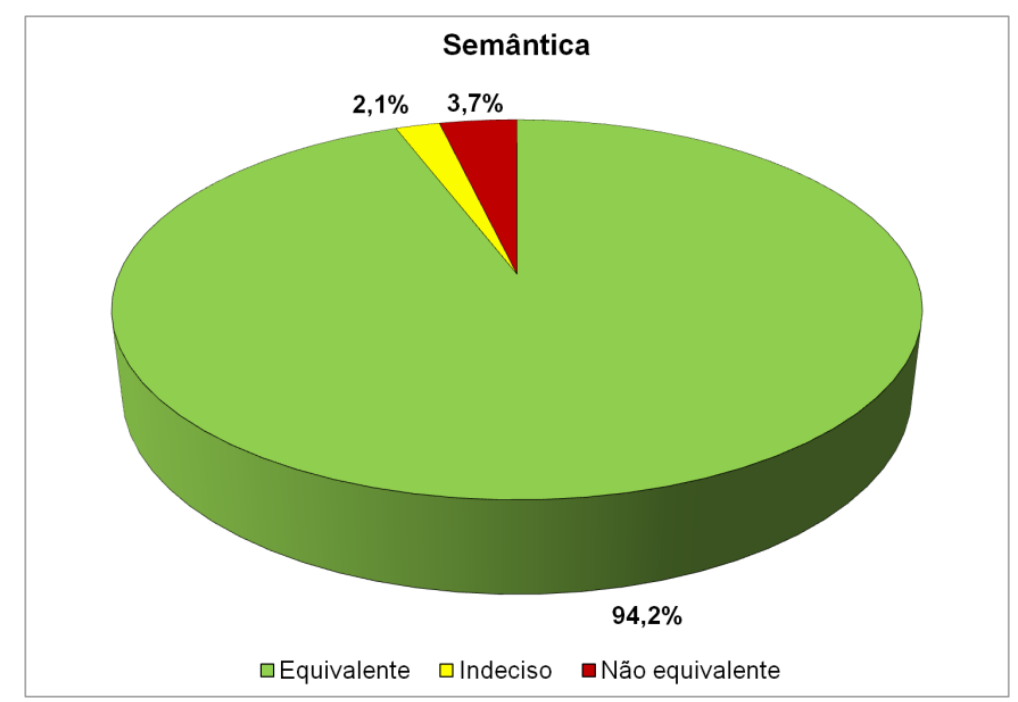

Figura 7 - Equivalência semântica entre a versão traduzida e a original avaliada pelos juízes, São Paulo - 2012

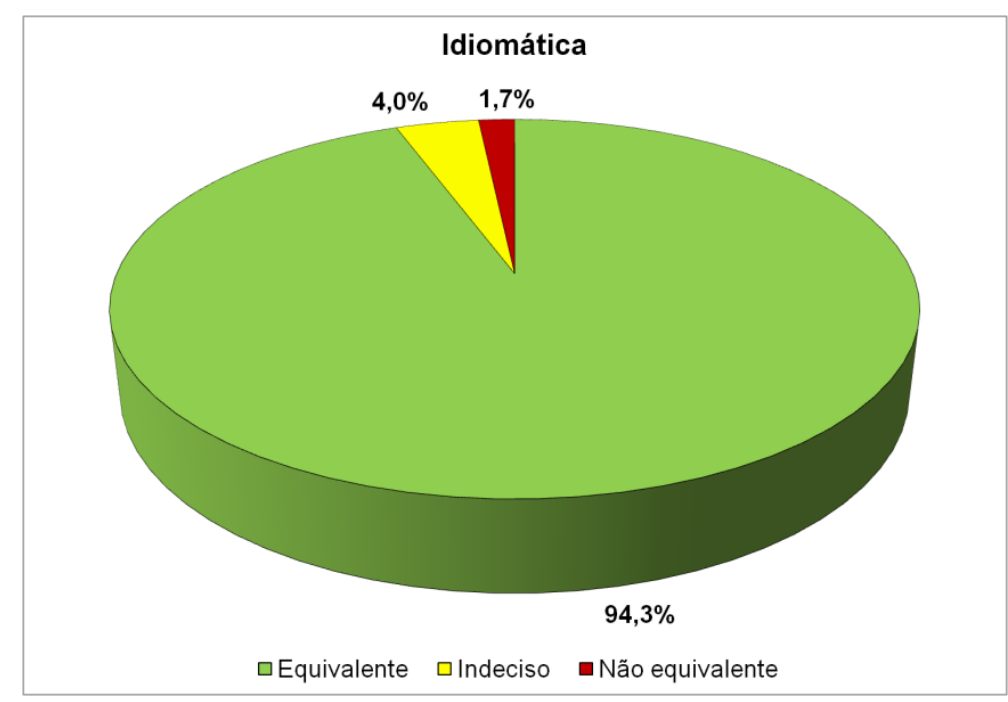

Figura 8 - Equivalência idiomática entre a versão traduzida e a original avaliada pelos juízes, São Paulo - 2012 


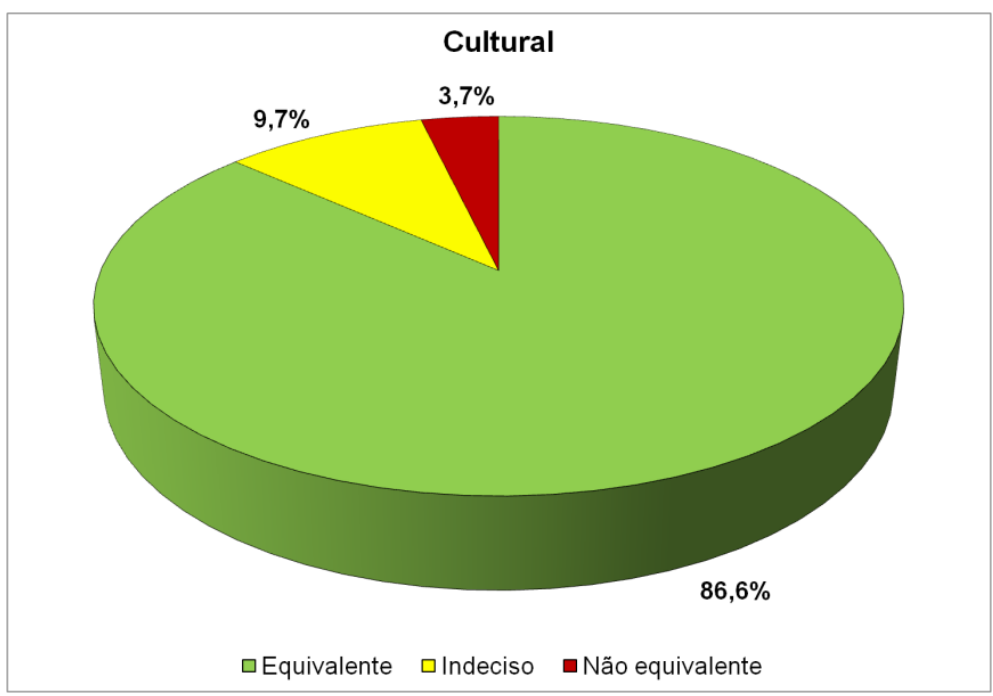

Figura 9 - Equivalência semântica entre a versão traduzida e a original avaliada pelos juízes, São Paulo - 2012

Após a devolução do material, o grupo de especialistas se reuniu em um grupo focal cuja finalidade foi buscar consenso. Durante a reunião, não houve grande discordância entre os juízes para alcançar um acordo sobre termos/expressões mais adequados. O Apêndice 5 contém as sugestões dos juízes para as questões do INTERMED e como foram resolvidas para gerar a segunda versão do instrumento.

A análise dos juízes contribuiu para uma melhor adequação do instrumento, originando a versão pré-final traduzida do método INTERMED, que foi testada no pré-teste. Como os dados do pré-teste mostraram que os participantes não tiveram dúvidas quanto aos itens das questões apresentadas, concluiu-se que o instrumento estava adequado para ser utilizado na pesquisa nos cenários do estudo. Assim, a versão pré-final testada originou a versão final de igual teor, a ser validada posteriormente.

A versão brasileira do método INTERMED é apresentada no Apêndice 6. 


\subsection{VALIDAÇÃO DO INTERMED}

\subsubsection{Caracterização dos participantes do estudo}

O instrumento foi aplicado a 100 pacientes em cada instituição, com um tempo de aplicação que variou de 20 a 40 minutos.

A distribuição dos pacientes quanto ao gênero foi similar no hospital público (instituição C), 49\% masculino, e nas instituições A (hospital privado) e $B$ (hospital de ensino) a maioria dos pacientes era do sexo masculino, 66\% e 60\% (Tabela 2). A idade média dos pacientes foi de 65,7 anos (desvio padrão 12,7) na instituição $A, 56,4$ anos na instituição $B$ (desvio padrão 15,1) e 51,2 anos na instituição $C$ (desvio padrão 16,5). Na instituição $A, 66 \%$ dos pacientes tinham mais de 60 anos, enquanto o percentual foi de $45 \%$ na instituição B e $29 \%$ na C. O tempo mediano de internação na instituição $A$ foi 10 dias, com máximo de 97 dias. Nas instituições $B$ e $C$ os tempos medianos foram 13 e 15, com durações máximas de 48 e 111 dias, respectivamente.

A maioria dos pacientes era casada, ativa e de cor branca ou parda. Chamou a atenção o número de aposentados na amostra, que representou 41\% na instituição A, 34\% na instituição B e $28 \%$ na C. Quanto à renda familiar, na instituição $A, 75 \%$ recebia 5 ou mais salários mínimos, enquanto nas instituições $\mathrm{B}$ e $\mathrm{C}$ a faixa salarial mais citada foi entre 1 e 3 salários mínimos (55\% e 52\%).

Quanto à escolaridade, na instituição A, 45,9\% possuíam ensino superior completo e nas instituições $B$ e $C$ a escolaridade mais citada foi $o$ ensino fundamental incompleto.

Nas três instituições os pacientes avaliavam seu estado de saúde como bom (49,5\%, 59,0\% e 54,0\%). A maioria dos pacientes possuía religião $(96 \%, 98 \%$ e $82 \%)$ e a considerava muito importante $(61,7 \%, 83,7 \%$ e $80,5 \%)$. 
As hipóteses diagnósticas mais frequentes foram doenças do sistema cardiovascular $(69 \%, 38 \%$ e $29 \%)$, seguidas das doenças do sistema respiratório (8\%, 19\% e 18\%). Estas hipóteses se confirmaram em maioria, sendo também os diagnósticos mais frequentes de alta (Tabela 3). 
Tabela 2 - Características sociodemográficas da amostra, São Paulo 2012

\begin{tabular}{|c|c|c|c|c|c|c|c|c|}
\hline & \multicolumn{8}{|c|}{ Identificação do centro } \\
\hline & \multicolumn{2}{|c|}{$\mathbf{A}$} & \multicolumn{2}{|c|}{ B } & \multicolumn{2}{|c|}{$\mathbf{C}$} & \multicolumn{2}{|c|}{ TOTAL } \\
\hline & $\mathbf{n}$ & $\%$ & $\mathbf{n}$ & $\%$ & $\mathbf{n}$ & $\%$ & $\mathbf{n}$ & $\%$ \\
\hline \multicolumn{9}{|l|}{ Sexo } \\
\hline Feminino & 34 & 34 & 40 & 40 & 51 & 51 & 125 & 41,7 \\
\hline Masculino & 66 & 66 & 60 & 60 & 49 & 49 & 175 & 58,3 \\
\hline $\begin{array}{l}\text { Idade (anos) } \\
\text { Média / (desvio padrão) } \\
\text { Idade - categorias }\end{array}$ & 65,7 & $(12,7)$ & 56,4 & $(15,1)$ & 51,2 & $(16,5)$ & 57,8 & $(15,9)$ \\
\hline 21 a 39 anos & 4 & 4 & 13 & 13 & 29 & 29 & 46 & 15 \\
\hline 40 a 59 anos & 30 & 30 & 42 & 42 & 42 & 42 & 114 & 38 \\
\hline 60 anos ou mais & 66 & 66 & 45 & 45 & 29 & 29 & 140 & 46 \\
\hline $\begin{array}{l}\text { Tempo de internação } \\
\text { (dias) } \\
\text { Mediana (mín; máx) }\end{array}$ & 10 & $(5 ; 97)$ & 13 & $(5 ; 48)$ & 15 & $(5 ; 111)$ & 12 & $(5 ; 111)$ \\
\hline \multicolumn{9}{|l|}{ Estado civil } \\
\hline Solteiro & 5 & 5 & 17 & 17 & 24 & 24,2 & 46 & 15,4 \\
\hline Casado & 66 & 66 & 51 & 51 & 47 & 47,5 & 164 & 54,8 \\
\hline separado/divorciado & 15 & 15 & 19 & 19 & 13 & 13,1 & 47 & 15,7 \\
\hline Viúvo & 14 & 14 & 13 & 13 & 15 & 15,2 & 42 & 14 \\
\hline \multicolumn{9}{|l|}{ Cor } \\
\hline Branca & 92 & 92 & 35 & 35 & 41 & 42,7 & 168 & 56,8 \\
\hline Parda & 4 & 4 & 44 & 44 & 35 & 36,5 & 83 & 28 \\
\hline Negra & 2 & 2 & 18 & 18 & 20 & 20,8 & 40 & 13,5 \\
\hline Amarela & 2 & 2 & 3 & 3 & - & - & 5 & 1,7 \\
\hline \multicolumn{9}{|l|}{ Ocupação } \\
\hline Estudante & - & - & - & - & 2 & 2 & 2 & 0,7 \\
\hline Ativo & 43 & 44,3 & 38 & 38 & 52 & 52,5 & 133 & 44,9 \\
\hline Inativo & 7 & 7,2 & 16 & 16 & 16 & 16,2 & 39 & 13,2 \\
\hline Aposentado & 40 & 41,2 & 34 & 34 & 28 & 28,3 & 102 & 34,5 \\
\hline Pensionista & 2 & 2,1 & 1 & 1 & 1 & 1 & 4 & 1,4 \\
\hline Do lar & 5 & 5,2 & 11 & 11 & - & - & 16 & 5,4 \\
\hline \multicolumn{9}{|l|}{$\begin{array}{l}\text { Renda Familiar } \\
\text { (N salários mínimos) }\end{array}$} \\
\hline$<=1$ & 2 & 2,1 & 28 & 28 & 33 & 33,3 & 63 & 21,4 \\
\hline$>1 \mathrm{e}<=3$ & 10 & 10,4 & 55 & 55 & 52 & 52,5 & 117 & 39,7 \\
\hline$>3 \mathrm{e}<=5$ & 12 & 12,5 & 11 & 11 & 11 & 11,1 & 34 & 11,5 \\
\hline$>5$ & 72 & 75,0 & 6 & 6 & 3 & 3 & 81 & 27,5 \\
\hline \multicolumn{9}{|l|}{ Escolaridade } \\
\hline Sem escolaridade & - & - & 23 & 23 & 11 & 11 & 34 & 11,4 \\
\hline Fundamental incompleto & 12 & 12,2 & 38 & 38 & 44 & 44 & 94 & 31,5 \\
\hline Fundamental completo & 9 & 9,2 & 27 & 27 & 22 & 22 & 58 & 19,5 \\
\hline Ensino médio completo & 32 & 32,7 & 10 & 10 & 18 & 18 & 60 & 20,1 \\
\hline Superior completo & 45 & 45,9 & 2 & 2 & 5 & 5 & 52 & 17,4 \\
\hline \multicolumn{9}{|l|}{$\begin{array}{l}\text { Autoavaliação do estado } \\
\text { de saúde }\end{array}$} \\
\hline Bom & 47 & 49,5 & 59 & 59 & 54 & 54 & 160 & 54,2 \\
\hline Regular & 35 & 36,8 & 35 & 35 & 36 & 36 & 106 & 35,9 \\
\hline Ruim & 13 & 13,7 & 6 & 6 & 10 & 10 & 29 & 9,8 \\
\hline \multicolumn{9}{|l|}{ Religião } \\
\hline Não & 4 & 4 & 2 & 2 & 18 & 18 & 24 & 8 \\
\hline Sim & 95 & 96 & 98 & 98 & 82 & 82 & 275 & 92 \\
\hline \multicolumn{9}{|l|}{ Importância da religião } \\
\hline Pouco & 8 & 8,5 & 5 & 5,1 & 6 & 7,3 & 19 & 6,9 \\
\hline Razoável & 28 & 29,8 & 11 & 11,2 & 10 & 12,2 & 49 & 17,9 \\
\hline Muito & 58 & 61,7 & 82 & 83,7 & 66 & 80,5 & 206 & 75,2 \\
\hline
\end{tabular}

Nota: Porcentagens descritas por instituição. 
Tabela 3 - Hipóteses diagnósticas e diagnósticos de alta, São Paulo 2012

\begin{tabular}{|c|c|c|c|c|c|c|c|c|}
\hline & \multicolumn{8}{|c|}{ Identificação do centro } \\
\hline & \multicolumn{2}{|c|}{$\mathbf{A}$} & \multicolumn{2}{|c|}{ B } & \multicolumn{2}{|c|}{$\mathbf{C}$} & \multicolumn{2}{|c|}{ TOTAL } \\
\hline & $\mathbf{n}$ & $\%$ & $\mathbf{n}$ & $\%$ & $\mathbf{n}$ & $\%$ & $\mathbf{n}$ & $\%$ \\
\hline \multicolumn{9}{|l|}{ Hipótese diagnóstica } \\
\hline Doenças cardiovasculares & 69 & 69,0 & 38 & 38,0 & 29 & 29,0 & 136 & 45,3 \\
\hline Doenças respiratórias & 8 & 8,0 & 19 & 19,0 & 18 & 18,0 & 45 & 15,0 \\
\hline $\begin{array}{l}\text { Fatores que influenciam o } \\
\text { estado de saúde/contato } \\
\text { com os serviços de saúde }\end{array}$ & 6 & 6,0 & - & - & 7 & 7,0 & 13 & 4,3 \\
\hline Neoplasias & 4 & 4,0 & 4 & 4,0 & 1 & 1,0 & 9 & 3,0 \\
\hline $\begin{array}{l}\text { Doenças osteomusculares } \\
\text { e do tecido conjuntivo }\end{array}$ & 3 & 3,0 & 1 & 1,0 & 2 & 2,0 & 6 & 2,0 \\
\hline $\begin{array}{l}\text { Doenças infecciosas e } \\
\text { parasitárias }\end{array}$ & 2 & 2,0 & 13 & 13,0 & - & - & 15 & 5,0 \\
\hline $\begin{array}{l}\text { Doenças do sistema } \\
\text { digestório }\end{array}$ & 2 & 2,0 & 3 & 3,0 & 14 & 14,0 & 19 & 6,3 \\
\hline $\begin{array}{l}\text { Lesões, envenenamento e } \\
\text { causas externas }\end{array}$ & 2 & 2,0 & 2 & 2,0 & 6 & 6,0 & 10 & 3,3 \\
\hline $\begin{array}{l}\text { Doenças endócrinas, } \\
\text { nutricionais e metabólicas }\end{array}$ & 1 & 1,0 & 9 & 9,0 & 1 & 1,0 & 11 & 3,7 \\
\hline $\begin{array}{l}\text { Doenças do sistema } \\
\text { nervoso }\end{array}$ & 1 & 1,0 & 1 & 1,0 & - & - & 2 & 0,7 \\
\hline $\begin{array}{l}\text { Causas externas de } \\
\text { morbidade e mortalidade }\end{array}$ & 1 & 1,0 & - & - & 10 & 10,0 & 11 & 3,7 \\
\hline Malformações congênitas & 1 & 1,0 & - & - & - & - & 1 & 0,3 \\
\hline $\begin{array}{l}\text { Doenças do aparelho } \\
\text { geniturinário }\end{array}$ & - & - & 8 & 8,0 & 10 & 10,0 & 18 & 6,0 \\
\hline $\begin{array}{l}\text { Doenças da pele e do } \\
\text { tecido subcutâneo }\end{array}$ & - & - & 2 & 2,0 & 1 & 1,0 & 3 & 1,0 \\
\hline Gravidez, parto, puerpério & - & - & - & - & 1 & 1,0 & 1 & 0,3 \\
\hline \multicolumn{9}{|l|}{ Diagnóstico de alta } \\
\hline Doenças cardiovasculares & 64 & 71,9 & 44 & 44,9 & 22 & 24,7 & 130 & 47,1 \\
\hline Doenças respiratórias & 8 & 9,0 & 9 & 9,2 & 20 & 22,5 & 37 & 13,4 \\
\hline Neoplasias & 6 & 6,7 & 9 & 9,2 & 1 & 1,1 & 16 & 5,8 \\
\hline $\begin{array}{l}\text { Doenças osteomusculares } \\
\text { e do tecido conjuntivo }\end{array}$ & 3 & 3,4 & 3 & 3,1 & 1 & 1,1 & 7 & 2,5 \\
\hline $\begin{array}{l}\text { Doenças infecciosas e } \\
\text { parasitárias }\end{array}$ & 2 & 2,2 & 10 & 10,2 & - & - & 12 & 4,3 \\
\hline $\begin{array}{l}\text { Doenças do aparelho } \\
\text { geniturinário }\end{array}$ & 1 & 1,1 & 6 & 6,1 & 6 & 6,7 & 13 & 4,7 \\
\hline $\begin{array}{l}\text { Lesões, envenenamento e } \\
\text { causas externas }\end{array}$ & 1 & 1,1 & 3 & 3,1 & 10 & 11,2 & 14 & 5,1 \\
\hline $\begin{array}{l}\text { Doenças da pele e do } \\
\text { tecido subcutâneo }\end{array}$ & 1 & 1,1 & 1 & 1,0 & - & - & 2 & 0,7 \\
\hline $\begin{array}{l}\text { Doenças do sistema } \\
\text { nervoso }\end{array}$ & 1 & 1,1 & 1 & 1,0 & - & - & 2 & 0,7 \\
\hline $\begin{array}{l}\text { Causas externas de } \\
\text { morbidade e mortalidade }\end{array}$ & 1 & 1,1 & - & - & 7 & 7,9 & 8 & 2,9 \\
\hline Malformações congênitas & 1 & 1,1 & - & - & - & - & 1 & 0,4 \\
\hline $\begin{array}{l}\text { Doenças endócrinas, } \\
\text { nutricionais e metabólicas }\end{array}$ & - & - & 9 & 9,2 & 1 & 1,1 & 10 & 3,6 \\
\hline $\begin{array}{l}\text { Doenças do sistema } \\
\text { digestório }\end{array}$ & - & - & 3 & 3,1 & 17 & 19,1 & 20 & 7,2 \\
\hline $\begin{array}{l}\text { Fatores que influenciam o } \\
\text { estado de saúde/contato } \\
\text { com os serviços de saúde }\end{array}$ & - & - & - & - & 2 & 2,2 & 2 & 0,7 \\
\hline Gravidez, parto, puerpério & - & - & - & - & 1 & 1,1 & 1 & 0,4 \\
\hline $\begin{array}{l}\text { Transtornos mentais/ } \\
\text { comportamentais }\end{array}$ & - & - & - & - & 1 & 1,1 & 1 & 0,4 \\
\hline
\end{tabular}

Nota: Porcentagens descritas por instituição. 


\subsubsection{Respostas obtidas com a aplicação do INTERMED}

A descrição das respostas obtidas em cada item do instrumento está apresentada nas Tabelas 4, 5, 6 e 7, separadamente por domínios.

No domínio biológico (Tabela 4), 60\% dos pacientes da instituição A, $58 \%$ da B e $13 \%$ da C possuíam várias doenças crônicas. Na instituição C, $42 \%$ dos pacientes possuíam menos de três meses de disfunção física. Nos três hospitais a maioria dos pacientes possuía sintomas moderados, que interferiam na funcionalidade (67\%, $77 \%$ e $55,6 \%)$. Chamou a atenção o grau de vulnerabilidade biológica desses pacientes, com risco moderado de limitações permanentes e/ou significativas nas atividades de vida diária (47\%, 44\% e $45,9 \%)$.

De acordo com o item barreiras de enfrentamento no domínio psicológico, parte considerável dos pacientes possuía algum tipo de restrição para enfrentamento ( $43 \%$ na instituição A, 52\% na B e $42 \%$ na C). Considerando os três cenários do estudo, no domínio psicológico, chamou a atenção que $45 \%$ dos pacientes tinham habilidades mínimas ou insuficientes para enfrentamento das barreiras psicológicas, sendo que 12,8\% deles possuíam histórico de disfunção psiquiátrica e 9,75\% apresentavam grau de vulnerabilidade com risco de transtorno psiquiátrico (Tabela 5).

Além disso, 32,7\% dos pacientes possuíam algum tipo de disfunção social (por instituição: 24\%, 34\% e 40\%); 41,8\% apresentavam alguma limitação relacionada à rede de apoio social, sendo $42 \%$ dos pacientes na instituição $A, 56 \%$ na B e $24,3 \%$ na C; e $36,8 \%$ possuíam maior necessidade de suporte social e integração (Tabela 6 ).

No domínio sistema de saúde, 38,7\% dos pacientes possuíam algum tipo de limitação no acesso ao cuidado e $26,1 \%$ tiveram experiência negativa com profissionais de saúde. Com relação à vulnerabilidade, 38,1\% dos pacientes apresentavam risco de leve a moderado de impedimentos ao 
cuidado, sendo que, por instituição, $49 \%$ na $A, 29 \%$ na B e $21,2 \%$ na $C$ possuíam risco leve de impedimentos ao cuidado (Tabela 7 ).

Tabela 4 - Respostas obtidas no domínio biológico, São Paulo - 2012

\begin{tabular}{|c|c|c|c|c|c|c|c|c|}
\hline \multirow{3}{*}{ Biológico } & \multicolumn{8}{|c|}{ Identificação do centro } \\
\hline & \multicolumn{2}{|c|}{$\mathbf{A}$} & \multicolumn{2}{|c|}{ B } & \multicolumn{2}{|c|}{ C } & \multicolumn{2}{|c|}{ TOTAL } \\
\hline & $\mathbf{n}$ & $\%$ & $\mathbf{n}$ & $\%$ & $\mathbf{n}$ & $\%$ & $\mathbf{n}$ & $\%$ \\
\hline \multicolumn{9}{|l|}{ Cronicidade (histórico) } \\
\hline Menos que 3 meses de disfunção física & 11 & 11,0 & 7 & 7,0 & 42 & 42,4 & 60 & 20,1 \\
\hline $\begin{array}{l}\text { Mais que } 3 \text { meses de disfunção física ou } \\
\text { vários períodos de menos de } 3 \text { meses }\end{array}$ & 12 & 12,0 & 6 & 6,0 & 24 & 24,2 & 42 & 14,0 \\
\hline Uma doença crônica & 17 & 17,0 & 29 & 29,0 & 20 & 20,2 & 66 & 22,1 \\
\hline Várias doenças crônicas & 60 & 60,0 & 58 & 58,0 & 13 & 13,1 & 131 & 43,8 \\
\hline \multicolumn{9}{|l|}{ Dilema no diagnóstico (histórico) } \\
\hline $\begin{array}{l}\text { Sem períodos de complexidade } \\
\text { diagnóstica }\end{array}$ & 23 & 23,0 & 13 & 13,0 & 24 & 24,7 & 60 & 20,2 \\
\hline $\begin{array}{l}\text { Diagnóstico e etiologia foram rapidamente } \\
\text { esclarecidos }\end{array}$ & 47 & 47,0 & 33 & 33,0 & 51 & 52,6 & 131 & 44,1 \\
\hline $\begin{array}{l}\text { Dilema no diagnóstico resolvido, mas com } \\
\text { esforço considerável }\end{array}$ & 23 & 23,0 & 42 & 42,0 & 16 & 16,5 & 81 & 27,3 \\
\hline Dilema no diagnóstico não resolvido & 7 & 7,0 & 12 & 12,0 & 6 & 6,2 & 25 & 8,4 \\
\hline \multicolumn{9}{|l|}{ Gravidade sintomas (estado atual) } \\
\hline $\begin{array}{l}\text { Sem sintomas ou sintomas reversíveis } \\
\text { sem esforços médicos intensivos }\end{array}$ & 4 & 4,0 & 2 & 2,0 & 14 & 14,1 & 20 & 6,7 \\
\hline $\begin{array}{l}\text { Sintomas leves, significativos, que não } \\
\text { interferem na funcionalidade atual }\end{array}$ & 21 & 21,0 & 14 & 14,0 & 19 & 19,2 & 54 & 18,1 \\
\hline $\begin{array}{l}\text { Sintomas moderados a graves, que } \\
\text { interferem na funcionalidade atual }\end{array}$ & 67 & 67,0 & 77 & 77,0 & 55 & 55,6 & 199 & 66,6 \\
\hline $\begin{array}{l}\text { Sintomas graves que levam à } \\
\text { incapacidade de realizar quaisquer } \\
\text { atividades funcionais }\end{array}$ & 8 & 8,0 & 7 & 7,0 & 11 & 11,1 & 26 & 8,7 \\
\hline \multicolumn{9}{|l|}{$\begin{array}{l}\text { Desafio diagnóstico/terapêutico (estado } \\
\text { atual) }\end{array}$} \\
\hline $\begin{array}{l}\text { Diagnósticos claros e/ou tratamento não } \\
\text { complicado }\end{array}$ & 8 & 8,0 & 2 & 2,0 & 27 & 27,6 & 37 & 12,4 \\
\hline $\begin{array}{l}\text { Diagnósticos diferenciais claros e/ou } \\
\text { diagnóstico esperado com tratamentos } \\
\text { definidos }\end{array}$ & 70 & 70,0 & 54 & 54,0 & 52 & 53,1 & 176 & 59,1 \\
\hline $\begin{array}{l}\text { Dificuldade para diagnosticar a } \\
\text { causa/origem física e tratá-la da forma } \\
\text { esperada }\end{array}$ & 17 & 17,0 & 42 & 42,0 & 15 & 15,3 & 74 & 24,8 \\
\hline $\begin{array}{l}\text { Dificuldade de diagnosticar ou tratar, } \\
\text { outros problemas além de causas físicas } \\
\text { interferindo no diagnóstico e no processo } \\
\text { terapêutico }\end{array}$ & 5 & 5,0 & 2 & 2,0 & 4 & 4,1 & 11 & 3,7 \\
\hline \multicolumn{9}{|l|}{$\begin{array}{l}\text { Complicações/ameaça à vida } \\
\text { (vulnerabilidades) }\end{array}$} \\
\hline $\begin{array}{l}\text { Nenhum risco de limitações nas atividades } \\
\text { da vida diária }\end{array}$ & 6 & 6,0 & 4 & 4,0 & 11 & 11,0 & 21 & 7,0 \\
\hline $\begin{array}{l}\text { Risco leve de limitações nas atividades da } \\
\text { vida diária }\end{array}$ & 28 & 28,0 & 39 & 39,0 & 33 & 33,7 & 100 & 33,6 \\
\hline $\begin{array}{l}\text { Risco moderado de limitações } \\
\text { permanentes e/ou significativas nas } \\
\text { atividades da vida diária }\end{array}$ & 47 & 47,0 & 44 & 44,0 & 45 & 45,9 & 136 & 45,6 \\
\hline $\begin{array}{l}\text { Risco elevado de complicações físicas } \\
\text { com sérios déficits funcionais permanentes } \\
\text { e/ou morte }\end{array}$ & 19 & 19,0 & 13 & 13,0 & 9 & 9,2 & 41 & 13,8 \\
\hline
\end{tabular}

Nota: Porcentagens descritas por instituição. 
Tabela 5 - Respostas obtidas no domínio psicológico, São Paulo - 2012

\begin{tabular}{|c|c|c|c|c|c|c|c|c|}
\hline \multirow{3}{*}{ Psicológico } & \multicolumn{8}{|c|}{ Identificação do centro } \\
\hline & \multicolumn{2}{|c|}{$\mathbf{A}$} & \multicolumn{2}{|c|}{$\mathbf{B}$} & \multicolumn{2}{|c|}{ C } & \multicolumn{2}{|c|}{ TOTAL } \\
\hline & $\mathbf{n}$ & $\%$ & $\mathbf{n}$ & $\%$ & $\mathbf{n}$ & $\%$ & $\mathbf{n}$ & $\%$ \\
\hline \multicolumn{9}{|l|}{$\begin{array}{l}\text { Barreiras de enfrentamento } \\
\text { (histórico) }\end{array}$} \\
\hline $\begin{array}{l}\text { Capacidade de manejar o } \\
\text { estresse }\end{array}$ & 57 & 57,0 & 48 & 48,0 & 58 & 58,0 & 163 & 54,3 \\
\hline $\begin{array}{l}\text { Habilidades restritas de } \\
\text { enfrentamento }\end{array}$ & 38 & 38,0 & 23 & 23,0 & 31 & 31,0 & 92 & 30,7 \\
\hline $\begin{array}{l}\text { Habilidades insuficientes de } \\
\text { enfrentamento }\end{array}$ & 3 & 3,0 & 20 & 20,0 & 9 & 9,0 & 32 & 10,7 \\
\hline $\begin{array}{l}\text { Habilidades mínimas de } \\
\text { enfrentamento }\end{array}$ & 2 & 2,0 & 9 & 9,0 & 2 & 2,0 & 13 & 4,3 \\
\hline \multicolumn{9}{|l|}{ Disfunção psiquiátrica (histórico) } \\
\hline Nenhuma disfunção psiquiátrica & 43 & 43,0 & 52 & 52,0 & 61 & 61,6 & 156 & 52,2 \\
\hline $\begin{array}{l}\text { Disfunção psiquiátrica sem efeitos } \\
\text { claros na funcionalidade diária }\end{array}$ & 44 & 44,0 & 26 & 26,0 & 32 & 32,3 & 102 & 34,1 \\
\hline $\begin{array}{l}\text { Disfunção psiquiátrica com efeitos } \\
\text { claros na funcionalidade diária }\end{array}$ & 11 & 11,0 & 21 & 21,0 & 6 & 6,0 & 38 & 12,7 \\
\hline $\begin{array}{l}\text { Hospitalização(ões) } \\
\text { psiquiátrica(s) e/ou efeitos } \\
\text { permanentes na funcionalidade } \\
\text { diária }\end{array}$ & 2 & 2,0 & 1 & 1,0 & - & - & 3 & 1,0 \\
\hline
\end{tabular}

\section{Resistência ao tratamento (estado}

atual)

Interessado em receber

$\begin{array}{lllllllll}\text { tratamento e disposto a cooperar } & 46 & 46,0 & 67 & 67,0 & 72 & 72,0 & 185 & 61,0\end{array}$ ativamente

Alguma ambivalência, apesar de

$\begin{array}{lllllllll}\text { disposto a cooperar com o } & 43 & 43,0 & 23 & 23,0 & 22 & 22,0 & 88 & 29,3\end{array}$

tratamento

$\begin{array}{lllllllll}\text { Resistência considerável } & 11 & 11,0 & 10 & 10,0 & 5 & 5,0 & 26 & 8,7\end{array}$

Resistência ativa ao cuidado

médico

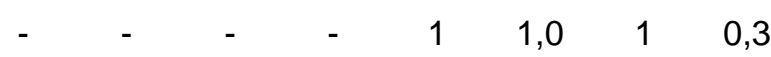

\section{Sintomas psiquiátricos (estado \\ atual)}

Sem sintomas psiquiátricos

Sintomas psiquiátricos leves, tais

$\begin{array}{lllllllll}\text { como dificuldade de concentração } & 39 & 39,0 & 15 & 15,0 & 16 & 16,0 & 70 & 23,3\end{array}$

ou tensão

Sintomas psiquiátricos

moderados

Sintomas psiquiátricos graves e/ou distúrbios comportamentais

$\begin{array}{llllllll}18 & 18,0 & 42 & 42,0 & 71 & 71,0 & 131 & 43,7\end{array}$

Ameaça à saúde mental

(vulnerabilidades)

Sem risco de transtorno

psiquiátrico

$\begin{array}{llllllll}41 & 41,0 & 42 & 42,0 & 12 & 12,0 & 95 & 31,7\end{array}$

Risco leve de sintomas

psiquiátricos

$\begin{array}{llllllll}2 & 2,0 & 1 & 1,0 & 1 & 1,0 & 4 & 1,3\end{array}$

Risco moderado de transtorno

psiquiátrico

Risco grave de transtorno

psiquiátrico

$\begin{array}{llllllll}16 & 16,0 & 34 & 34,0 & 65 & 65,0 & 115 & 38,3\end{array}$

$\begin{array}{llllllll}74 & 74,0 & 50 & 50,0 & 32 & 32,0 & 156 & 52,0\end{array}$

$\begin{array}{llllllll}10 & 10,0 & 14 & 14,0 & 3 & 3,0 & 27 & 9,0\end{array}$

Nota: Porcentagens descritas por instituição. 
Tabela 6 - Respostas obtidas no domínio social, São Paulo - 2012

\begin{tabular}{|c|c|c|c|c|c|c|c|c|}
\hline \multirow{3}{*}{ Social } & \multicolumn{8}{|c|}{ Identificação do centro } \\
\hline & \multicolumn{2}{|c|}{$\mathbf{A}$} & \multicolumn{2}{|c|}{ B } & \multicolumn{2}{|c|}{ C } & \multicolumn{2}{|c|}{ TOTAL } \\
\hline & $\mathbf{n}$ & $\%$ & $\mathbf{n}$ & $\%$ & $\mathbf{n}$ & $\%$ & $\mathbf{n}$ & $\%$ \\
\hline \multicolumn{9}{|l|}{$\begin{array}{l}\text { Problemas no trabalho e lazer } \\
\text { (histórico) }\end{array}$} \\
\hline $\begin{array}{l}\text { Trabalho/ocupação e tem atividades } \\
\text { de lazer }\end{array}$ & 79 & 79,0 & 29 & 29,0 & 57 & 57,6 & 165 & 55,2 \\
\hline $\begin{array}{l}\text { Trabalho/ocupação e sem atividades } \\
\text { de lazer }\end{array}$ & 18 & 18,0 & 52 & 52,0 & 31 & 31,3 & 101 & 33,8 \\
\hline $\begin{array}{l}\text { Desempregado e pelo menos } 6 \\
\text { meses com atividades de lazer }\end{array}$ & 2 & 2,0 & 3 & 3,0 & 5 & 5,1 & 10 & 3,3 \\
\hline $\begin{array}{l}\text { Desempregado e pelo menos } 6 \\
\text { meses sem atividades de lazer }\end{array}$ & 1 & 1,0 & 16 & 16,0 & 6 & 6,1 & 23 & 7,7 \\
\hline \multicolumn{9}{|l|}{ Disfunção social (histórico) } \\
\hline Sem ruptura social & 76 & 76,0 & 66 & 66,0 & 60 & 60,6 & 202 & 67,6 \\
\hline Dificuldade de interação social leve & 18 & 18,0 & 23 & 23,0 & 32 & 32,3 & 73 & 24,4 \\
\hline $\begin{array}{l}\text { Dificuldade de interação social } \\
\text { moderada }\end{array}$ & 4 & 4,0 & 9 & 9,0 & 7 & 7,1 & 20 & 6,7 \\
\hline Dificuldade de interação social grave & 2 & 2,0 & 2 & 2,0 & - & - & 4 & 1,3 \\
\hline \multicolumn{9}{|l|}{ Condições no domicílio (estado atual) } \\
\hline $\begin{array}{l}\text { Domicílio estável; capaz de viver } \\
\text { independentemente }\end{array}$ & 40 & 40,0 & 47 & 47,0 & 61 & 61,6 & 148 & 49,5 \\
\hline Domicílio estável com ajuda de outros & 58 & 58,0 & 49 & 49,0 & 34 & 34,3 & 141 & 47,2 \\
\hline $\begin{array}{l}\text { Domicílio instável; necessária } \\
\text { mudança da situação de vida atual }\end{array}$ & 2 & 2,0 & 1 & 1,0 & 3 & 3,0 & 6 & 2,0 \\
\hline $\begin{array}{l}\text { Sem domicílio atual satisfatório; é } \\
\text { necessária mudança imediata }\end{array}$ & - & - & 3 & 3,0 & 1 & 1,0 & 4 & 1,3 \\
\hline \multicolumn{9}{|l|}{$\begin{array}{l}\text { Rede apoio social precária (estado } \\
\text { atual) }\end{array}$} \\
\hline $\begin{array}{l}\text { Suporte prontamente disponível, em } \\
\text { todos os momentos }\end{array}$ & 58 & 58,0 & 44 & 44,0 & 75 & 75,8 & 177 & 59,2 \\
\hline $\begin{array}{l}\text { Suporte disponível, porém } \\
\text { inconstante }\end{array}$ & 31 & 31,0 & 18 & 18,0 & 15 & 15,2 & 64 & 21,4 \\
\hline Suporte limitado & 11 & 11,0 & 35 & 35,0 & 7 & 7,1 & 53 & 17,7 \\
\hline Sem nenhum suporte & - & - & 3 & 3,0 & 2 & 2,0 & 5 & 1,7 \\
\hline \multicolumn{9}{|l|}{$\begin{array}{l}\text { Vulnerabilidade social } \\
\text { (vulnerabilidades) }\end{array}$} \\
\hline $\begin{array}{l}\text { Sem risco de mudanças na situação } \\
\text { de vida }\end{array}$ & 48 & 48,0 & 50 & 50,0 & 70 & 70,7 & 168 & 56,2 \\
\hline $\begin{array}{l}\text { Sem risco de mudanças na situação } \\
\text { de vida, mas são necessários maior } \\
\text { suporte social e integração }\end{array}$ & 44 & 44,0 & 42 & 42,0 & 24 & 24,2 & 110 & 36,8 \\
\hline $\begin{array}{l}\text { Risco de admissão temporária ou } \\
\text { permanente em instituição no futuro } \\
\text { previsível }\end{array}$ & 8 & 8,0 & 7 & 7,0 & 5 & 5,1 & 20 & 6,7 \\
\hline $\begin{array}{l}\text { Necessidade imediata de admissão } \\
\text { temporária ou permanente em } \\
\text { instituição }\end{array}$ & - & - & 1 & 1,0 & - & - & 1 & 0,3 \\
\hline
\end{tabular}

Nota: Porcentagens descritas por instituição. 
Tabela 7 - Respostas obtidas no domínio sistema de saúde, São Paulo $-2012$

\begin{tabular}{|c|c|c|c|c|c|c|c|c|}
\hline \multirow{3}{*}{ Sistema de Saúde } & \multicolumn{8}{|c|}{ Identificação do centro } \\
\hline & \multicolumn{2}{|c|}{$\mathbf{A}$} & \multicolumn{2}{|c|}{ B } & \multicolumn{2}{|c|}{$\mathbf{C}$} & \multicolumn{2}{|c|}{ TOTAL } \\
\hline & $\mathbf{n}$ & $\%$ & $\mathbf{n}$ & $\%$ & $\mathbf{n}$ & $\%$ & $\mathbf{n}$ & $\%$ \\
\hline \multicolumn{9}{|l|}{ Acesso ao cuidado (histórico) } \\
\hline Acesso adequado ao cuidado & 48 & 48,0 & 64 & 64,0 & 69 & 69,7 & 181 & 60,5 \\
\hline $\begin{array}{l}\text { Alguma limitação no acesso ao } \\
\text { cuidado }\end{array}$ & 34 & 34,0 & 24 & 24,0 & 25 & 25,3 & 83 & 27,8 \\
\hline Dificuldades no acesso ao cuidado & 14 & 14,0 & 12 & 12,0 & 4 & 4,0 & 30 & 10,0 \\
\hline Sem acesso adequado ao cuidado & 4 & 4,0 & - & - & 1 & 1,0 & 5 & 1,7 \\
\hline \multicolumn{9}{|l|}{ Experiência do tratamento (histórico) } \\
\hline $\begin{array}{l}\text { Sem problemas com profissionais de } \\
\text { saúde }\end{array}$ & 50 & 50,0 & 66 & 66,0 & 81 & 81,8 & 197 & 65,9 \\
\hline $\begin{array}{l}\text { Experiência negativa com } \\
\text { profissionais de saúde (sua ou de } \\
\text { parentes) }\end{array}$ & 32 & 32,0 & 30 & 30,0 & 16 & 16,2 & 78 & 26,1 \\
\hline $\begin{array}{l}\text { Pedidos de segunda opinião ou } \\
\text { mudança de médicos mais de uma } \\
\text { vez; múltiplos profissionais }\end{array}$ & 17 & 17,0 & 4 & 4,0 & 2 & 2,0 & 23 & 7,7 \\
\hline $\begin{array}{l}\text { Repetidos conflitos com médicos, } \\
\text { visitas frequentes ao serviço de } \\
\text { emergência, ou hospitalizações } \\
\text { involuntárias }\end{array}$ & 1 & 1,0 & - & - & - & - & 1 & 0,3 \\
\hline \multicolumn{9}{|l|}{$\begin{array}{l}\text { Coordenação do cuidado (estado } \\
\text { atual) }\end{array}$} \\
\hline $\begin{array}{l}\text { Comunicação completa com o } \\
\text { profissional e boa coordenação do } \\
\text { cuidado }\end{array}$ & 50 & 50,5 & 95 & 95,0 & 62 & 63,3 & 207 & 69,7 \\
\hline $\begin{array}{l}\text { Comunicação limitada com o } \\
\text { profissional e coordenação do } \\
\text { cuidado }\end{array}$ & 27 & 27,3 & 5 & 5,0 & 26 & 26,5 & 58 & 19,5 \\
\hline $\begin{array}{l}\text { Comunicação precária e coordenação } \\
\text { do cuidado entre os profissionais }\end{array}$ & 18 & 18,2 & - & - & 9 & 9,2 & 27 & 9,1 \\
\hline $\begin{array}{l}\text { Nenhuma comunicação e } \\
\text { coordenação do cuidado entre os } \\
\text { profissionais }\end{array}$ & 4 & 4,0 & - & - & 1 & 1,0 & 5 & 1,7 \\
\hline \multicolumn{9}{|l|}{$\begin{array}{l}\text { Impedimentos do sistema/plano de } \\
\text { saúde (vulnerabilidades) }\end{array}$} \\
\hline $\begin{array}{l}\text { Sem risco de impedimentos para } \\
\text { coordenar cuidado }\end{array}$ & 43 & 43,0 & 68 & 68,0 & 74 & 74,7 & 185 & 61,9 \\
\hline $\begin{array}{l}\text { Risco leve de impedimentos ao } \\
\text { cuidado }\end{array}$ & 49 & 49,0 & 29 & 29,0 & 21 & 21,2 & 99 & 33,1 \\
\hline $\begin{array}{l}\text { Risco moderado de impedimentos ao } \\
\text { cuidado }\end{array}$ & 5 & 5,0 & 2 & 2,0 & 3 & 3,0 & 10 & 3,3 \\
\hline $\begin{array}{l}\text { Risco elevado de impedimentos ao } \\
\text { cuidado }\end{array}$ & 3 & 3,0 & 1 & 1,0 & 1 & 1,0 & 5 & 1,7 \\
\hline
\end{tabular}

Nota: Porcentagens descritas por instituição. 


\subsubsection{Escores obtidos e consistência interna}

Os escores médios obtidos com o INTERMED estão apresentados na Tabela 8. Foram observados valores maiores nas instituições A e B (20 e 21) que na instituição C (15).

Os coeficientes alpha de Cronbach calculados com os 19 itens restantes foram 0,806 (A), 0,818 $(\mathrm{B})$ e 0,808 (C), e mostraram boa consistência interna e precisão do instrumento nas três instituições consideradas (Tabela 8).

Tabela 8 - Descrição dos escores obtidos e avaliação da consistência interna do INTERMED, São Paulo - 2012

\begin{tabular}{lcccc}
\hline & \multicolumn{4}{c}{ Instituição } \\
\cline { 2 - 5 } & A & B & C & TOTAL \\
\hline $\begin{array}{l}\text { Escore INTERMED } \\
\quad \text { Geral * } \\
\text { Domínios } \\
\quad \text { Biológico * }\end{array}$ & $20(7)$ & $21(7)$ & $15(7)$ & $19(7)$ \\
Psicológico * $_{\text {Social * }}$ & $8(2)$ & $9(2)$ & $6(3)$ & $8(3)$ \\
Sistema de saúde* $^{*}$ & $4(2)$ & $4(3)$ & $2(2)$ & $3(3)$ \\
\hline \multicolumn{1}{c}{ a de Cronbach } & $2(2)$ & $4(3)$ & $2(2)$ & $3(2)$ \\
\hline
\end{tabular}

Nota: *Dados descritos em média (desvio padrão).

As correlações entre os domínios foram positivas e significantes em sua maioria, excetuando-se as avaliações entre domínio biológico e acesso ao sistema de saúde (instituições $B$ e $C$ ), e entre psicológico e acesso ao sistema de saúde (instituições A e C) (Tabela 9). 
Tabela 9 - Correlação entre os escores dos domínios, São Paulo - 2012

\begin{tabular}{|c|c|c|c|c|c|}
\hline \multirow[b]{2}{*}{ Domínio } & \multirow[b]{2}{*}{ Instituição } & \multicolumn{4}{|c|}{ Domínio } \\
\hline & & Biológico & Psicológico & Social & $\begin{array}{c}\text { Acesso ao } \\
\text { sistema de } \\
\text { saúde }\end{array}$ \\
\hline \multirow{3}{*}{ Biológico } & A & 1 & $0,338^{*}$ & $0,442^{*}$ & $0,430^{*}$ \\
\hline & B & 1 & $0,217^{*}$ & $0,386^{*}$ & 0,146 \\
\hline & C & 1 & $0,419^{*}$ & $0,291^{*}$ & 0,030 \\
\hline \multirow{3}{*}{ Psicológico } & A & - & 1 & $0,360^{*}$ & 0,126 \\
\hline & B & - & 1 & $0,494^{*}$ & $0,228^{*}$ \\
\hline & $\mathrm{C}$ & - & 1 & $0,528^{*}$ & 0,188 \\
\hline \multirow{3}{*}{ Social } & A & - & - & 1 & $0,513^{*}$ \\
\hline & B & - & - & 1 & $0,247^{*}$ \\
\hline & $\mathrm{C}$ & - & - & 1 & $0,227^{*}$ \\
\hline \multirow{3}{*}{$\begin{array}{l}\text { Sistema de } \\
\text { saúde }\end{array}$} & $A$ & - & - & - & 1 \\
\hline & B & - & - & - & 1 \\
\hline & C & - & - & - & 1 \\
\hline
\end{tabular}

Nota: Coeficientes de correlação de Spearman.

*: valor $p<0,05$ no teste de correlação nula.

\subsubsection{Validade preditiva}

A relação entre os escores obtidos com o INTERMED e o tempo de internação foi investigada com o intuito de verificar a validade preditiva do instrumento. Foram observados tempos maiores de internação em pacientes com escore maior, porém, sem evidência suficiente de associação entre o escore geral e o tempo de internação nas instituições $A(p=0,186)$ e $C$ $(p=0,091)$, enquanto na instituição $B$, concluiu-se que o escore geral obtido pode ser utilizado para estimar o tempo total de internação $(p=0,036)$, sendo que o acréscimo estimado no tempo de internação é $2 \%$ a cada acréscimo de um ponto no escore. Quanto aos domínios do INTERMED, verificou-se que na instituição $A$ apenas a pontuação do domínio biológico apresentou associação significante com o tempo de internação, com um acréscimo de $6 \%$ no tempo médio de internação a cada ponto acrescido no escore biológico ( $p=0,014)$. Na instituição $B$, verificou-se associação positiva entre o tempo de internação e os domínios biológico e social do instrumento, sendo que o acréscimo esperado no tempo de internação a cada ponto adicional 
dos escores social e biológico foi $6 \%(p=0,003)$, resultado semelhante ao observado na instituição $\mathrm{A}$. $\mathrm{Na}$ instituição $\mathrm{C}$, nenhum dos domínios apresentou evidências fortes de associação com o tempo de internação (Tabela 10 e Figuras 10 a 13).

Tabela 10 - Relação entre pontuação geral no escore INTERMED e tempo de internação, São Paulo - 2012

\begin{tabular}{lccc}
\hline Escore & Instituição & $\begin{array}{c}\text { Razão de médias } \\
\text { Intervalo de confiança (95\%) }\end{array}$ & $\mathbf{p}$ \\
\hline Geral & $\mathrm{A}$ & $1,01(0,99 ; 1,03)$ & 0,197 \\
(0 a 57) & $\mathrm{B}$ & $1,02(1,00 ; 1,03)$ & 0,036 \\
& $\mathrm{C}$ & $1,02(1,00 ; 1,04)$ & 0,091 \\
\hline Biológico & $\mathrm{A}$ & $1,06(1,01 ; 1,11)$ & 0,016 \\
(0 a 15) & $\mathrm{B}$ & $1,06(1,01 ; 1,11)$ & 0,022 \\
\hline Psicológico & $\mathrm{C}$ & $1,00(0,95 ; 1,05)$ & 0,967 \\
(0 a 15) & $\mathrm{A}$ & $1,03(0,98 ; 1,08)$ & 0,232 \\
& $\mathrm{~B}$ & $1,00(0,97 ; 1,04)$ & 0,851 \\
Social & $\mathrm{C}$ & $1,06(1,00 ; 1,13)$ & 0,069 \\
(0 a 15) & $\mathrm{A}$ & $1,01(0,95 ; 1,08)$ & 0,705 \\
\hline Sistema de saúde & $\mathrm{B}$ & $1,06(1,02 ; 1,10)$ & 0,003 \\
(0 a 12) & $\mathrm{C}$ & $1,07(1,00 ; 1,15)$ & 0,063 \\
\hline
\end{tabular}

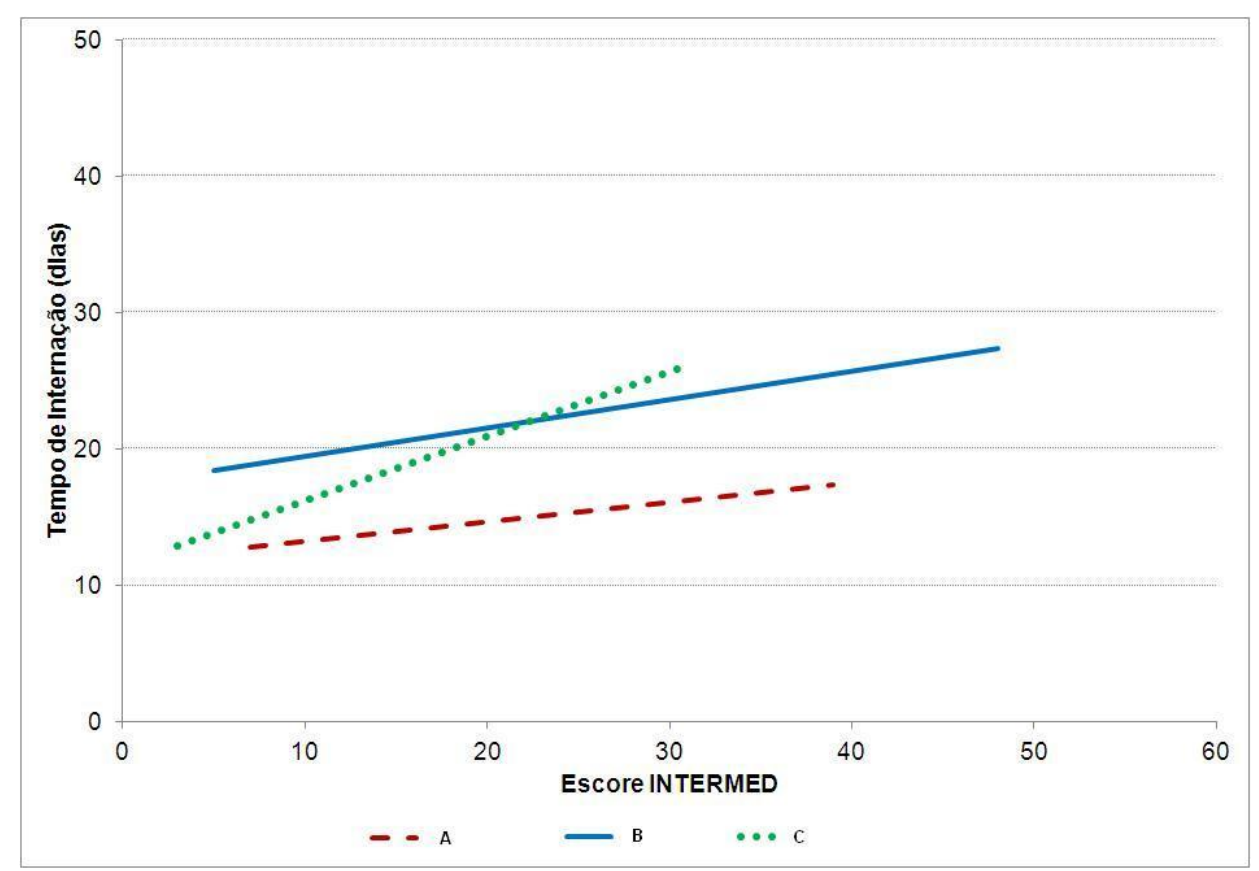

Figura 10 - Relação entre pontuação geral no escore INTERMED e tempo de internação, São Paulo - 2012 


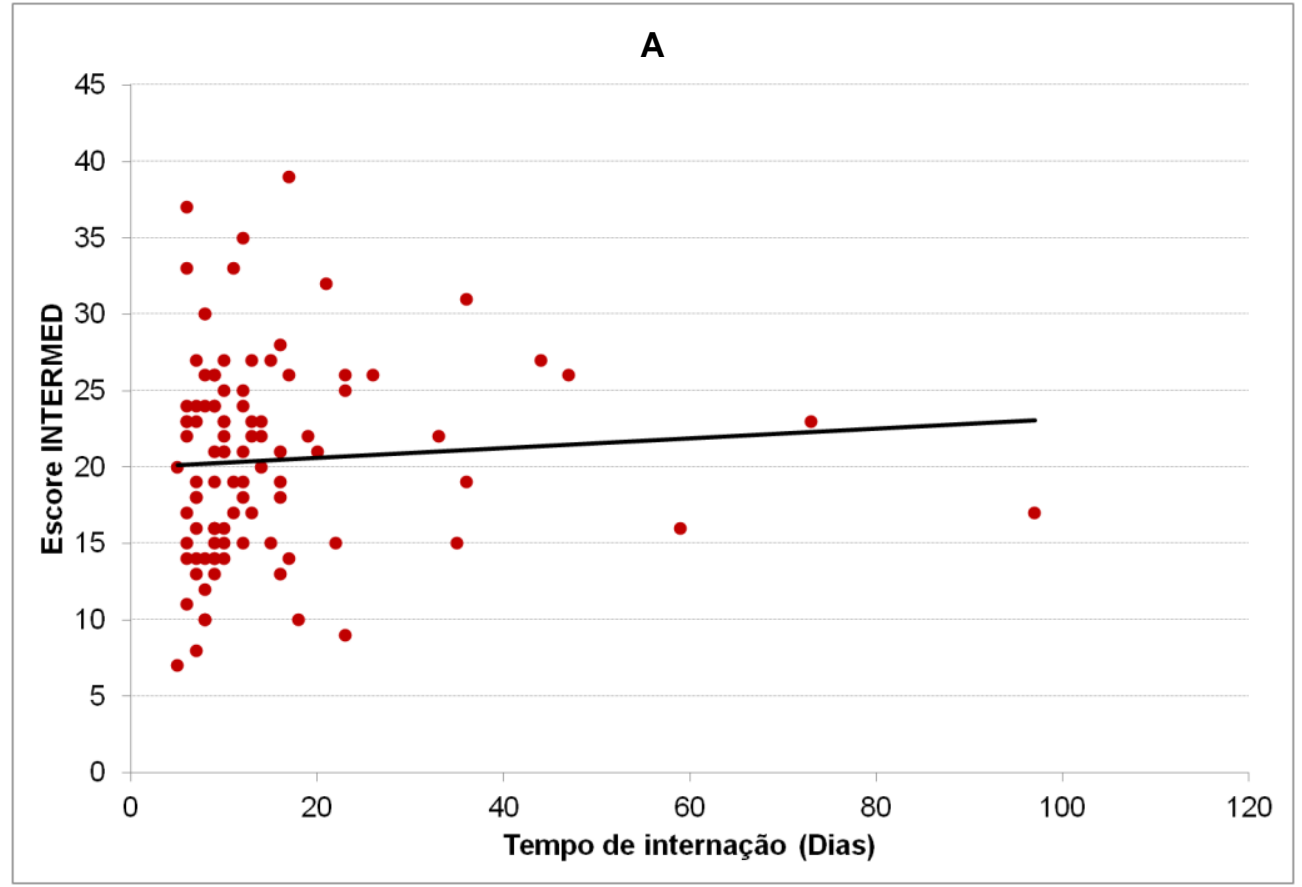

Figura 11 - Relação entre pontuação geral no escore INTERMED e tempo de internação na instituição A, São Paulo - 2012

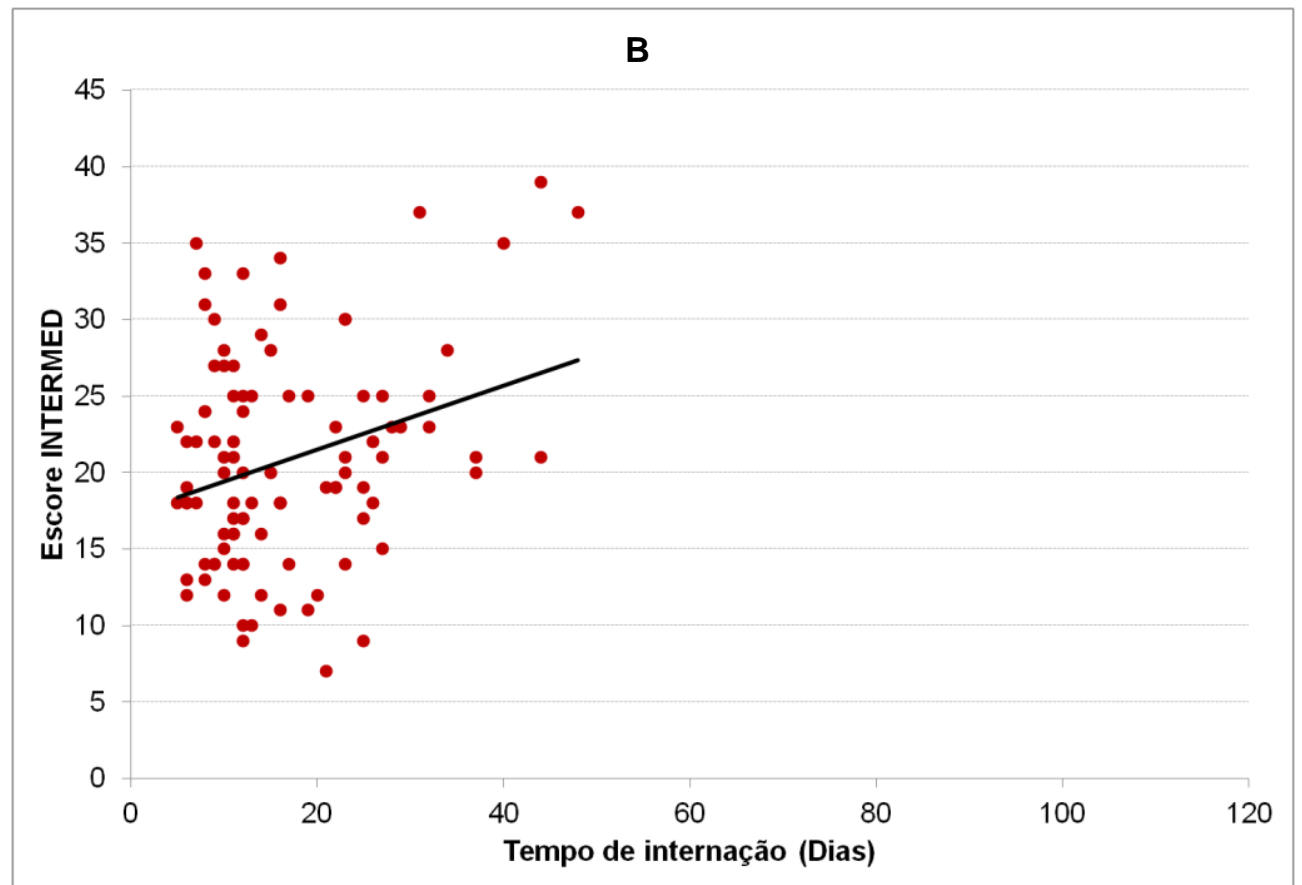

Figura 12 - Relação entre pontuação geral no escore INTERMED e tempo de internação na instituição B, São Paulo - 2012 


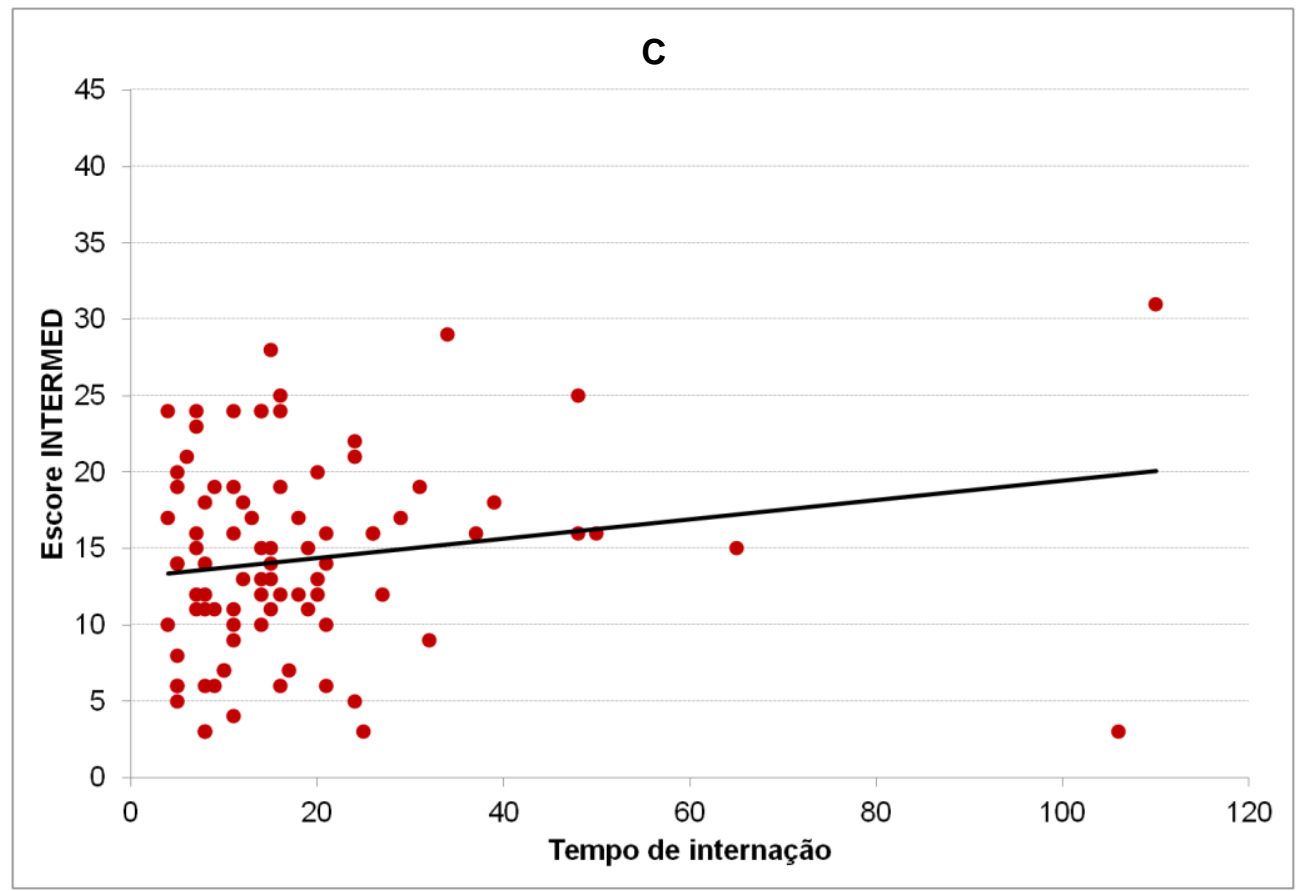

Figura 13 - Relação entre pontuação geral no escore INTERMED e tempo de internação na instituição C, São Paulo - 2012

\subsubsection{Relação entre características sociodemográficas e escore INTERMED}

Foi investigada a relação entre a idade, escolaridade e renda familiar dos pacientes e os resultados obtidos com o INTERMED (Tabela 11). Quanto à idade, foram observadas correlações positivas em sua maioria e fracas entre a idade e os resultados do INTERMED em todos os domínios. Correlações negativas e fracas entre escolaridade e renda familiar e os resultados do INTERMED foram observadas em todos os domínios e instituições (Tabelas 12 e 13). 
Tabela 11 - Relação entre idade e pontuação INTERMED, São Paulo 2012

\begin{tabular}{|c|c|c|c|}
\hline & \multicolumn{3}{|c|}{$\begin{array}{l}\text { Idade na data de } \\
\text { inclusão no estudo } \\
\text { (anos) }\end{array}$} \\
\hline & $\mathbf{A}$ & B & $\mathbf{C}$ \\
\hline \multicolumn{4}{|l|}{ Biológico } \\
\hline Cronicidade (histórico) & $0,324^{*}$ & $0,417^{*}$ & $0,344^{*}$ \\
\hline Dilema diagnóstico (histórico) & $-0,047$ & 0,141 & 0,127 \\
\hline Gravidade dos sintomas (estado atual) & 0,322 & $0,248^{*}$ & 0,201 \\
\hline Desafio diagnóstico/terapêutico (estado atual) & $-0,030$ & 0,116 & 0,105 \\
\hline Complicações e ameaça à vida (vulnerabilidades) & $0,273^{x}$ & 0,396 & 0,104 \\
\hline \multicolumn{4}{|l|}{ Psicológico } \\
\hline Barreiras de enfrentamento (histórico) & $-0,091$ & $-0,206^{*}$ & 0,126 \\
\hline Disfunção psiquiátrica (histórico) & $0,208^{*}$ & $-0,156$ & $-0,067$ \\
\hline Resistência ao tratamento (estado atual) & $-0,071$ & $-0,041$ & 0,011 \\
\hline Sintomas psiquiátricos (estado atual) & $-0,123$ & $-0,052$ & $-0,010$ \\
\hline Ameaça à saúde mental (vulnerabilidades) & $-0,043$ & $-0,280^{*}$ & $-0,041$ \\
\hline \multicolumn{4}{|l|}{ Social } \\
\hline Problemas no trabalho e no lazer (histórico) & $-0,031$ & $-0,004$ & 0,165 \\
\hline Situação social (histórico) & 0,140 & $-0,109$ & $-0,173$ \\
\hline Condições no domicílio (estado atual) & $0,380^{*}$ & 0,107 & $0,212^{*}$ \\
\hline Apoio social precário (estado atual) & $0,198^{*}$ & $-0,193$ & 0,024 \\
\hline Vulnerabilidade social (vulnerabilidades) & $0,423^{*}$ & 0,172 & 0,025 \\
\hline \multicolumn{4}{|l|}{ Sistema de saúde } \\
\hline Acesso ao cuidado (histórico) & $0,286^{*}$ & $-0,114$ & 0,152 \\
\hline Experiência do tratamento (histórico) & $-0,041$ & $-0,102$ & 0,131 \\
\hline Coordenação do cuidado (estado atual) & $0,237^{*}$ & $-0,106$ & 0,043 \\
\hline Impedimentos do sistema de saúde (vulnerabilidades) & $0,203^{x}$ & $-0,046$ & 0,294 \\
\hline Escore & 0,276 & 0,007 & $0,244^{*}$ \\
\hline \multicolumn{4}{|l|}{ Escore dos domínios } \\
\hline Biológico & $0,277^{*}$ & $0,428^{*}$ & $0,255^{*}$ \\
\hline Psicológico & $-0,029$ & $-0,213^{*}$ & 0,038 \\
\hline Social & $0,379^{*}$ & $-0,034$ & 0,044 \\
\hline Sistema de saúde & $0,233^{*}$ & $-0,142$ & 0,151 \\
\hline
\end{tabular}

Nota: Coeficientes de correlação de Spearman.

*: valor $p<0,05$ no teste de correlação nula. 
Tabela 12 - Relação entre escolaridade e pontuação INTERMED, São Paulo - 2012

\begin{tabular}{|c|c|c|c|}
\hline & \multicolumn{3}{|c|}{ Escolaridade } \\
\hline & $\mathbf{A}$ & B & C \\
\hline \multicolumn{4}{|l|}{ Biológico } \\
\hline Cronicidade (histórico) & $-0,079$ & $-0,190$ & $-0,140$ \\
\hline Dilema diagnóstico (histórico) & $-0,146$ & $-0,060$ & $-0,070$ \\
\hline Gravidade dos sintomas (estado atual) & $-0,267$ & $-0,264^{x}$ & $-0,117$ \\
\hline Desafio diagnóstico/terapêutico (estado atual) & 0,156 & $-0,208^{*}$ & $-0,120$ \\
\hline Complicações e ameaça à vida (vulnerabilidades) & $-0,104$ & $-0,222^{*}$ & $-0,099$ \\
\hline \multicolumn{4}{|l|}{ Psicológico } \\
\hline Barreiras de enfrentamento (histórico) & 0,103 & $-0,107$ & $-0,067$ \\
\hline Disfunção psiquiátrica (histórico) & $-0,107$ & $-0,179$ & 0,092 \\
\hline Resistência ao tratamento (estado atual) & 0,012 & $-0,221^{*}$ & $-0,205^{x}$ \\
\hline Sintomas psiquiátricos (estado atual) & $-0,041$ & $-0,057$ & 0,064 \\
\hline Ameaça à saúde mental (vulnerabilidades) & 0,049 & $-0,009$ & 0,035 \\
\hline \multicolumn{4}{|l|}{ Social } \\
\hline Problemas no trabalho e no lazer (histórico) & $-0,132$ & $-0,162$ & $-0,149$ \\
\hline Situação social (histórico) & $-0,034$ & $-0,061$ & 0,027 \\
\hline Condições no domicílio (estado atual) & $-0,264$ & $-0,266$ & $-0,157$ \\
\hline Apoio social precário (estado atual) & $-0,075$ & $-0,063$ & $-0,212$ \\
\hline Vulnerabilidade social (vulnerabilidades) & $-0,239^{*}$ & $-0,163$ & $-0,092$ \\
\hline \multicolumn{4}{|l|}{ Sistema de saúde } \\
\hline Acesso ao cuidado (histórico) & $-0,197$ & 0,017 & $-0,125$ \\
\hline Experiência do tratamento (histórico) & $-0,057$ & 0,180 & 0,008 \\
\hline Coordenação do cuidado (estado atual) & $-0,173$ & $-0,083$ & $-0,097$ \\
\hline Impedimentos do sistema de saúde (vulnerabilidades) & $-0,193$ & $-0,106$ & $-0,187$ \\
\hline Escore & $-0,208$ & $-0,224$ & $-0,176$ \\
\hline \multicolumn{4}{|l|}{ Escore dos domínios } \\
\hline Biológico & $-0,175$ & $-0,291^{*}$ & $-0,143$ \\
\hline Psicológico & $-0,005$ & $-0,131$ & $-0,037$ \\
\hline Social & $-0,250^{*}$ & $-0,177$ & $-0,143$ \\
\hline Sistema de saúde & $-0,200^{*}$ & 0,079 & $-0,111$ \\
\hline
\end{tabular}

Nota: Coeficientes de correlação de Spearman.

*: valor $p<0,05$ no teste de correlação nula. 
Tabela 13 - Relação entre renda e pontuação INTERMED, São Paulo 2012

\section{Renda Familiar}

( $\mathrm{N}$ salários mínimos)

\begin{tabular}{|c|c|c|c|}
\hline & & & \\
\hline & A & B & C \\
\hline \multicolumn{4}{|l|}{ Biológico } \\
\hline Cronicidade (histórico) & $-0,176$ & $-0,147$ & $-0,162$ \\
\hline Dilema diagnóstico (histórico) & $-0,058$ & $-0,071$ & $-0,209$ \\
\hline Gravidade dos sintomas (estado atual) & $-0,264^{*}$ & $-0,179$ & $-0,293^{*}$ \\
\hline Desafio diagnóstico/terapêutico (estado atual) & $-0,015$ & $-0,027$ & $-0,192$ \\
\hline Complicações e ameaça à vida (vulnerabilidades) & $-0,113$ & $-0,218^{*}$ & $-0,337^{*}$ \\
\hline \multicolumn{4}{|l|}{ Psicológico } \\
\hline Barreiras de enfrentamento (histórico) & 0,024 & $-0,128$ & $-0,101$ \\
\hline Disfunção psiquiátrica (histórico) & $-0,070$ & $-0,189$ & $-0,059$ \\
\hline Resistência ao tratamento (estado atual) & $-0,034$ & $-0,132$ & $-0,009$ \\
\hline Sintomas psiquiátricos (estado atual) & 0,063 & $-0,122$ & $-0,092$ \\
\hline Ameaça à saúde mental (vulnerabilidades) & 0,055 & $-0,058$ & $-0,114$ \\
\hline \multicolumn{4}{|l|}{ Social } \\
\hline Problemas no trabalho e no lazer (histórico) & $-0,152$ & $-0,342^{x}$ & $-0,210^{*}$ \\
\hline Situação social (histórico) & 0,039 & $-0,195$ & $-0,090$ \\
\hline Condições no domicílio (estado atual) & $-0,205^{*}$ & $-0,410^{*}$ & $-0,303^{*}$ \\
\hline Apoio social precário (estado atual) & $-0,230^{*}$ & $-0,170$ & $-0,072$ \\
\hline Vulnerabilidade social (vulnerabilidades) & $-0,299^{*}$ & $-0,311^{*}$ & $-0,140$ \\
\hline \multicolumn{4}{|l|}{ Sistema de Saúde } \\
\hline Acesso ao cuidado (histórico) & $-0,269$ & $-0,127$ & 0,042 \\
\hline Experiência do tratamento (histórico) & $-0,163$ & 0,074 & 0,069 \\
\hline Coordenação do cuidado (estado atual) & $-0,204$ & $-0,098$ & 0,238 \\
\hline Impedimentos do sistema de saúde (vulnerabilidades) & $-0,259^{*}$ & $-0,074$ & $0,337^{*}$ \\
\hline Escore & $-0,249^{*}$ & $-0,326^{*}$ & $-0,198^{*}$ \\
\hline \multicolumn{4}{|l|}{ Escore dos domínios } \\
\hline Biológico & $-0,152$ & $-0,214^{*}$ & $-0,283^{*}$ \\
\hline Psicológico & 0,011 & $-0,152$ & $-0,125$ \\
\hline Social & $-0,325^{*}$ & $-0,390^{*}$ & $-0,255^{*}$ \\
\hline Sistema de saúde & $-0,301$ & $-0,048$ & 0,232 \\
\hline
\end{tabular}

Nota: Coeficientes de correlação de Spearman.

*: valor $p<0,05$ no teste de correlação nula. 
Foi investigada a existência de diferenças no escore INTERMED, considerando os grupos com e sem religião/crença (Tabela 14). Os valores do escore foram maiores entre os pacientes que possuíam religião, exceto no domínio biológico, em que foi observada uma diferença média de 1,6 ponto no escore.

Tabela 14 - Relação entre religião e pontuação INTERMED, São Paulo 2012

\begin{tabular}{lccc}
\hline \multicolumn{1}{c}{ INTERMED } & Não & Sim & p \\
\hline $\begin{array}{lccc}\text { Escore geral } \\
\text { Domínios }\end{array}$ & $16,5(6,0)$ & $18,8(7,3)$ & 0,125 \\
$\quad$ Biológico & & & \\
Psicológico & $6,3(2,9)$ & $7,9(2,9)$ & 0,009 \\
Social & $3,3(2,8)$ & $3,4(2,8)$ & 0,899 \\
Sistema de saúde & $2,5(2,0)$ & $2,7(2,4)$ & 0,698 \\
& $1,4(1,9)$ & $1,9(2,1)$ & 0,270 \\
\hline
\end{tabular}

Nota: Dados descritos em média (desvio padrão).

Quanto à importância da religião, no domínio biológico os pacientes que consideravam a religião muito importante tiveram escores maiores, indício de maior gravidade, no entanto, com diferenças discretas (1,4 ponto no escore, comparando pacientes que davam pouca importância e aqueles que davam muita importância). No domínio sistema de saúde, escores maiores foram observados nos pacientes que consideravam a religião pouco importante, assim como no escore geral e nos domínios psicológico e social (Tabela 15). 
Tabela 15 - Relação entre importância da religião e pontuação INTERMED, São Paulo - 2012

\begin{tabular}{lcccc}
\hline \multicolumn{1}{c}{ INTERMED } & \multicolumn{2}{c}{ Importância da religião } & p \\
& Pouco & Razoável & Muito & \\
\hline $\begin{array}{l}\text { Escore geral } \\
\text { Domínios }\end{array}$ & $18,7(7,9)$ & $20,0(6,9)$ & $18,5(7,3)$ & 0,462 \\
$\quad$ & & & \\
$\quad$ Biológico & $6,6(3,6)$ & $7,8(3,0)$ & $8,0(2,8)$ & 0,107 \\
Psicológico & $4,1(2,6)$ & $3,8(2,3)$ & $3,2(2,9)$ & 0,222 \\
$\quad$ Social & $3,1(2,4)$ & $2,8(1,9)$ & $2,7(2,6)$ & 0,757 \\
$\quad$ Sistema de saúde & $2,0(2,3)$ & $2,6(2,3)$ & $1,7(2,0)$ & 0,021 \\
\hline
\end{tabular}

Nota: Dados descritos em média (desvio padrão).

Os resultados obtidos com o INTERMED entre as diferentes classificações de autoavaliação do estado de saúde foram avaliados (Tabela 16). Os pacientes que classificaram seu estado de saúde como ruim apresentaram valores maiores no escore geral e por domínios.

Tabela 16 - Relação entre autoavaliação do estado de saúde e pontuação INTERMED, São Paulo - 2012

\begin{tabular}{|c|c|c|c|c|}
\hline \multirow{2}{*}{ INTERMED } & \multicolumn{3}{|c|}{ Estado de saúde } & \multirow[t]{2}{*}{$p$} \\
\hline & Bom & Regular & Ruim & \\
\hline Escore geral & $16,5(6,8)$ & $20,6(6,9)$ & $23,6(6,4)$ & $<0,001$ \\
\hline \multicolumn{5}{|l|}{ Domínios } \\
\hline Biológico & $7,0(3,1)$ & $8,4(2,7)$ & $9,4(1,6)$ & $<0,001$ \\
\hline Psicológico & $2,9(2,7)$ & $3,7(2,8)$ & $4,7(2,8)$ & 0,002 \\
\hline Social & $2,2(2,2)$ & $3,3(2,4)$ & $3,9(3,0)$ & $<0,001$ \\
\hline Sistema de saúde & $1,4(1,6)$ & $2,2(2,5)$ & $2,6(2,4)$ & 0,003 \\
\hline
\end{tabular}

Nota: Dados descritos em média (desvio padrão).

Adicionalmente, a relação entre sintomas psicológicos e autoavaliação do estado de saúde dos pacientes indicou que as barreiras de enfrentamento não interferem na autoavaliação do estado de saúde ( $p=0,203$ ), enquanto o histórico de disfunções psiquiátricas parece favorecer a autoavaliação regular ou ruim $(p=0,013)$. Os pacientes com menor resistência ao tratamento tenderam a classificar seu estado de saúde como 
melhor do que aqueles com algum tipo de restrição ao tratamento $(p=0,004)$ (Tabela 17).

Tabela 17 - Relação entre sintomas psicológicos e autoavaliação do estado de saúde, São Paulo - 2012

\begin{tabular}{|c|c|c|c|c|c|c|c|c|c|}
\hline \multirow{3}{*}{ Psicológico } & \multicolumn{8}{|c|}{ Estado de saúde } & \multirow{3}{*}{$\mathbf{p}$} \\
\hline & \multicolumn{2}{|c|}{ Bom } & \multicolumn{2}{|c|}{ Regular } & \multicolumn{2}{|c|}{ Ruim } & \multicolumn{2}{|c|}{ TOTAL } & \\
\hline & $\mathbf{N}$ & $\%$ & $\mathbf{n}$ & $\%$ & $\mathbf{n}$ & $\%$ & $\mathbf{n}$ & $\%$ & \\
\hline \multicolumn{9}{|l|}{ Barreiras de enfrentamento } & \multirow{5}{*}{0,203} \\
\hline $\begin{array}{l}\text { Capacidade de administrar o } \\
\text { estresse }\end{array}$ & 97 & 60,2 & 52 & 32,3 & 12 & 7,5 & 161 & 100 & \\
\hline $\begin{array}{l}\text { Restritas habilidades para } \\
\text { enfrentamento }\end{array}$ & 39 & 43,8 & 39 & 43,8 & 11 & 12,4 & 89 & 100 & \\
\hline $\begin{array}{l}\text { Insuficientes habilidades } \\
\text { para enfrentamento }\end{array}$ & 16 & 50,0 & 11 & 34,4 & 5 & 15,6 & 32 & 100 & \\
\hline $\begin{array}{l}\text { Mínimas habilidades para } \\
\text { enfrentamento }\end{array}$ & 8 & 61,5 & 4 & 30,8 & 1 & 7,7 & 13 & 100 & \\
\hline \multicolumn{9}{|l|}{ Disfunção psiquiátrica } & \multirow{5}{*}{0,013} \\
\hline Sem disfunção psiquiátrica & 96 & 62,7 & 48 & 31,4 & 9 & 5,9 & 153 & 100 & \\
\hline $\begin{array}{l}\text { Disfunção psiquiátrica sem } \\
\text { efeitos claros no } \\
\text { funcionamento diário }\end{array}$ & 45 & 45,0 & 44 & 44,0 & 11 & 11,0 & 100 & 100 & \\
\hline $\begin{array}{l}\text { Disfunção psiquiátrica com } \\
\text { efeitos claros no } \\
\text { funcionamento diário }\end{array}$ & 18 & 47,4 & 12 & 31,6 & 8 & 21,1 & 38 & 100 & \\
\hline $\begin{array}{l}\text { Admissão(ões) } \\
\text { psiquiátrica(s) e/ou efeitos } \\
\text { permanentes no } \\
\text { funcionamento diário }\end{array}$ & 1 & 33,3 & 2 & 66,7 & - & - & 3 & 100 & \\
\hline \multicolumn{9}{|l|}{ Resistência ao tratamento } & \multirow{4}{*}{0,004} \\
\hline $\begin{array}{l}\text { Interessado em receber } \\
\text { tratamento e disposto a } \\
\text { cooperar ativamente }\end{array}$ & 105 & 57,1 & 63 & 34,2 & 16 & 8,7 & 184 & 100 & \\
\hline $\begin{array}{l}\text { Algum pensamento } \\
\text { ambivalente apesar de } \\
\text { disposto a cooperar com o } \\
\text { tratamento }\end{array}$ & 43 & 50,6 & 33 & 38,8 & 9 & 10,6 & 85 & 100 & \\
\hline Resistência considerável & 12 & 46,2 & 10 & 38,5 & 4 & 15,4 & 26 & 100 & \\
\hline \multicolumn{9}{|l|}{ Sintomas psiquiátricos } & \multirow{4}{*}{0,002} \\
\hline Sem sintomas psiquiátricos & 83 & 63,8 & 40 & 30,8 & 7 & 5,4 & 130 & 100 & \\
\hline Sintomas psiquiátricos leves & 39 & 58,2 & 22 & 32,8 & 6 & 9,0 & 67 & 100 & \\
\hline $\begin{array}{l}\text { Sintomas psiquiátricos } \\
\text { moderados }\end{array}$ & 38 & 38,8 & 44 & 44,9 & 16 & 16,3 & 98 & 100 & \\
\hline \multicolumn{9}{|l|}{ Ameaça à saúde mental } & \multirow{4}{*}{0,022} \\
\hline $\begin{array}{l}\text { Sem risco de transtorno } \\
\text { psiquiátrico }\end{array}$ & 73 & 64,0 & 36 & 31,6 & 5 & 4,4 & 114 & 100 & \\
\hline $\begin{array}{l}\text { Risco leve de sintomas } \\
\text { psiquiátricos }\end{array}$ & 74 & 48,4 & 60 & 39,2 & 19 & 12,4 & 153 & 100 & \\
\hline $\begin{array}{l}\text { Risco moderado ou severo } \\
\text { de transtorno psiquiátrico }\end{array}$ & 13 & 46,4 & 10 & 35,7 & 5 & 17,9 & 28 & 100 & \\
\hline
\end{tabular}


A relação entre renda e escolaridade e coordenação do cuidado foi investigada. Dentre os pacientes com renda familiar menor ou igual a um salário mínimo, 85,7\% consideraram a coordenação do cuidado boa. O percentual entre os pacientes com renda de três a cinco salários foi de $55,9 \%$. Houve indícios de que quanto maior a renda familiar, mais pacientes consideraram a coordenação do cuidado como limitada ou precária (Tabela 18).

Tabela 18 - Relação entre coordenação do cuidado e renda, São Paulo 2012

\begin{tabular}{|c|c|c|c|c|c|c|c|c|}
\hline \multirow{3}{*}{$\begin{array}{l}\text { Sistema de Saúde - } \\
\text { Coordenação do Cuidado }\end{array}$} & \multicolumn{8}{|c|}{ Renda Familiar (número de salários mínimos) } \\
\hline & \multicolumn{2}{|c|}{$<=1$} & \multicolumn{2}{|c|}{$>1 \mathrm{e}<=3$} & \multicolumn{2}{|c|}{$>3$ e $<=5$} & \multicolumn{2}{|c|}{$>5$} \\
\hline & $n$ & $\%$ & $\mathbf{n}$ & $\%$ & $n$ & $\%$ & $\mathbf{n}$ & $\%$ \\
\hline $\begin{array}{l}\text { Comunicação completa e boa } \\
\text { coordenação do cuidado }\end{array}$ & 54 & 85,7 & 82 & 71,3 & 19 & 55,9 & 50 & 62,5 \\
\hline $\begin{array}{l}\text { Limitada comunicação e } \\
\text { coordenação do cuidado }\end{array}$ & 8 & 12,7 & 22 & 19,1 & 10 & 29,4 & 16 & 20,0 \\
\hline $\begin{array}{l}\text { Precária ou nula comunicação } \\
\text { e coordenacão do cuidado }\end{array}$ & 1 & 1,6 & 11 & 9,6 & 5 & 14,7 & 14 & 17,5 \\
\hline
\end{tabular}

Nota: Porcentagens descritas por categoria de renda familiar.

Com relação à escolaridade, notou-se que a porcentagem de pacientes que consideraram a coordenação do cuidado precária foi maior entre aqueles com ensino médio completo ou superior completo (Tabela 19). 
Tabela 19 - Relação entre coordenação do cuidado e escolaridade, São Paulo - 2012

\begin{tabular}{|c|c|c|c|c|c|c|c|c|c|c|}
\hline \multirow{3}{*}{$\begin{array}{l}\text { Sistema de Saúde - } \\
\text { Coordenação do } \\
\text { Cuidado }\end{array}$} & \multicolumn{10}{|c|}{ Escolaridade } \\
\hline & \multicolumn{2}{|c|}{$\begin{array}{c}\text { Sem } \\
\text { escolaridade }\end{array}$} & \multicolumn{2}{|c|}{$\begin{array}{l}\text { Fundamental } \\
\text { incompleto }\end{array}$} & \multicolumn{2}{|c|}{$\begin{array}{l}\text { Fundamental } \\
\text { completo }\end{array}$} & \multicolumn{2}{|c|}{$\begin{array}{l}\text { Ensino } \\
\text { médio } \\
\text { completo }\end{array}$} & \multicolumn{2}{|c|}{$\begin{array}{l}\text { Superior } \\
\text { completo }\end{array}$} \\
\hline & $\mathbf{n}$ & $\%$ & $\mathbf{n}$ & $\%$ & $\mathbf{n}$ & $\%$ & $\mathbf{n}$ & $\%$ & $\mathbf{n}$ & $\%$ \\
\hline $\begin{array}{l}\text { Comunicação } \\
\text { completa e boa } \\
\text { coordenação do } \\
\text { cuidado }\end{array}$ & 28 & 82,4 & 63 & 67,7 & 49 & 86,0 & 32 & 53,3 & 33 & 64,7 \\
\hline $\begin{array}{l}\text { Limitada } \\
\text { comunicação com o } \\
\text { profissional e } \\
\text { coordenação do } \\
\text { cuidado }\end{array}$ & 3 & 8,8 & 23 & 24,7 & 6 & 10,5 & 17 & 28,3 & 9 & 17,6 \\
\hline $\begin{array}{l}\text { Precária ou nula } \\
\text { comunicação e } \\
\text { coordenação do } \\
\text { cuidado }\end{array}$ & 3 & 8,8 & 7 & 7,5 & 2 & 3,6 & 11 & 18,3 & 9 & 17,7 \\
\hline
\end{tabular}

Nota: Porcentagens descritas por categoria de escolaridade. 
Discussaña 


\section{DISCUSSÃO}

A atenção voltada para a avaliação e gestão da complexidade do cuidado como uma abordagem sistêmica para o tratamento de pacientes é considerada cada vez mais importante e tende a ser prevalente, destacandose a identificação de necessidades no sistema psicológico, social e de saúde, para além da abordagem estritamente biológica e universalmente utilizada. São vários os estudos de validação do método INTERMED em diferentes países, que evidenciam a lacuna na identificação de necessidades, para além da biológica. É comum nestas publicações a recomendação de ampliar os estudos sobre instrumentos de gestão do cuidado do paciente, que tenham abordagem interprofissional e multidisciplinar (Stiefel et al., 1999, 2001; de Jonge et al., 2001).

O processo de tradução e adaptação transcultural do método INTERMED realizado nesta pesquisa seguiu as recomendações da literatura internacional para estudos dessa natureza.

A primeira fase da tradução originou duas traduções, sendo uma com o sentido mais literal das palavras e a outra com o sentido contido nos termos. A reunião de pesquisadores para gerar a versão síntese foi importante para definir, dentre as duas traduções, quais termos ofereciam maior clareza na interpretação contextual e que estavam mais adequados em relação ao instrumento original. Nesse sentido, o grupo optou por manter as traduções mais próximas do sentido original das palavras, uma vez que essa versão seria retrotraduzida.

A ausência de diferenças de sentido entre as duas retrotraduções e o instrumento original demonstrou semelhança de significado e conceito entre as versões, o que representou a boa qualidade das traduções realizadas. 
A disponibilidade dos autores que desenvolveram o método INTERMED e o apoio e atenção recebidos pela pesquisadora que promoveu o treinamento da equipe foram fatores que contribuíram para um desfecho consistente do estudo.

A participação do grupo de pesquisadores nas fases de tradução e retrotradução foi importante para melhor ajuste do instrumento, uma vez que todos conheciam a versão original, as traduções, a síntese e as retrotraduções, e puderam enriquecer as discussões.

As versões retrotraduzidas foram validadas pela pesquisadora consultora indicada pela equipe que desenvolveu o instrumento original.

A participação de profissionais com diferentes formações e com experiência em pesquisa e assistência no comitê de juízes contribuiu para alcançar a equivalência entre 0 instrumento traduzido e o original. $O$ consenso desse comitê foi um processo reflexivo e indicou um esforço coletivo na busca da melhor qualidade da versão brasileira do método INTERMED.

As interferências dos especialistas deram-se no sentido de identificar os termos ou expressões que mais se adequariam à prática clínica nas diferentes profissões aptas a manusear o instrumento. Por isso, foram eliminados itens considerados irrelevantes, ambíguos ou inadequados, substituídos por outros que garantissem a compreensibilidade do instrumento, mas que mantivessem o conceito dos termos.

Este processo de construção do consenso ocorreu de acordo ao preconizado pela literatura, segundo a qual, são necessários disponibilidade de tempo, comprometimento e flexibilidade do grupo, pois cada membro deve estar aberto a discutir determinado tema em busca de uma definição que seja aceita como comum (Mininel, 2010).

$\mathrm{Na}$ aplicação do pré-teste, o fato dos participantes não apresentarem dúvidas com relação às questões do instrumento indicou que 
o rigor metodológico empregado neste estudo possibilitou o desenvolvimento de um instrumento com qualidade de tradução e adaptação transcultural, com potencial para ser incorporado no sistema de saúde brasileiro, público estatal ou privado, como uma ferramenta que contribui para a integralidade do cuidado.

Neste estudo, o tempo empregado na realização das entrevistas (de 20 a 40 minutos) foi maior do que o recomendado pela literatura (de 15 a 20 minutos) (Stiefel et al., 1999; Latour, 2006, Wild et al., 2011). Isto pode ter ocorrido pelo fato das entrevistadoras não fazerem parte da equipe assistencial, visto que o tempo de entrevista pode variar de acordo com as informações prévias que o entrevistador possui do paciente (Wild et al., 2011). Um fator que pode ter contribuído para aumentar o tempo de entrevista foi a inclusão da ficha sociodemográfica para caracterização dos participantes da pesquisa, a qual continha questões sobre autoavaliação do estado de saúde e religião/crença. Outras possíveis razões para o ocorrido incluem as diferenças culturais e do sistema de saúde existentes entre o Brasil e os outros países onde o método INTERMED foi utilizado; e a necessidade que os pacientes têm de serem escutados, pois em geral prolongavam as manifestações durante as entrevistas.

Estudo realizado no Brasil com pacientes cirúrgicos destacou que $70 \%$ deles afirmaram que os profissionais não esclareceram suficientemente sobre seus estados clínicos ou que motivaram a internação, $24 \%$ dos entrevistados disseram que os profissionais perguntaram sobre o estado geral, $40 \%$ referiram que os profissionais conversaram especificamente sobre a doença e $26 \%$ informaram que os profissionais detiveram-se nos exames físicos ou consulta aos prontuários, sem comunicação pessoal efetiva (Alves Pereira, Azevêdo, 2005).

A efetiva comunicação com o profissional de saúde pode auxiliar o paciente na conceituação e no enfrentamento de seus problemas e na visualização de alternativas para sua solução; além de ajudá-lo a encontrar novos padrões de comportamento (Paes da Silva, 2006). 
A escuta do paciente como uma forma de comunicação é importante, pois, através dela, os profissionais orientam, informam, apoiam e confortam os pacientes, atendendo às suas necessidades básicas (Pontes, Leitão, Ramos, 2008). O profissional deve considerar que o paciente, além de um doente no leito, possui uma história de vida, um lar, uma família, um trabalho e todos esses aspectos devem ser considerados no cuidado (Mezzomo, 2003).

A comunicação deve ser utilizada para o alcance do cuidado humanizado, centrado na pessoa. Quando a escuta é inadequada e a comunicação é insuficiente, os pacientes permanecem deprimidos, inseguros, temerosos e ansiosos, sentindo falta de cuidado e de apoio por parte da equipe de saúde (Silva, Nakata, 2005; Razera, Braga, 2011).

No processo de validação, a análise dos dados sociodemográficos dos participantes revelou que, em média, a proporção de homens internados foi maior do que a de mulheres e que, dentre os pacientes, houve predominância de idosos.

Estudos demonstraram que, no Brasil, há mais homens internados em estado grave do que mulheres (Figueiredo, 2005), pois, em geral, estas utilizam mais os serviços de saúde para prevenção e, apesar de terem mais doenças crônicas, a severidade é menor. Os homens adoecem de modo mais severo por cuidarem menos da saúde devido a dificuldades de se afastarem do trabalho e por procurarem auxílio médico apenas perante situações críticas e agudas que limitam a vida social (Costa-Junior, Maia, 2009).

A ausência dos homens nos serviços de saúde é associada à desvalorização do autocuidado, à incipiente preocupação com a saúde e à escassez de programas voltados para a saúde masculina (Figueiredo, 2005), portanto, a relação entre saúde e gênero dá-se por fatores biológicos, psicológicos, sociais e culturais (Doyal, 2001). Quando se trata da mortalidade, sabe-se que os homens têm menor expectativa de vida ao 
nascer, morrendo em maior quantidade e mais cedo que a população feminina (Figueiredo, 2005).

No hospital público, a similaridade entre homens e mulheres internados pode ser explicada pela faixa etária entre adulto e jovem, com hipóteses diagnósticas e diagnósticos de alta distribuídos entre doenças respiratórias, cardiovasculares, causas externas, aparelho digestório e geniturinário.

A idade média dos participantes e a cronicidade associada foram semelhantes aos dados encontrados na Pesquisa Nacional por Amostra de Domicílios (PNAD), em que a proporção da população que referiu internação nos doze meses antecedentes à pesquisa foi de $7,3 \%$ para a faixa etária de 40 a 59 anos e 12,3\% para os idosos (IBGE, 2008). Pesquisa sobre as internações hospitalares no Brasil demonstrou que, na distribuição etária das internações, $53,5 \%$ dos indivíduos estavam na faixa etária entre 20 e 59 anos e 18,2\%, com 60 anos e mais (Moreira, Dutilhnovaes, 2011).

Em razão da transição demográfica, há um peso relativo maior de adultos e idosos na pirâmide etária da população. Esse fato, aliado a fatores como aumento da renda, urbanização, industrialização e mecanização da produção, maior acesso aos alimentos e adoção de hábitos menos saudáveis pela população levaram ao maior risco e prevalência de doenças crônicas não transmissíveis, que são a principal carga da doença no Brasil (Schmidt et al., 2011) e representam $45,9 \%$ da carga de doenças no mundo (OPAS, 2003).

Dentre essas doenças, as cardiovasculares são a principal causa de morte no Brasil e que geram o maior custo de internações hospitalares no sistema de saúde nacional (Schmidt et al., 2011).

Dentre as variáveis sociais, a cor branca esteve associada a uma pequena diferença positiva na probabilidade de internação hospitalar. As variáveis necessidades de saúde e escolaridade estiveram associadas ao uso de serviços hospitalares, identificando possibilidades desfavoráveis às 
pessoas com menos escolaridade (Castro, 2002), o que está de acordo com os achados desta pesquisa, confirmando o potencial do método INTERMED para identificar pacientes complexos.

Esse mesmo achado pode ser observado com relação à renda. $\mathrm{A}$ falta de condições financeiras pode desencadear piora no estado de saúde do paciente, principalmente se houver prejuízos nas condições familiares e sociais. Nesse contexto, o estudo baseado em dados da PNAD apontou que a menor renda mensal dos idosos brasileiros denota piores condições de saúde, menor mobilidade física e menor uso dos serviços de saúde (LimaCosta et al., 2003).

Considerando o percentual alto de aposentados na amostra, estudo indicou que o Brasil é um dos países que possui um dos mais baixos salários de aposentadorias, fator que contribui para a perda de autoestima e desqualificação profissional (Assis, 2004). Para muitas pessoas, a aposentadoria significa uma diminuição da renda que demanda uma nova adaptação de estilo de vida, o que pode interferir negativamente no estado de saúde física e mental e na situação social, aumentando a complexidade desses pacientes.

A partir das respostas obtidas com a aplicação do método INTERMED, verificou-se que em duas instituições, o percentual médio de pacientes diagnosticados com doenças cardiovasculares foi semelhante à proporção de pacientes com idade acima de 60 anos e se aproximou da quantidade de portadores de mais de uma doença associada. Este dado pode ser confirmado por estudos como o SABE (Saúde, Bem-estar e Envelhecimento), desenvolvido no município de São Paulo, que revelou que $76 \%$ dos idosos pesquisados possuíam pelo menos uma doença crônica e $58 \%$ apresentavam mais de uma enfermidade concomitantemente (Lebrão, Laurenti, 2005).

O tratamento dessas doenças geralmente é prolongado e complexo, exigindo continuidade do cuidado e, quando inadequado, pode levar à dependência e à incapacidade, aumentando o risco de morte 
(Fratezi, Gutierrez, Falcão, 2010). Por isso, neste estudo considerou-se importante a porcentagem de pacientes que possuíam sintomas moderados a graves, com interferência na funcionalidade atual.

Esse dado é enfatizado quando se avalia o percentual de pacientes com risco de moderado a elevado de limitações físicas, indicando a necessidade de uma abordagem interprofissional e multidisciplinar na avaliação e gestão clínica desses pacientes, numa sistemática que permita linguagem comum entre os profissionais de saúde, caracterizada pela linha de cuidado, com ações curativas, preventivas e de reabilitação, e com mensurações objetivas que possam resultar em indicadores clínicoassistenciais.

O elevado número de pacientes com mais de uma doença associada remete às necessidades de ampliar a incorporação de tecnologias de suporte ao diagnóstico de vulnerabilidades e riscos, com abrangência preconizada na assistência pautada no modelo da integralidade compatível com a integralidade preconizada no sistema de saúde brasileiro. Neste contexto, o paciente deve ser o centro das ações, o agente do processo e o núcleo central do cuidado e as equipes são como células ordenadas por um conjunto de disciplinas suficientes para responder às necessidades biopsicossociais (Weber, Demenegui, 1997).

A questão da integralidade da atenção à saúde deve ser vista sob o aspecto da organização dos recursos disponíveis e, especialmente, do fluxo do usuário para o acesso a esses recursos. Para garantir a integralidade é necessário operar mudanças na produção do cuidado, a partir da rede básica, secundária, atenção à urgência e todos os outros níveis assistenciais, incluindo a atenção hospitalar (Franco C, Franco T [s.d.]; JCl, 2010).

No Brasil, as doenças crônicas representaram $66 \%$ dos anos de vida perdidos ajustados por incapacidade (Schramm, Oliveira, Leite, 2004) e, em decorrência delas, a perda da força de trabalho e a diminuição das 
poupanças familiares levarão a uma perda econômica de US\$ 4,18 bilhões entre 2006 e 2015 no país (Abegunde et al., 2007).

Nesse sentido, estudo recomendou a implementação de políticas para prevenção e controle das doenças crônicas, citando a necessidade de alta tecnologia e de mudanças nos tratamentos hospitalares, legislações e regulamentações voltadas para a prevenção e promoção que permitam um cuidado de qualidade e o fortalecimento do vínculo entre governo, instituições acadêmicas e sociedade civil para responder com mais facilidade e agilidade aos desafios impostos por essas doenças (Schmidt et al., 2011). O Plano de Ações Estratégicas para o Enfrentamento das Doenças Crônicas Não Transmissíveis no Brasil, elaborado pelo Ministério da Saúde (Brasil, 2011), definiu diretrizes e ações em vigilância, informação, avaliação, monitoramento e promoção em saúde e atenção integral para essas doenças e fatores de risco associados. O INTERMED, como uma ferramenta de classificação da complexidade do cuidado, identificação de necessidades e vulnerabilidades pode ser um facilitador nesse processo.

Por outro lado, ainda com relação aos sintomas, observou-se presença de sintomas leves ou ausência destes em $24,8 \%$ dos pacientes que fizeram parte do estudo, sugerindo possibilidade de cuidado fora do ambiente hospitalar, com a utilização de outras modalidades assistenciais, como o hospital-dia, a cirurgia ambulatorial e a assistência domiciliar. Esta questão, porém, depara-se com limitações na gestão do cuidado fora do ambiente hospitalar, pelas fragilidades de todas as ordens, na organização das estruturas de ofertas, na ausência de uma rede de referência que permita a continuidade de cuidado fora do hospital, contribuindo para o aumento do tempo de permanência. Este contexto é igualmente frágil no SUS e na saúde suplementar, também identificado neste estudo nas considerações sobre o acesso ao sistema de saúde.

No domínio psicológico, chamou a atenção o percentual de pacientes que apresentaram sintomas psiquiátricos moderados a graves. Ao considerar a alta prevalência de pacientes idosos portadores de doenças 
crônicas no grupo estudado, pode-se inferir que existe uma relação entre idade, doença crônica e depressão. Dentre as doenças crônicas, a depressão representa $19 \%$ da carga dessas enfermidades (Schmidt et al., 2011), afetando de $5 \%$ a $10 \%$ dos adultos (Vorcaro, 2001; Andrade, 2002). A região metropolitana de São Paulo possui a maior prevalência de depressão em comparação com dez países desenvolvidos e oito em desenvolvimento (Kessler et al., 2010). Estudo realizado em 2003 indicou que 18,8\% dos brasileiros relataram ter recebido diagnóstico de depressão nos doze meses anteriores (WHO, 2010).

Entre idosos brasileiros, pesquisa constatou a prevalência de sintomas depressivos em 20,9\% dos entrevistados, com maior frequência entre os idosos com dificuldade para dormir e com dependência funcional para atividades instrumentais de vida diária (Hoffmann et al., 2010). Nos hospitais gerais, a prevalência de depressão varia de $13 \%$ a $50 \%$ entre os pacientes com doenças crônicas (Peveler, Carson, Rodin, 2002; Mikkelsen et al., 2004; Al Windi, 2005).

A depressão pode interferir na qualidade de vida, no autocuidado e na adesão ao tratamento, aumentando a morbidade, a mortalidade e os custos com os cuidados em saúde (Ciechanowski, Katon, Russo, 2000; Goldney et al., 2004; Cully et al., 2006). O diagnóstico precoce e a organização adequada do tratamento tem efeitos positivos sobre o curso, os custos e os efeitos colaterais da depressão (Horn et al., 2007).

Os achados referentes às limitações nas habilidades de enfrentamento são relevantes e coerentes com a ausência de recursos de assistência psicológica e psiquiátrica em hospitais gerais, que comumente desconsideram a necessidade clínica de atenção psicoemocional, como por exemplo, a interconsulta psiquiátrica. Estudos apontaram para a alta prevalência de problemas psicossociais em pacientes médico-cirúrgicos, que aumentam a complexidade da gestão clínica na hospitalização e o consumo dos serviços intra e extra hospitalares (Lobo et al., 2003). 
Problemas sociais e de saúde mental interferem no tratamento da depressão, por exemplo, no que diz respeito ao ajustamento dos antidepressivos para as necessidades das morbidades físicas, o gerenciamento da conformidade do tratamento, as interações medicamentosas, ou para a situação social dos pacientes (Stiefel et al., 1999; Huyse et al., 2001; de Jonge et al., 2001).

No geral, ao atender um paciente com um problema clínico que não pertence à área de conhecimento e atuação de um médico, parece apropriado que o procedimento padrão seja consultar um colega. No entanto, pesquisas demonstraram que tais modelos clássicos ad hoc não são muito eficientes na identificação e tratamento de certos pacientes como, por exemplo, aqueles que têm comorbidade psiquiátrica no hospital geral (Stiefel et al., 1999; Huyse et al., 2001; de Jonge et al., 2001).

A presença da consultoria psiquiátrica em hospitais gerais é rara, e mesmo a psicologia hospitalar tende a ser paliativa. Isto nos permite afirmar que uma pessoa com várias doenças associadas demanda maior integração entre as especialidades e uma gestão do cuidado integrado e integral.

No Brasil, estima-se que de $30 \%$ a $50 \%$ dos pacientes internados em um hospital geral possuem uma patologia psiquiátrica, no entanto, somente $1 \%$ a $12 \%$ deles são encaminhados para avaliação (Smaira, KerrCorrêa, Contel, 2003). Em alguns países desenvolvidos, a estimativa é que $27 \%$ dos pacientes internados possuem distúrbios psiquiátricos (de Jonge et al., 2003a). O INTERMED, utilizado como um instrumento de triagem para detectar vulnerabilidade psicológica nesses pacientes nos primeiros dias de internação pode auxiliar a equipe ao traçar o plano de cuidado integral, beneficiando o tratamento do paciente em relação a um menor tempo de permanência no hospital e à qualidade de vida no momento da alta, o que pode levar à diminuição dos custos tanto para o sistema de saúde como para o paciente. 
Ao investigar os efeitos da intervenção psiquiátrica em um hospital geral, utilizando o INTERMED, pesquisadores identificaram um efeito positivo na qualidade de vida dos pacientes em geral e no tempo de internação, principalmente entre os idosos, sugerindo as possibilidades de uma melhora nos desfechos gerais desses pacientes (de Jonge, 2003).

Ao analisar o aspecto social, os índices relativos à necessidade de suporte social de família, amigos ou rede social de apoio indicam limitação de interação com a gestão das redes de apoio social, que são importantes para auxiliar o indivíduo a desenvolver estratégias e competências para enfrentar as adversidades, ajudando em seu manejo e fornecendo suporte emocional (Fratezi, Gutierrez, 2011).

As comorbidades psicossociais influenciam os resultados de várias doenças e são relacionadas ao uso excessivo dos serviços de saúde (Ciechanowski, Katon, Russo, 2000), diminuição da qualidade de vida (de Jonge, Ormel, Slaets, 2004), não sobrevivência (Frasure-Smith, Lesperance, Talajic, 1993) e baixa adesão ao tratamento, o que representa um obstáculo para um cuidado de saúde efetivo (Dimatteo, Lepper, Croghan, 2000). A detecção precoce desses problemas poderia diminuir os custos médicos e melhorar a organização da assistência, evitando a longa permanência (Lobo et al., 2003).

Os achados no domínio sistema de saúde podem indicar dificuldade de acesso à saúde suplementar mais significativa do que no SUS, pois, respectivamente, $14 \%$ e $4 \%$ dos pacientes referiram limitação no acesso ao sistema de saúde. Apesar da utilização dos serviços variar entre pessoas que têm plano/seguro de saúde e aquelas que não os possuem, a diferença entre esses dois grupos diminuiu consideravelmente nos últimos dez anos. Em 1998, pessoas com seguro-saúde tinham $200 \%$ mais chances de utilizar um serviço de saúde do que pessoas sem planos de saúde, e, em 2008, essa diferença caiu para 70\% (IBGE, 2008).

Em relação ao SUS, na base do sistema estão as Unidades Básicas de Saúde, que deveriam funcionar como a "porta de entrada" para 
os níveis de maior complexidade, como serviços ambulatoriais clínicos e cirúrgicos, serviços de diagnósticos e de apoio terapêutico, serviços de urgência e hospitais. No entanto, a ineficiência da atenção básica tornou os prontos-socorros e hospitais as "portas de entrada" do sistema. Nesse caso, para os pacientes, o fato de receber atendimento pode significar menor dificuldade de acesso (Silva, 2007).

Já na saúde suplementar, as principais barreiras de acesso ao sistema, que podem romper ou fragmentar a linha de cuidado, relacionam-se com problemas do plano/seguro de saúde, como: ausência de práticas de promoção e prevenção, deficiência da rede de serviços, segmentação dos planos, atitudes de desresponsabilização do cuidado, atitudes de cerceamento do acesso por parte da operadora e prestador, falta de insumos, perda de exames e qualidade questionável na prestação da assistência (Malta et al., 2004).

O acesso e o uso dos serviços de saúde também estão relacionados à renda e à escolaridade. Apesar da desigualdade de acesso entre as pessoas com maior e menor escolaridade estar diminuindo, ela ainda persiste. As diferenças socioeconômicas no acesso ao sistema de saúde podem ser verificadas pelo fato de que, em $2008,76 \%$ das pessoas com renda mais alta disseram ter consultado um médico, em comparação com $59 \%$ das pessoas com renda mais baixa (IBGE, 2008).

Um dado interessante é que essa desigualdade não existe entre pessoas que autoclassificam seu estado de saúde como ruim (Braga Neto, Barbosa, Santos, 2009), demonstrando que pacientes com problemas de saúde graves buscam o cuidado e recebem tratamento, independentemente de sua situação socioeconômica. Isso leva a pensar que as diferenças sociais no uso de serviços podem ser atribuídas ao comportamento adotado pelo indivíduo ao buscar o cuidado (Almeida-Filho, 2011).

Há necessidade de melhor gestão do cuidado nas instituições no que se refere à comunicação e coordenação da assistência, uma vez que $22 \%$ dos pacientes referiram comunicação e coordenação precárias ou 
ausentes na instituição $\mathrm{A}$. Este achado remete à necessidade de aprofundar a discussão sobre a organização do time assistencial, responsável pelo cuidado de beira de leito. As estruturas organizacionais em geral são definidas a partir de departamentos ou corporações profissionais em lugar do foco no paciente e suas necessidades. $O$ formato departamentalizado induz à gestão segmentada e verticalizada, enquanto o cuidado integral preconiza uma estrutura baseada na gestão do paciente, organizando o time assistencial na perspectiva do indivíduo e não das equipes isoladamente, conforme o modelo de assistência integral descrito como um facilitador para o doente visualizar as possibilidades que se apresentam, diante das circunstâncias da internação, dependente, no entanto, de equipes capazes de atuar em busca do consenso para o melhor cuidado, conforme indicação da literatura:

\footnotetext{
Entende-se que é por meio dessa prática comunicativa, caracterizada pela busca de consensos, que os profissionais podem arguir mutuamente $\mathrm{o}$ trabalho cotidiano executado $\mathrm{e}$ construir um projeto comum pertinente às necessidades de saúde dos usuários, além de reiterar o projeto técnico já dado, no que se fizer necessário (Peduzzi, 2001).
}

Ao abordar as limitações da gestão integrada do cuidado, defronta-se com outra questão mais complexa: a gestão de pessoas na área da saúde. Dentre as várias perspectivas desta problemática, apontou-se a percepção dos profissionais de enfermagem quanto ao seu papel na cadeia do cuidado. Nesse sentido, é importante que ocorra uma maior horizontalização das decisões e relações de poder entre os profissionais, o que levaria a processos de participação da equipe no plano de cuidados, indo ao encontro de uma visão mais integrada do cuidado. Pesquisadores identificaram que a horizontalização de poderes constitui-se em um dos elementos facilitadores para que se mantenha o foco nas necessidades do paciente, uma vez que as necessidades de reconhecimento do papel e autonomia de cada profissional pertencente às equipes de saúde tenham 
sido tomadas em consideração e respeitadas em sua articulação no conjunto das ações e decisões (Shimizu, Ciampone, 2002).

Quanto ao preparo das equipes, as estratégias do trabalho em equipe dos profissionais da saúde não são suficientes para as ações integradas repercutirem na forma de trabalho. Contudo, há evidências de que equipes integradas podem assegurar o desafio da gestão do cuidado pelos requisitos da comunicação eficaz e pela liderança na coordenação da assistência (Peduzzi, Ciampone, 2005).

Outro aspecto a ser considerado, é que a experiência de hospitalização pode sensibilizar para uma possibilidade de mudança de valores e visão de mundo de uma pessoa, e levá-la à compreensão da vida a partir da possibilidade de morte, entendendo na hospitalização um espaço de cuidado em todas as dimensões. Ao suprir a esperança, além das demandas físicas, está suprindo-se o ser cuidado, o sentido de vida. Trazendo para reflexão, o maior desafio de uma equipe assistencial, que tem no componente educativo a medida que pode auxiliar e facilitar a compreensão das possibilidades de saúde ao coordenar as ações nas diferentes dimensões do cuidado. Assistir integralmente é também criar espaços, no momento da hospitalização, para o "vir a ser" saúde (Weber, 2008). Nesse sentido também, o uso do método INTERMED facilita a coordenação do cuidado, a organização do time assistencial e a comunicação entre os profissionais, melhorando os resultados clínicos e a satisfação dos pacientes (Lobo at al., 2011).

Observou-se que os escores totais obtidos com a aplicação do instrumento em população brasileira hospitalizada estão de acordo com os encontrados em diversos estudos que utilizaram o método INTERMED, que variaram de 15,5, em pacientes com esclerose múltipla (de Jonge, Ormel, Slaets, 2004), a 29,6, em pacientes com dor lombar crônica (Scerri et al., 2006). Em estudo realizado em uma unidade geral de internação, o escore médio foi 20,3 (de Jonge et al., 2001). Outras pesquisas encontraram os seguintes resultados: 27,1 para pessoas encaminhadas a um serviço de 
interconsulta psiquiátrica (de Jonge et al., 2000), 19,1 para pacientes dialíticos (de Jonge et al., 2003a), 17,2 em portadores de artrite reumatoide (Koch et al., 2001) e 23,3 para pessoas com diabetes mellitus (Fischer et al.; 2000).

Dentre os três cenários em que o presente estudo foi desenvolvido, o menor escore médio foi observado na instituição $C$, que se trata de um hospital em que os pacientes eram mais jovens e possuíam menos doenças crônicas e necessidades psicológicas do que nas outras instituições.

Com relação à consistência interna do INTERMED, os achados de estudos anteriores resultaram em coeficientes $\alpha$ de Cronbach de 0,78 (pacientes encaminhados a um serviço de interconsulta psiquiátrica) (de Jonge et al., 2000); 0,79 (pacientes dialíticos) (de Jonge et al., 2003a); 0,83 (portadores de artrite reumatoide) (Koch et al., 2001); 0,84 (pacientes com esclerose múltipla) (de Jonge, Ormel, Slaets, 2004); 0,86 (pacientes internados unidade geral (de Jonge et al., 2001) e pessoas com diabetes mellitus) (Fischer et al.; 2000); e 0,94 (pacientes com dor lombar crônica) (Scerri et al., 2006).

No estudo de validação da versão espanhola do INTERMED foi encontrado um valor de $\alpha$ de 0,71 (Lobo et al., 2011), na validação para o japonês, um valor de 0,89 (Kishi et al., 2010) e na versão original do INTERMED, o valor de a foi de 0,78 (de Jonge et al., 2003a). Neste estudo, o valor de a de 0,82 encontrado indicou que o instrumento tem uma boa consistência interna; e a inter-relação entre os domínios demonstra que a complexidade de caso pode ser operacionalizada com o INTERMED como um conceito unidimensional.

Em estudo sobre a consistência interna do método INTERMED (de Jonge, Stiefel, 2003), as correlações entre os escores dos domínios foram avaliadas e, dentre os pacientes encaminhados para interconsulta psiquiátrica, o escore do domínio biológico não foi significativamente correlacionado com os escores dos domínios psicológico e social. Nos 
portadores de diabetes, o domínio biológico não esteve correlacionado com o psicológico. No geral, a menor correlação foi observada entre os escores dos domínios biológico e psicológico e a maior, entre os domínios psicológico e social. Os escores dos domínios biológico, psicológico e social correlacionaram-se de forma similar com os escores do domínio sistema de saúde. Finalmente, as correlações entre os escores dos domínios em amostras de pacientes ambulatoriais foram maiores do que em amostras de pacientes hospitalizados.

No presente estudo, a correlação não significativa entre os domínios biológico e acesso ao sistema de saúde, em duas instituições estudadas, indicaram que a condição de saúde dos pacientes não interfere no acesso ao sistema, o que pode ser explicado pelo perfil de atendimento desses hospitais, um caracterizado pelo atendimento exclusivo pelo SUS e o outro por ser um hospital de ensino que atende estudantes e profissionais da universidade e seus dependentes, bem como a população de abrangência pelo SUS, numa região onde existe a rede de atenção disponível.

Os domínios psicológico e acesso ao sistema de saúde não foram significativamente correlacionados em uma instituição, o que pode ser explicado pelo fato de que os pacientes referiram adequado acesso ao sistema de saúde e por serem mais agudizados. Com relação a esse achado em outra instituição, percebeu-se que os pacientes possuíam maiores renda e escolaridade, fatores que estão relacionados a maior habilidade de coping (Bertolin et al., 2011).

Na década de 1930, Selye (1936 apud Chaves, 1994) postulou que o organismo na vigência de estímulos (estressores) desencadeava reações neuroendócrinas (respostas biológicas) e comportamentais com o objetivo de restaurar seu equilíbrio, o que ele denominou por Síndrome de Adaptação Geral. Esses estímulos não tinham especificidade, podendo ser de ordem física (infecção, trauma) ou emocional, decorrentes das relações interpessoais. Com os estudos sobre coping, foi possível compreender o stress além da esfera biológica, como um processo com componentes 
também de ordem psíquica, cognitiva e comportamental entendido não somente como nossas ações, mas também os pensamentos que emitimos. Coping é um conceito que tem sido importante em psicologia nos últimos quarenta anos. Nas décadas de 1940 e 1950 sua compreensão subsidiou a avaliação clínica, sendo atualmente bastante utilizada em psicoterapias e programas educacionais com o objetivo principal de desenvolver habilidades para enfrentar situações estressoras, ansiogênicas ou problemáticas, cada vez mais frequentes tanto no dia a dia como em momentos de doença (Chaves, 1994).

Acredita-se que mesmo diante de dificuldades de acesso ao sistema de saúde, a capacidade de enfrentamento dessas pessoas pode ser melhor se elas forem fortalecidas para tal, mesmo no curto período de tempo que permanecem internadas, desde que a equipe esteja focada nesse processo.

Com relação ao tempo de internação, as médias obtidas foram maiores do que a média de permanência nos hospitais do SUS em São Paulo, que é de cinco dias (Barata, Mendes, Andrade, 2010; Barata, Mendes, Bittar, 2010). No entanto, os dados encontrados sugerem que para além da gravidade biológica, o tempo de internação pode estar relacionado aos aspectos psicológicos, sociais ou do sistema de saúde, como a espera para realização de procedimentos.

As evidências encontradas sobre a pontuação do INTERMED e o tempo de internação estão de acordo com a literatura, em que pacientes admitidos em uma enfermaria geral com maior grau de complexidade no INTERMED tiveram o dobro de tempo de permanência no hospital, aumentaram 0 uso de medicamentos, intervenções de enfermagem e consultas com especialistas (de Jonge et al., 2001) e apresentaram pior qualidade de vida no momento da alta (de Jonge et al., 2003b). Novamente, esses dados sugerem a importância da coordenação adequada do cuidado e da comunicação entre os profissionais de saúde. A organização do sistema de saúde e a integração entre os diversos serviços nos diferentes níveis de 
assistência são fundamentais para garantir 0 atendimento dos pacientes no local mais adequado para suas necessidades.

Os achados relacionados à pontuação do INTERMED e religião estão de acordo com a literatura sobre o tema, porém, as diferenças encontradas foram insuficientes para detectar associação. Nesse sentido, pesquisa com pacientes usuários de hospital de ensino com idade entre $18 \mathrm{e}$ 84 anos, identificou que $76 \%$ dos participantes referiram a religião como bastante ou muitíssimo importante (Panzini et al., 2011).

Quando as pessoas se tornam fisicamente doentes, muitas dependem de crenças e práticas religiosas para aliviar o estresse, manter um senso de controle e de esperança e continuar o propósito na vida e seu significado. O envolvimento religioso parece ativar os doentes, particularmente aqueles com problema de saúde grave e incapacitante, ajudando-os a lidar com a experiência negativa relacionada às suas condições de saúde (Koeing, Larson D, Larson S, 2001). No conceito "pessoa", está implícito não apenas sua condição biológica de vida, mas também sua condição biográfica. Não é unicamente o corpo humano, enquanto categoria física, todavia o ser, enquanto realidade bio-psico-sócioespiritual que transparece neste conceito. É a pessoa tornada hóspede com suas inúmeras necessidades - o centro gravitacional de um hospital humanizado, por conseguinte, da equipe assistencial (Hoepfner, 2008).

A prática religiosa pode ser uma estratégia de enfrentamento do problema de saúde e de manutenção das esperanças por recuperar as forças perdidas com a internação. Acredita-se que os pacientes procuram na religião uma perspectiva de futuro frente ao sofrimento (Aquino, Zago, 2007). A religiosidade pode contribuir no restabelecimento dos sentimentos de controle pessoal e de autoestima alterados pelos desgastes ocasionados pela doença (Pereira, 2011).

Os dados da relação entre autoavaliação do estado de saúde e escore INTERMED indicaram concordância entre as autoavaliações e a complexidade avaliada pelo instrumento, tanto no escore geral como em 
todos os domínios, sugerindo que os pacientes conseguem avaliar adequadamente seu estado de saúde e que o instrumento realmente pode identificar os pacientes mais complexos.

Este estudo apresentou uma nova tecnologia para a classificação da complexidade de cuidados do paciente no âmbito biopsicossocial e do sistema de saúde. Acredita-se pelos achados desta pesquisa que o método INTERMED pode auxiliar na definição do plano de tratamento e na tomada de decisões, tanto para os profissionais de saúde quanto para o paciente e família.

O método INTERMED foi desenvolvido com base no pressuposto de que a recuperação da saúde depende da alteração dos fatores em todos os quatro domínios que interferem na capacidade do paciente de melhorar. Nesse sentido, é importante o engajamento da família no esclarecimento do tratamento, em especial quando o paciente apresenta uma depressão correlata que interfere na aderência; ou questões de âmbito social, como acesso ao transporte para uma consulta e recursos financeiros para a compra de medicamentos; ou se tem energia para encontrar um especialista em sua rede de prestadores para tratar de suas condições médicas gerais e psiquiátricas (Kathol, Perez, Cohen, 2010).

Inerente ao sistema INTERMED está o entendimento de que uma doença física sem complicações e/ou de tratamento simples poderia se tornar complexa pela presença de um ou mais fatores em outros domínios da vida do paciente.

O cuidado integrado enquanto modelo biopsicossocial de atenção ao doente não foi implementado como um modelo de cuidado de saúde, resultando em subtratamento de comorbidades psiquiátricas e psicossociais. Embora várias tentativas tenham sido feitas para operacionalizar o modelo biopsicossocial e desenvolver instrumentos de avaliação relacionados, ainda faltam métodos eficientes para serem usados no cuidado. A questão de como abordar a morbidade biopsicossocial continua sendo um desafio importante, abrangendo a rede de saúde (Kathol, Perez, Cohen, 2010). 
Pensando na aplicabilidade do INTERMED na realidade do sistema hospitalar brasileiro, visando à redução do tempo de permanência e ao gerenciamento de leitos, este estudo indicou o potencial favorável do INTERMED na gestão clínica dos pacientes. De acordo com dados deste estudo, esse método permite a otimização de cerca de $20 \%$ dos leitos hospitalares, tornando evidente sua contribuição no planejamento do cuidado, porém, sua aplicabilidade requer hospitais com estruturas operacionais suficientes para sistematizar 0 cuidado a partir das necessidades e vulnerabilidades do paciente.

Estudo demonstrou que a ronda interprofissional pode reduzir o tempo de permanência do paciente no hospital na medicina interna geral, mas a aplicação desse tipo de cuidado a todos os pacientes recémadmitidos não parece viável. Em vez disso, foi proposta a utilização desse tipo de cuidado apenas a pacientes detectados como complexos pelo INTERMED (Curley, McEachern, Speroff, 1998).

O método foi implantado no Departamento de Medicina Interna Geral do Hospital Universitário Groningen, na Holanda, em que todos os pacientes admitidos são avaliados com o INTERMED e os casos acima do ponto de corte são discutidos em reuniões da equipe assistencial. Estudo controlado demosntrou que é possível melhorar a qualidade de vida no momento da alta utilizando essa forma de prestação de cuidados em relação aos cuidados habituais (de Jonge, Latour, Huyse, 2003).

O INTERMED demonstra ser uma ferramenta relevante para os vários agentes envolvidos no processo de cuidado, pois fornece uma base para um tratamento interprofissional efetivo de pacientes de alta complexidade e induz uma mudança de paradigma orientada tanto para a especialidade como para um modelo de atenção interdisciplinar centrado no paciente, que promove uma avaliação abrangente e tratamento integrado do paciente complexo, com possibilidade de gestão de caso dentro das linhas de cuidado. 
Gondusãa 


\section{CONCLUSÃO}

Com base nos achados deste estudo, considera-se que a versão brasileira do INTERMED possui equivalência com o instrumento original; é confiável, uma vez que os itens do instrumento se relacionam e são complementares entre si; é válida, pois é capaz de medir o objeto ao qual se propõe.

A metodologia empregada para a tradução e adaptação cultural neste estudo foi considerada adequada, pois permitiu a inclusão de aspectos específicos da cultura brasileira e a adoção de uma linguagem clara, simples e de fácil acesso aos profissionais e pacientes.

Os resultados obtidos a partir das traduções, retrotraduções e índice de validade de conteúdo demonstram semelhança de significado e conceito entre $o$ instrumento traduzido e o original, indicando equivalência semântica idiomática e cultural.

Os desfechos decorrentes da aplicação do método INTERMED sinalizam a possibilidade de sua incorporação pelo sistema de saúde brasileiro, já que é uma ferramenta que permite a identificação de vulnerabilidades, riscos e necessidades de cuidados para além do campo biológico, visando à gestão integrada da assistência nas diferentes dimensões do cuidado à saúde.

O estudo mostrou que é possível haver uma ponte facilitadora entre a adoção de tecnologias de gestão clínica e o planejamento do cuidado interprofissional e multidisciplinar, gerando menor tempo de permanência hospitalar e aumento no giro, e otimização de leitos.

A fragmentação do cuidado, algumas vezes, resultante da dissonância do trabalho dos profissionais de saúde, necessita de tecnologias facilitadoras para a integração da assistência. Para isto, o método 
INTERMED pode ser uma ferramenta de triagem inicial, direcionando a equipe na gestão clínica do caso com foco nas necessidades dos pacientes, vulnerabilidades e riscos.

A detecção precoce de necessidades por meio de um instrumento como o método INTERMED destina-se, dentre outros fatores, a melhorar a comunicação entre os pacientes e os profissionais, bem como entre profissionais com formações distintas, e facilitar o desenvolvimento inicial do planejamento de cuidados individualizados e integrais, além da melhor articulação na coordenação do cuidado.

\subsection{CONSIDERAÇÕES FINAIS}

Considera-se que este estudo foi o passo inicial para a proposição de outras ferramentas que permitam a prestação de um cuidado integrado, e se reconhece a necessidade de expandir o conhecimento sobre o método INTERMED, incluindo o treinamento de profissionais para sua utilização.

Como próximos passos, sugere-se a realização de estudos em população brasileira que objetivem verificar a efetividade do método INTERMED na identificação dos pacientes complexos e na gestão do cuidado e no trabalho interprofissional, tendo em vista o tempo de hospitalização e os custos com internações e reinternações, assim como a realização de estudos em outras modalidades de serviços, como ambulatórios, atendimento domiciliário, programa de saúde da família e em populações específicas, como idosos, pacientes psiquiátricos e portadores de patologias específicas, como tem sido feito nos estudos internacionais nos cenários onde o INTERMED tem sido empregado.

Iniciativas como as propostas poderão favorecer a utilização do método INTERMED na prática clínica, o que pode ter implicações importantes na prestação de cuidados à saúde, coordenação de cuidados e alocação de recursos humanos e financeiros e na gestão da clínica. 
Finalizando, acredita-se que os achados decorrentes desta pesquisa trazem a possibilidade inovadora de uma tecnologia já reconhecida internacionalmente, que poderá proporcionar uma melhor visibilidade da qualidade dos cuidados prestados nos serviços de saúde brasileiros, pois os resultados, segundo a complexidade assistencial dos pacientes e sua demanda de cuidados, trarão subsídios aos gestores dos serviços e pesquisadores, que serão relevantes e poderão ser comparados aos dados advindos de pesquisas em outros países.

\subsection{RECOMENDAÇÕES}

Sendo a versão brasileira do INTERMED confiável conforme evidências deste estudo, recomenda-se sua incorporação como uma ferramenta de apoio à gestão do cuidado integral do paciente, podendo ser útil para:

- Identificar níveis de risco e vulnerabilidades de pacientes crônicos;

- Indicar necessidades biopsicossociais capazes de comprometer o curso da internação hospitalar;

- Permitir a gestão racional do tempo de permanência, a partir da gestão clínica multidisciplinar e interprofissional;

- Auxiliar na indicação de pacientes passíveis de cuidados domiciliares ou mesmo pela rede de atenção básica;

- Ajudar na constatação da necessidade de institucionalização do paciente decorrente de problemas sociais;

- Indicar a demanda de pacientes que precisarão de acompanhamento de serviços de saúde mental;

- Tornar a gestão assistencial mais efetiva, com consequente redução da morbimortalidade com a incorporação do método INTERMED em hospitais que atendem a alta complexidade; 
- Identificar nos domínios biológico, psicológico, social e acesso ao sistema de saúde fatores que interferem na capacidade do paciente melhorar;

- Gerenciamento de casos, na medida em que considera todos os componentes que influenciam a saúde e os seus resultados;

- Comparar os resultados da complexidade do cuidado aos existentes em literatura internacional. 
Referéncias 


\section{REFERÊNCIAS}

Abegunde DO, Mathers CD, Adam T, Ortegon M, Strong K. The burden and costs of chronic diseases in low-income and middleincome countries. The Lancet. 2007;370:1929-38.

Almeida-Filho N. Ensino superior e os serviços de saúde no Brasil. The Lancet. 2011;377:6-7.

Alves LC, Leimann BCQ, Vasconcelos MEL, Carvalho MS, Vasconcelos AGG, Fonseca TCO et al. A influência das doenças crônicas na capacidade funcional dos idosos do município de São Paulo, Brasil. Cad Saude Publ. 2007;23(8):1924-30.

Alves Pereira MG, Azevedo ES. A relação médico-paciente em Rio Branco/AC sob a ótica dos pacientes. Rev Assoc Med Bras. 2005;51(3):1537.

AI Windi A. Depression in general practice. Nord J Psychiatry. 2005;59:272277.

Andrade L, Walters EE, Gentil V, Laurenti R. Prevalence of ICD-10 mental disorders in a catchment area in the city of Sao Paulo, Brazil. Soc Psychiatry Psychiatr Epidemiol. 2002;37:316-25.

Aquino VV, Zago MMF. O significado das crenças religiosas para um grupo de pacientes oncológicos em reabilitação. Rev Latinoam Enferm. 2007;15(1):42-7.

Arouca ASS. O dilema preventivista: contribuição para a compreensão e crítica da medicina preventiva [tese]. Campinas: Faculdade de Ciências Médicas, Universidade Estadual de Campinas, 1975.

Assis M. Aspectos sociais do envelhecimento. In: Saldanha AL, Caldas CP, editores. Saúde do idoso: a arte de cuidar. $2^{\mathrm{a}}$ ed. Rio de Janeiro: Interciência, 2004. p.11-21.

Ayres JRCM. Cuidado e reconstrução das práticas de saúde. Interface Comun Saúde Educ. 2004;8(14):73-92.

Bandeira M, Calzavara MGP, Varella AAB. Escala de sobrecarga dos familiares de pacientes psiquiátricos: adaptação transcultural para o Brasil (FBIS-BR). J Bras Psiquiatr. 2005;54(3):206-14 .

Barata LRB, Mendes JDV, Andrade, MC. O gestor estadual e os desafios da atenção básica em saúde. In: Realidades e perspectivas da gestão estadual do SUS. Brasília: Conselho Nacional de Secretários de Saúde (CONASS); 2010. p.71-9. 
Barata LRB, Mendes JDV, Bittar OJNV. Hospitais de Ensino e o Sistema Único de Saúde. Rev Adm Saúde. 2010;12(46):7-14.

Beaton DE, Bombardier C, Guillemin F, Ferraz M.B. Guidelines for the process of cross-cultural adaptation of self-report measures. Spine. 2000;25(24):3186-91.

Bertolin DC, Pace AE, Kusumota L, Haas V. Associação entre os modos de enfrentamento e as variáveis sociodemográficas de pessoas em hemodiálise crônica. Rev Esc Enferm USP. 2011;45(5):1070-6.

Born T. Cuidado ao idoso em instituição. In: Papaléo Netto M. Gerontologia: a velhice e o envelhecimento em visão globalizada. São Paulo: Atheneu, 2005.

Braga Neto FC, Barbosa PR, Santos IS. Atenção hospitalar: evolução histórica e tendências. In: Giovanella L, Escorel S, Lobato LVC, Noronha JC, Carvalho Al, organizadores. Políticas e sistema de saúde no Brasil. Rio de Janeiro: Fiocruz, 2008. p. 665-704.

Brasil. Ministério da Previdência e Assistência Social. Sistema Nacional de Saúde. Brasília;1975.

Brasil. Ministério do Trabalho e Emprego. Portaria GM n. 397, de 9 de outubro de 2002. Aprova a Classificação Brasileira de Ocupações (CBO/2002), para uso em todo território nacional e autoriza a sua publicação. In: Brasil. Ministério do Trabalho e Emprego. Classificação Brasileira de Ocupações. Brasília; 2002.

Brasil. Conselho Nacional de Secretários de Saúde. Legislação do SUS. Brasília: CONASS; 2003a.

Brasil. Ministério da Saúde. Núcleo Técnico da Política Nacional de Humanização. Política Nacional de Humanização. Brasília; 2003b.

Brasil. Ministério da Saúde. Portaria GM n. 399, de 22 de fevereiro de 2006. Divulga o Pacto pela Saúde 2006 - Consolidação do SUS e aprova as Diretrizes Operacionais do Referido Pacto. In: Brasil. Ministério da Saúde. Pacto pela Saúde 2006. Brasília; 2006a.

Brasil. Ministério da Saúde. Secretaria de Atenção à Saúde. Departamento de Atenção Básica. Envelhecimento e saúde da pessoa idosa. Brasília: Ministério da Saúde; 2006b.

Brasil. Ministério da Saúde. Conselho Nacional de Secretários da Saúde. Conselho Nacional de Secretarias Municipais de Saúde. Instituto Sírio Libanês de Ensino e Pesquisa. Gestão da clínica nos hospitais do SUS: cadernos do curso. São Paulo; 2009.

Brasil. Ministério da Saúde. Secretaria de Vigilância em Saúde. Departamento de Análise de Situação de Saúde. Plano de ações 
estratégicas para o enfrentamento das doenças crônicas não transmissíveis (DCNT) no Brasil 2011-2022. Brasília; 2011.

Carvalhal A. Are women a different group of HIV-infected individuals? Arch Womens Ment Health. 2010;13:181-83.

Carvalho Filho ET. Fisiologia do Envelhecimento. In: Papaléo Netto M. Gerontologia - a velhice e o envelhecimento em visão globalizada. São Paulo: Atheneu, 2006.

Castro MSM, Travassos C, Carvalho MS. Fatores associados às internações hospitalares no Brasil. Cien Saude Colet. 2002;7(4):795-811.

Cecílio LCO. As necessidades de saúde como conceito estruturante na luta pela integrlidade e eqüidade na atenção em saúde. In. Pinheiro $R$, Mattos RA, organizadores.. Os sentidos da integralidade na atenção e no cuidado à saúde. Rio de Janeiro: ABRASCO, 2001.

Cecílio LCO, Merhy EE. A integralidade do cuidado como eixo da gestão hospitalar. In: Pinheiro R, Mattos RA. Construção da integralidade: cotidiano, saberes e práticas em saúde. Rio de Janeiro: ABRASCO, 2003.

Chaimowicz F. Os idosos brasileiros no século XXI: demografia, saúde e sociedade. Belo Horizonte: Postgraduate, 1998.

Chaves EC. Stress e trabalho do enfermeiro: a influência de características individuais no ajustamento e tolerância ao turno noturno [tese]. Instituto de Psicologia, Universidade de São Paulo, 1994.

Ciechanowski PS, Katon WJ, Russo JE: Depression and diabetes: impact of depressive symptoms on adherence, function, and costs. Arch Intern Med. 2000;160:3278-85.

Clark DW, MacMahon D. Preventive medicine. New York: Little Brown, 1967.

Coelho Filho JM. Modelos de serviços hospitalares para casos agudos em idosos. Rev Saude Publ. 2000;34:666-71.

Costa-Junior FM, Maia ACB. Concepções de homens hospitalizados sobre a relação entre gênero e saúde. Psic Teor Pesq. 2009;25(1):55-63.

Creditor MC. Hazards of hospitalization of the elderly. Ann Inter Med. 1993;118:219-23.

Cronbach LJ. Coefficient alpha and the internal structure of tests.

Psychometrika. 1951;16(3):297-334.

Cully JA, Graham DP, Stanley MA, Ferguson CJ, Sharafkhaneh A, Souchek $J$, et al. Quality of life in patients with chronic obstructive pulmonary disease and comorbid anxiety or depression. Psychosomatics. 2006;47:312-319. 
Curley C, McEachern JE, Speroff T. A firm trial of interdisciplinary rounds on the inpatient medical wards. Med Care. 1998;36:4-12.

de Jonge P, Bauer I, Huyse FJ, Latour CH. Medical inpatients at risk of extended hospital stay and poor discharge health status: detection with COMPRI and INTERMED. Psychosomatics. 2003b; 65:534-541.

de Jonge P, Huyse FJ, Ruinemans GM, Stiefel FC, Lyons JS, Slaets JP. Timing of psychiatric consultations: the impact of social vulnerability and level of psychiatric dysfunction. Psychosomatics. 2000;41(6):505-11.

de Jonge P, Huyse FJ, Stiefel FC, Slaets JP, Gans RO. INTERMED - a clinical instrument for biopsychosocial assessment. Psychosomatics. 2001;42(2):106-9.

de Jonge P, Latour C, Huyse FJ. Implementing psychiatric interventions on a general medical ward: effects on patients' quality of life and length of hospital stay. Psychosomatics. 2003;65:997-1002.

de Jonge P, Ormel J, Slaets JPJ. Depressive symptoms in the elderly predict poor adjustment following somatic events. Am J Geriatr Psychiatry. 2004;12:57-64.

de Jonge P, Ruinemans GMF, Huyse FJ, Ter Wee PM. A simple risk score predicts poor quality of life and non-survival at one year follow up in dialysis patients. Nephrol Dial Transplant. 2003a;18:2622-28.

de Jonge P, Stiefel F. Internal consistence of the INTERMED in patients with somatic diseases. J Psychosom Res. 2003;54:497-99.

Dimatteo MR, Lepper HS, Croghan TW. Depression is a risk factor for noncompliance with medical treatment. Arch Intern Med. 2000;160:2101-07.

Doyal L. Sex, gender, and health: the need for a new approach. Br Med J. 2001;323:1061-63.

Duarte YAO. Manual dos formadores de cuidadores de pessoas idosas. São Paulo: Secretaria Estadual de Assistência e Desenvolvimento Social: Fundação Padre Anchieta, 2009.

Engel GL. The need for a new medical model: a challenge for biomedicine. Science. 1997;196(4286):129-36.

Figueiredo W. Assistência à saúde dos homens: um desafio para os serviços de atenção primária. Cien Saude Colet. 2005;10:105-9.

Fischer CJ, Stiefel FC, de Jonge P, Guex P, Troendle A, Bulliard C et al. Case complexity and clinical outcome in diabetes mellitus: a prospective study using the INTERMED. Diabetes Metab. 2000;26:295-302.

Fletcher RH, Fletcher SW. Anormalidade. In: Fletcher RH, Fletcher SW. 
Epidemiologia clínica: elementos essenciais. 4를 ed. Porto Alegre: Artmed, 2006. p.36-55.

Franco CM, Franco TB. Linhas do cuidado integral: uma proposta de organização da rede de saúde [online]. [citado 2012 abr 15]. Disponível em: http://www.saude.rs.gov.br/upload/1337000728_Linha\%20cuidado\%20integr al\%20conceito\%20como\%20fazer.pdf.

Frasure-Smith N, Lesperance F, Talajic M. Depression following myocardial infarction. Impact on 6-month survival. J Am Med Assoc. 1993;270:1819-25.

Fratezi FR, Gutierrez BAO. Cuidador familiar do idoso em cuidados paliativos: o processo de morrer no domicílio. Cien Saude Colet. 2011;16(7):3241-48.

Fratezi FR, Gutierrez BAO, Falcão DVS. Doença crônica: o processo de morrer e a morte do idoso na família. In: Falcão DVS, organizadora. A família e o idoso: desafios da contemporaneidade. Campinas: Papirus, 2010. p.191210.

Geertz, C. A interpretação da cultura. Rio de Janeiro: LTC - Livros Técnicos e Científicos, 1989.

Goldim JR. Vulnerabilidade e pesquisa: aspectos éticos, morais e legais [online]. 2004. [citado 2012 mai 05]. Disponível em:

http://www.ufrgs.br/bioetica/vulnepes.htm

Goldney RD, Phillips PJ, Fisher LJ, Wilson DH. Diabetes, depression, and quality of life: a population study. Diabetes Care. 2004;27:1066-1070.

Guillemin, F. Cross-cultural adaptation and validation of health status measures. Scand J Rheumatol. 1995;24:61-3.

Hartz ZMA, Contandriopoulos AP. Integralidade da atenção e integração de serviços de saúde: desafios para avaliar a implantação de um sistema sem muros. Cad Saude Publ. 2004;20(S2):331-6.

Heidegger, M. Ser e tempo. Petrópolis: Vozes, 1995.

Hilleboe HE, Larimore GW. Medicina Preventiva. Princípios de prevenção aplicáveis à ocorrência e à evolução das doenças. São Paulo: Serpel, 1965.

Hoepfner D. Fundamentos bíblico-teológicos da capelania hospitalar: uma contribuição para o cuidado integral da pessoa [dissertação]. São Leopoldo: Escola Superior de Teologia, 2008.

Hoffmann EJ, Ribeiro F, Farnese JM, Lima EWB. Sintomas depressivos e fatores associados entre idosos residentes em uma comunidade no norte de Minas Gerais, Brasil. J Bras Psiquiatr. 2010; 59(3):190-197. 
Hoogervorst ELJ, de Jonge P, Huyse FJ, Polman CH. The INTERMED: a screening instrument to identify multiple sclerosis patients in need of multidisciplinary treatment. J Neurol Neurosurg Psychiatry. 2003;74:20-24.

Horn EK, van Benthem TB, Hakkaart-van Roijen L, van Marwijk HW, Beekman AT, Rutten FF et al. Cost-effectiveness of collaborative care for chronically ill patients with comorbid depressive disorder in the general hospital setting, a randomised controlled trial. BMC Health Serv Res. 2007;7:28.

Hulley SB, Martin JN, Cummings SR. Planejando as medições: precisão e acurácia. In: Hulley SB, Cummings SR, Browner WS, Grady D, Hearst N, Newman TB. Delineando a pesquisa clínica: uma abordagem epidemiológica. $2^{\mathrm{a}}$ ed. Porto Alegre: Artmed, 2003. p. 55-68.

Huyse FJ, Lyons JS, Stiefel FC, Slaets JPJ, de Jonge P, Fink P et al. INTERMED: a method to assess health service needs. I. Development and reliability. Gen Hosp Psychiatry. 1999; 21:39-48.

Huyse FJ, Lyons JS, Stiefel F, Slaets J, de Jonge P, Latour C. Operationalizing the biopsychosocial model - The INTERMED. Psychosomatics. 2001;42:1.

Instituto Brasileiro de Geografia e Estatística (IBGE). Pesquisa Nacional por Amostra de Domicílios (PNAD) 2008. Rio de Janeiro: IBGE, 2004.

Instituto Brasileiro de Geografia e Estatística (IBGE). Pesquisa Nacional por Amostra de Domicílios (PNAD) 2008. Rio de Janeiro: IBGE, 2008.

Intermed Foundation [homepage na Internet]. Amsterdam; 2010. [atualizado 2010 maio 16]. Disponível em: www.intermedfoundation.org

Joint Comission International. Padrões da Joint Commission Internacional para Certificação de Programas de Cuidados Clínicos. Rio de Janeiro: Consórcio Brasileiro de Acreditação de Sistemas e Serviços de Saúde, 2010.

Jorge MR. Adaptação transcultural de instrumentos de pesquisa em saúde mental. In: Gorestein C, Andrade LHS, Zuardi AW, editores. Escalas de avaliação clínica em psiquiatria e psicofarmacologia. São Paulo: Leitura Médica, 2008. p. 53-58.

Kalache A, Veras RP, Ramos LR. O envelhecimento da população mundial: um desafio novo. Rev Saude Publ. 1987;21:200-10. 
Kathol RG, Perez R, Cohen JS. The integrated case management manual: assisting complex patients regain physical and mental health. New York: Springer Publishing Company, 2010.

Kessler RC, Birnbaum HG, Shahly V, Bromet E, Hwang I, McLaughlin KA et al. Age differences in the prevalence and co-morbidity of DSM-IV major depressive episodes: results from the World Mental Health Survey Initiative. Depress Anxiety. 2010;27: 351-64.

Kishi Y, Matsuki M, Mizushima H, Matsuki H, Ohmura Y, Horikawa N. The INTERMED Japanese version: inter-rater reliability and internal consistency. J Psychosom Res. 2010;69(6):583-6.

Koch N, Stiefel F, de Jonge P, Fransen J, Chamot AM, Gerster JC, Huyse FJ, So AK. Identification of case complexity and increased health care utilization in patients with rheumatoid arthritis. Arthritis Rheum. 2001,45(3):216-21.

Koenig HG, Larson DB, Larson SS. Religion and coping with serious medical illness. Ann Pharmacother. 2001;35(3):352-59.

Latour, CHM. Co-ordination of care for the complex medically ill. Febodruk BV: Amsterdam, Netherlands, 2006.

Lebrão ML, Laurenti R. Saúde, bem-estar e envelhecimento: o estudo SABE no município de São Paulo. Rev Bras Epidemiol. 2005;8(2),127-41.

Lidz T. A pessoa: seu desenvolvimento durante o ciclo vital. Porto Alegre: Artes Médicas, 1983.

Lima-Costa MF, Barreto S, Giatti L, Uchoa E. Desigualdade social e saúde entre idosos brasileiros: um estudo baseado na Pesquisa. Cad. Saude Publ. 2003;19(3):745-57.

Lobo E, Bellido M, Campos R, Saz P, Huyse FJ, de Jonge P et al. Primera validación en español del método INTERMED: un sistema de temprana detección de problemas biopsicosociales y de consumo de servicios en pacientes médico-quirúrgicos. Cuad Med Psicosom Psiquiatr Enlace. 2003;67(68):89-98.

Lobo E, Rabanaque MJ, Bellido ML, Lobo A. Reliability of INTERMED Spanish version and applicability in liver transplant patients: a cross-sectional study. Health Serv Res. 2011;11:160.

Lobo E, Soto-Terceño N. Hacia un cuidado integral: valoración de enfermeira, con el método INTERMED, de una paciente compleja. Enferm Clin. 2010;20(5):309-312. 
Magalhães MN, Lima ACP. Noções de Probabilidade e Estatística. São Paulo: IME-USP, 2000.

Malta DC, Cecílio LCO, Merhy EE, Franco TB, Jorge AO, Costa MA. Perspectivas da regulação na saúde suplementar diante dos modelos assistenciais. Cien Saude Colet. 2004;9(2):433-44.

Marandola Junior E, Hogan DJ. Vulnerabilidade e riscos: entre geografia e demografia. Rev Bras Estud Popul. 2005;22(1):29-53.

Martins GA. Sobre confiabilidade e validade. RBGN. 2006;8(20):1-12.

Mattos RA. A integralidade na prática (ou sobre a prática da integralidade). Cad Saude Publ. 2004;20(5):1411-16.

Mendes EV. A modelagem das redes de atenção à saúde. Belo Horizonte: Secretaria de Estado de Saúde de Minas Gerais, 2007.

Mendes W, Martins M, Rozenfeld S, Travassos C. The assessment of adverse events in hospitals in Brazil. Int J Qual Health Care. 2009;21:27984.

Merhy EE. Saúde: a cartografia do trabalho vivo. São Paulo: Hucitec, 2002.

Merhy EE, Cecílio LCO. O singular processo de coordenação dos hospitais. Rev Saude Debate. 2003;22(64):110-22.

Mezzomo AA. Fundamentos da humanização hospitalar: uma versão multiprofissional. Santos (SP): Loyola, 2003.

Mikkelsen RL, Middelboe T, Pisinger C, Stage KB. Anxiety and depression in patients with chronic obstructive pulmonary disease (COPD). A review. Nord J Psychiatry. 2004;58:65-70.

Mininel VA. Adaptação transcultural do Work Disdability Diagnosis Interview (WoDDI) para o contexto brasileiro [tese]. São Paulo: Escola de Enfermagem, Universidade de São Paulo, 2010.

Moreira ML, Dutilhnovaes HM. Internações no sistema de serviços hospitalares, SUS e não SUS: Brasil, 2006. Rev Bras Epidemiol. 2011;14(3):411-22.

Nichiata LYI, Bertolozzi MR, Takahashi RF, Fracolli LA. A utilização do conceito de vulnerabilidade pela enfermagem. Rev Latinoam Enferm. 2008;16(5). 
Oliveira DLC, Goretti LC, Pereira LSM. O desempenho de idosos institucionalizados com alterações cognitivas em atividades de vida diária e mobilidade: estudo piloto. Rev Bras Fisioter. 2006;10(1): 91-6.

Organização Pan-Americana de Saúde. Doenças crônico-degenarativas e obesidade: estratégia mundial sobre alimentação saudável, atividade física e saúde. Brasília: Organização Pan-Americana de Saúde; 2003.

Paes da Silva MJ. Comunicação tem remédio: a comunicação nas relações interpessoais em saúde. São Paulo: Edições Loyola, 2006.

Paim JS. Saúde, política e reforma sanitária. Salvador: CEPS-ISC, 2002.

Paim JS. Atenção à saúde no Brasil. In: Brasil Ministério da Saúde. Saúde no Brasil - Contribuições para a agenda de prioridades de pesquisa/Ministério da Saúde. Brasília: Ministério da Saúde, 2004. p.15-40.

Panzini RG, Maganha C, Rocha NS, Bandeira DR, Fleck M. Validação brasileira do Instrumento de Qualidade de Vida/espiritualidade, religião e crenças pessoais. Rev Saude Publ. 2011;45(1):153-65.

Peduzzi M. Equipe multiprofissional de saúde: conceito e tipologia. Rev Saude Publ. 2001;35(1):103-9.

Peduzzi M, Ciampone MHT. Trabalho em equipe e trabalho em grupo no Programa de Saúde da Família. Rev Bras Enferm. 2005;53(n.esp):143-47.

Pereira CVC. A influência da religiosidade na adesão ao uso de medicamentos por idosos [dissertação]. Brasília: Universidade Católica de Brasília, 2011.

Peveler R, Carson A, Rodin G. Depression in medical patients. BMJ. 2002;325:149-52.

Pontes AC, Leitão IMTA, Ramos IC. Comunicação terapêutica em Enfermagem: instrumento essencial do cuidado. Rev Bras Enferm. 2008;61(3):312-8.

Ramos FRS, Bertoncini JH, Machado RR, Flor RC, Pires DEP, Gelbcke FL. Trabalho, educação e política em seus nexos na produção bibliográfica sobre o cuidado. Texto Contexto Enferm. 2009;18(2):361-8.

Ramos LR. Fatores determinantes do envelhecimento saudável em idosos residentes em centro urbano: Projeto Epidoso, São Paulo. Cad. Saude Publ. 2003;19(3):793-98. 
Razera APR, Braga EM. A importância da comunicação durante o período de recuperação pós-operatória. Rev Esc Enferm USP. 2011;45(3):632-7.

Reichenheim ME, Moraes CL. Operacionalização de adaptação transcultural de instrumentos de aferição usados em epidemiologia. Rev Saude Publ. 2007;41(4):665-73.

Rosa TEC, Benício MHD, Latorre MRDO, Ramos LR. Fatores determinantes da capacidade funcional entre idosos. Rev Saude Publ. 2003;37(1):40-8.

Sapnas KG, Zeller RA. Minimizing sample size when using exploratory factor analysis for measurement. J Nurs Meas. 2002;10(2):135-54.

Scerri M, de Goumoëns P, Fritsch C, Van Melle G, Stiefel F, So A. The INTERMED questionnaire for predicting return to work after a multidisciplinary rehabilitation program for chronic low back pain. Joint Bone Spine. 2006;73(6):736-41.

Schmidt MI, Duncan BB, Silva GA, Menezes AM, Monteiro CA, Barreto SM et al. Doenças crônicas não-transmissíveis no Brasil: carga e desafios atuais. The Lancet. 2011;377:61-74.

Schramm JM, Oliveira AF, Leite IC. Transição epidemiológica e o estudo de carga de doenças no Brasil. Cien Saúde Coletiva 2004; 9: 897-908.

Shimizu HE, Ciampone MHT. As representações sociais dos trabalhadores de enfermagem não enfermeiros (técnicos e auxiliares de enfermagem) sobre o trabalho em Unidade Intensiva em um hospital-escola. Rev Esc Enferm USP. 2002;36(2):148-55.

Silva TTR. Modelos assistenciais em saúde. In: Vilarta R. Saúde coletiva e atividade física: conceitos e aplicações dirigidos à graduação em educação física. $1^{\underline{a}}$ ed. Campinas: Ipês Editorial, 2007. p.45-9.

Silva WV, Nakata S. Comunicação: uma necessidade percebida no período pré-operatório de pacientes cirúrgicos. Rev Bras Enferm. 2005;58(6):673-6.

Siqueira AB, Cordeiro RC, Perracini MR, Ramos LR. Impacto funcional da internação hospitalar de pacientes idosos. Rev Saude Publ. 2004;38(5):68794.

Smaira SI, Kerr-Corrêa F, Conte JOB. Psychiatric disorders and psychiatric consultation in a general hospital: a case- control study. Rev. Bras. Psiquiatr. 2003;25(1):18-25.

Stiefel FC, de Jonge P, Huyse FJ, Guex P, Slaets JPJ, Lyons JS et al. 
INTERMED: a method to assess health service needs. Results on its validity and clinical use. Gen Hosp Psychiatry. 1999;21:39-48.

Streiner DL, Norman GR. Health measurement scales: a practical guide to their development and use. $2^{\text {nd }}$ ed. New York: Oxford University Press, 1996.

Takahashi LT. Avaliação da vulnerabilidade ao estresse no trabalho de operadores de telemarketingpor meio da EVENT [dissertação]. Itatiba: Universidade São Francisco, 2009.

Vorcaro CM, Lima-Costa MF, Barreto SM, Uchoa E. Unexpected high prevalence of 1-month depression in a small Brazilian community: the Bambui Study. Acta Psychiatr Scand. 2001;104: 257-63.

Waltz CF, Strickland OL, Lens ER. Measurement in nursing research. Philadelphia: F.A. Davis Company, 1991.

Weber, B. Assistência integral no Hospital Moinhos de Vento: estudo de caso de um modelo de gestão assistencial com foco na pessoa [dissertação]. Porto Alegre: Pontifícia Universidade Católica do Rio Grande do Sul, 2008.

Weber B, Demeneghi LS. Assistência integral: o paciente como núcleo, a equipe como célula. Porto Alegre: Hospital Moinhos de Vento, 1997.

Wild B, Lechnera S, Herzoga W, Maatouka I, Weschea D, Raumb E et al. Reliable integrative assessment of health care needs in elderly persons: the INTERMED for the elderly (IM-E). J Psychosom Res. 2011;70:169-78.

World Health Organization. World Health Survey Results 2010. [citado 2010 ago 10]. Disponível em:

http://www.who.int/healthinfo/survey/whsresults/en/index.html. 
Apéndices 


\title{
APÊNDICES
}

\author{
APÊNDICE 1 \\ FORMULÁRIO DE INSTRUÇÕES PARA OS JUÍZES
}




\section{FORMULÁRIO DE INSTRUÇÕES - INTERMED}

O INTERMED é composto por 4 domínios: biológico, psicológico, social e sistema de saúde, com variáveis relacionadas e história, estado atual e prognóstico, resultando em 20 variáveis. Os escores para cada variável obedecem a uma escala tipo Likert, com valores estimados de 0 a 3.

Cada uma das questões deverá ser avaliada quanto a:

1. Equivalência semântica: denota a equivalência no significado das palavras, envolvendo o vocabulário e a gramática. Existem palavras que podem não possuir adequada tradução em outros idiomas, ou sua tradução pode ter diferentes significados, dependendo do contexto no qual está inserida;

2. Equivalência idiomática: representa a equivalência de expressões idiomáticas e coloquiais, pois algumas vezes, a simples tradução da expressão original pode acarretar numa total perda de significado no outro idioma; sendo necessária a substituição por expressões equivalentes, para preservar o seu significado original;

3. Equivalência cultural: refere-se às situações evocadas ou retratadas nos itens que devem corresponder às vivências em nosso contexto cultural.

Para determinar sua avaliação, os juízes deverão apontar sua concordância ou discordância quanto à forma final de cada questão marcando uma das seguintes opções:

Escala de equivalência

$-1=$ não equivalente

$0=$ indeciso

1 = equivalente

Se assinalar -1 ou 0 , favor acrescentar sugestões ao lado de cada item. 


\section{APÊNDICE 2}

TERMO DE CONSENTIMENTO LIVRE E ESCLARECIDO 


\section{TERMO DE CONSENTIMENTO LIVRE E ESCLARECIDO}

O senhor(a) está sendo convidado(a) para participar de uma pesquisa para a tradução e validação de um instrumento (denominado INTERMED) de avaliação de risco que envolve o seu estado físico, emocional e social (biopsicossocial) visando um gerenciamento e otimização da sua permanência hospitalar.

Esta pesquisa envolve uma entrevista que visa entender melhor as suas queixas e o significado da sua enfermidade. Essas informações ajudarão a organizar o cuidado médico adaptando as suas necessidades individuais específicas.

Para tanto, gostaria que o(a) senhor(a) participasse desta pesquisa, na qual me comprometo a seguir a portaria do Conselho Nacional de Saúde CNS/96 relacionada à Pesquisa com Seres Humanos respeitando o seu direito de:

1. Ter liberdade de participar ou não do estudo, sem que isso the traga algum prejuízo ou risco. Caso aceite participar, poderá interromper a participação em qualquer momento caso se sinta incomodado(a);

2. Manter o seu nome em sigilo absoluto, sendo que o que disser não lhe resultará em qualquer dano à sua integridade;

3. Responder as questões levantadas pelo pesquisador durante a internação caso seja solicitado(a) para uma entrevista, onde será marcado um local na instituição, horário e data em que possa se sentir mais confortável fisicamente e emocionalmente;

4. Garantia de receber esclarecimentos a qualquer dúvida durante ou após a entrevista.

Em caso de dúvida o senhor poderá obter mais esclarecimentos ou informações sobre o estudo e sua participação com as Pesquisadoras Responsáveis nos seguintes telefones:

Bernadete Weber: 1130536611 Ramal: 1124 ou 1174348503

Prof ${ }^{a}$ Dr ${ }^{a}$ Beatriz A. O. Gutierrez: 1138643927 ou 1192890838

Prof $^{\mathrm{a}}$ Dr $^{\mathrm{a}}$ Maria Helena Trench Ciampone: 1130617551 ou 1130617552

Caso aceite, por favor, responda ao questionário. Esta pesquisa tem finalidade acadêmica e os resultados serão apresentados ao Ministério da Saúde na incorporação de tecnologia de gestão. Além disso, será objeto de tese de doutorado e consequentes publicações em revistas científicas da área da saúde.

Obrigada pela atenção.

Nome do Pesquisador

Assinatura do Pesquisador

Declaro que, após convenientemente esclarecido pelo pesquisador e ter entendido o que me foi explicado, consinto em participar do presente Projeto de Pesquisa.

$\overline{\text { Nome do Participante }}$

Assinatura do Participante

Nome do Representante Legal

(se aplicável)

Assinatura do Representante Legal

(se aplicável)

São Paulo, 
APÊNDICE 3

QUESTIONÁRIO SÓCIO DEMOGRÁFICO 


\section{InTERMED}

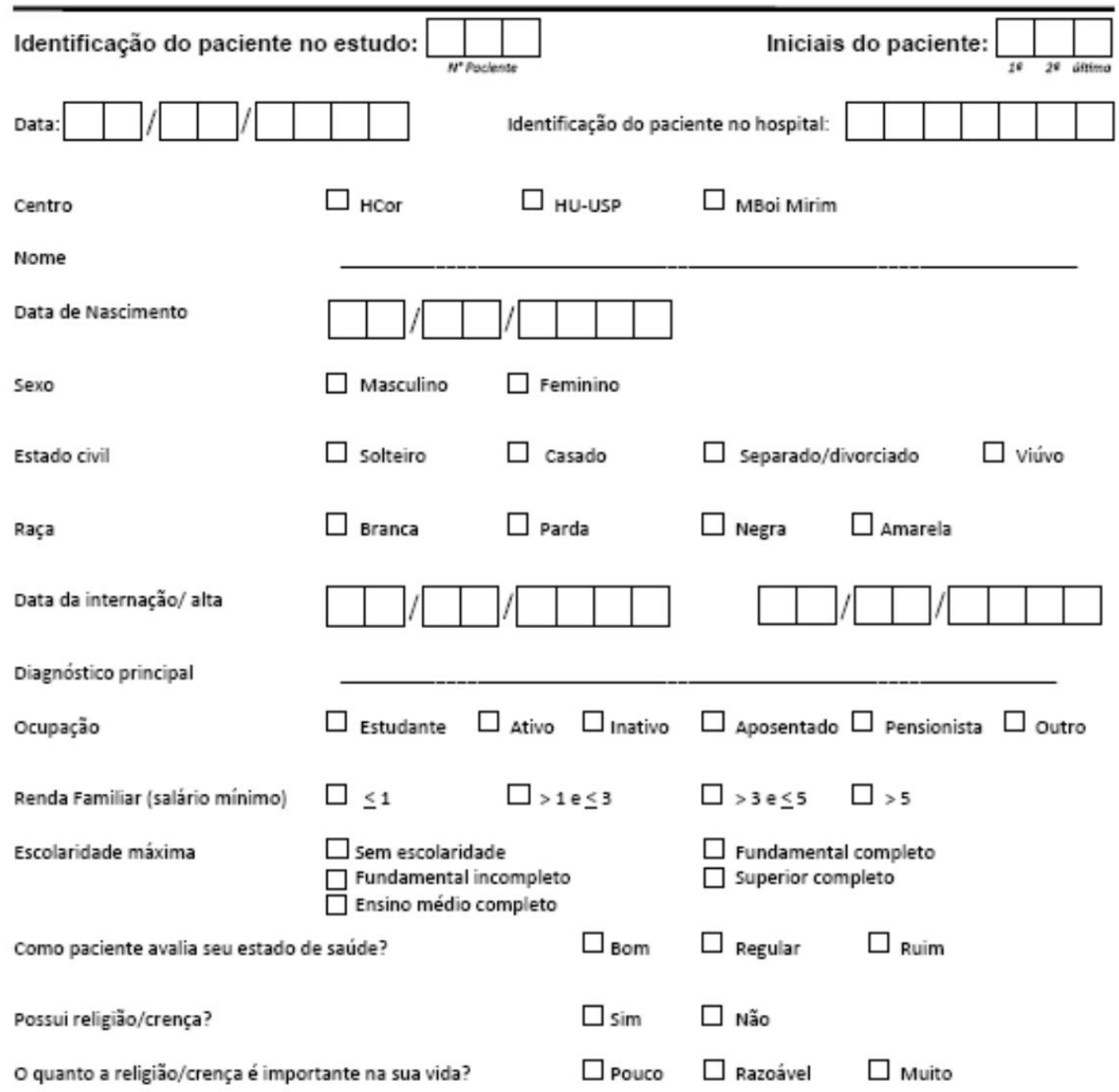

\begin{tabular}{|c|c|c|c|}
\hline DOMínIOS & HISTÓRIA & ESTADO ATUAL & VULNERABILIDADE \\
\hline BIOLóGico & $\begin{array}{l}\text { Cronicidade } \\
\text { (0) (1) (2) (3) } \\
\text { Dilema diagnóstico } \\
\text { (0) (1) (2) (3) }\end{array}$ & $\begin{array}{l}\text { Gravidade sintomas } \\
\text { (0) (1) (2) (3) } \\
\text { Desafio diagnóstico } \\
\text { (0) (1) (2) (3) }\end{array}$ & $\begin{array}{l}\text { Complicações e ameaça à vida } \\
\text { (0) (1) (2) (3) (?) }\end{array}$ \\
\hline PSicológico & $\begin{array}{l}\text { Barreiras para o enfrentamento } \\
\text { (0) (1) (2) (3) } \\
\text { Disfunção psiquiátrica } \\
\text { (0) (1) (2) (3) } \\
\text { (HP2) }\end{array}$ & $\begin{array}{l}\text { Resisténcia ao tratamento } \\
\text { (0) (1) (2) (3) } \\
\text { Sintomas psiquiátricos } \\
\text { (0) (1) (2) (3) }\end{array}$ & $\begin{array}{l}\text { Ameaça à saúde mental } \\
\text { (0) (1) (2) (3) }\end{array}$ \\
\hline SOCIAL & $\begin{array}{l}\text { Problemas trabalho e lazer } \\
\begin{array}{ll}\text { (0) }(1)(2)(3) & \\
\text { Disfunção social } \\
\text { (0) (1) (2) }(3)\end{array} \\
\text { (HS2) }\end{array}$ & $\begin{array}{l}\text { Instabilidade residencial } \\
\text { (0) (1) (2) (3) } \\
\text { Apoio social precário } \\
\text { (0) (1) (2) (3) }\end{array}$ & $\begin{array}{l}\text { Vulnerabilidade social } \\
\text { (0) (1) (2) (3) }\end{array}$ \\
\hline SISTEMA DE SAÚDE & $\begin{array}{l}\text { Acesso ao cuidado } \\
\text { (0) (1) (2) (3) (HHS1) } \\
\text { Experiência do tratamento } \\
\text { (0) (1) (2) (3) }\end{array}$ & $\begin{array}{l}\text { Organização do cuidado } \\
\text { (0) (1) (2) (3) } \\
\text { Coordenação do cuidado } \\
\text { (0) (1) (2) (3) } \\
\text { [CHS2] }\end{array}$ & $\begin{array}{l}\text { Impedimentos do sistema de } \\
\text { saúde } \\
\text { (0) (1) (2) (3) (?) }\end{array}$ \\
\hline
\end{tabular}

Preenchido por: 


\section{APÊNDICE 4 \\ PRIMEIRA VERSÃO TRADUZIDA PARA O PORTUGUÊS DO MÉTODO INTERMED}




\section{As questões direcionadoras [1-17] do INTERMED - entrevista}

\section{Introdução}

Conforme combinado, nós teremos esta entrevista visando entender melhor o que suas queixas atuais ou doença significam para você e o que é necessário para melhor controlar sua situação. Agora que nós sabemos sobre sua situação clínica, eu gostaria de ter uma ideia melhor de que tipo de pessoa você é e como você está lidando com seus problemas clínicos; estas informações ajudarão a organizar o cuidado, adaptado às suas necessidades individuais específicas. Durante a entrevista vários tópicos serão abordados. Pode ser que haja certas questões, as quais você realmente gostaria de refletir um pouco mais. Para poder elaborar um plano de tratamento apropriado, é necessário na nossa primeira conversa ter/criar uma visão geral dos problemas. Quando necessário, nós podemos focar nestas questões na próxima fase. Você entende e concorda ou você tem alguma dúvida?

Considere se o paciente é capaz de ser entrevistado.

Bom.

1. Eu vou te contar o que eu sei sobre a razão de seu encaminhamento/admissão e seu estado físico atual. Você deve me corrigir quando eu estiver errado. [Gravidade dos Sintomas/Comprometimento; Desafio diagnóstico; Cronicidade]

2. Agora eu gostaria de saber como você se sente fisicamente? Sua condição física tem um impacto no seu funcionamento físico? [Gravidade dos Sintomas]

3. Agora que você me informou como você se sente fisicamente, eu gostaria de ter mais alguma informação a respeito de suas doenças físicas e tratamentos nos últimos cinco anos. [Cronicidade]

4. Os médicos tiveram alguma dificuldade de achar um diagnóstico com as queixas/doenças que você tinha nos últimos 5 anos? Estas queixas não foram solucionadas? Atualmente, essas queixas estão sendo investigadas? [Dilema diagnóstico]

5. Quem tem sido os profissionais - médicos, psicólogos, enfermeiros ou assistentes sociais - que estão cuidando de você? Eles trabalham todos na mesma instituição e as consultas são coordenadas? [Organização do cuidado]

6. Existe comunicação mútua entre seus cuidadores para discutir e ajustar seu tratamento? [Coordenação do cuidado]

7. Houve conflitos com médicos durante os últimos cinco anos, os quais te causaram uma má impressão, que pode interferir na sua confiança em médicos? [Experiência do Tratamento]

8. Agora, eu gostaria de saber se você tem um bom seguro-saúde? Você já teve problemas com seu seguro-saúde? A distância das instituições onde você é tratado é apropriada ou você perdeu consultas devido à distância?

1. Até onde é de meu conhecimento você pode ter uma formação cultural diferente. Seus prestadores levam isso em consideração? (Há problemas de comunicação devido a problemas de linguagem?) [Acesso]

9. Agora eu gostaria de mudar de assunto e te perguntar sobre o modo em que você vive. Você tem um trabalho atualmente? Qual nível de instrução você alcançou e você conseguiu um diploma? [Problemas de trabalho e lazer]

10. Você é uma pessoa que consegue ter lazer? O que você faz para ter alguma distração? Você tem hobbies? [Problemas de trabalho e lazer]

11. Você pode me contar como você vive atualmente? $E$ no caso de doença ou deficiência, há alguém com quem você possa contar? [Instabilidade residencial; Apoio social precário] 
12. Agora eu gostaria de saber que tipo de pessoa você é. No geral, você é uma pessoa calma e estável? Você é alguém que consegue ter um bom relacionamento com outras pessoas ou há conflitos às vezes? [Disfunção social; Barreiras para enfrentamento]

13. Eu gostaria de te perguntar sobre seus hábitos de fumo e bebida e a relação destes com os seus problemas atuais? Você usa analgésico? Você às vezes se preocupa que você possa usá-los em excesso? [Barreiras para enfrentamento]

14. Como você lida com situações difíceis? Esta seria uma razão para usar álcool, tabaco ou drogas? Você é propenso a adiar decisões? Isso o levaria a falar demais ou ficar em silêncio? [Barreiras para enfrentamento]

15. Agora eu gostaria de saber como você se sentiu emocionalmente durante a última semana? Eu quero dizer, tenso, ansioso, desanimado ou esquecido? [Sintomas psiquiátricos]

16. Você já consultou um psiquiatra alguma vez na sua vida ou houve períodos que você esteve ansioso, deprimido ou confuso? [Disfunção psiquiátrica]

17. Finalmente, eu gostaria de saber como você segue as recomendações do seu médico. Você é uma pessoa que é no geral propensa a fazer o que os médicos recomendam? [Resistência ao tratamento]

Agora, chegando ao final da entrevista, eu gostaria de enfatizar que você forneceu informações muito úteis. Vou elaborá-las e discuti-las com a equipe. Nós podemos discuti-las durante nossa próxima consulta.

Eu finalmente gostaria de saber como você se sentiu nesta entrevista? Você acha que estas informações serão úteis para te tratar bem ou há informações importantes que faltaram? Você acha que não foi adequado fazer essas perguntas a você?

Obrigada por sua paciência e disposição em fornecer informações. Se você quiser eu resumirei os principais pontos levantados.

\section{As variáveis e seus pontos clínicos de ancoragem}

\section{BIOLÓGICO}

Cronicidade (HB1) (Histórico)

Explicação

0 - Menos que 3 meses de disfunção física

1 - Mais que 3 meses de disfunção física ou vários períodos de menos de 3 meses

2 - Uma doença crônica

3 - Várias doenças crônicas

\section{Dilema Diagnóstico (HB2) (Histórico)}

\section{Explicação}

0 - Sem períodos de complexidade diagnóstica

1 - Diagnóstico e etiologia foram rapidamente esclarecidos

2 - Dilema diagnóstico resolvido mas somente com esforço diagnóstico considerável

3 - Dilema diagnóstico não resolvido apesar de esforços diagnósticos consideráveis

\section{Gravidade dos Sintomas/Comprometimento (CB1) (Estado Atual)}

Explicação

0 - Sem sintomas ou sintomas reversíveis sem esforços médicos intensivos

1 - Sintomas leves, mas significativos, que não interferem no funcionamento atual

2 - Sintomas moderados a graves, que interferem no funcionamento atual

3 - Sintomas graves que levam à incapacidade de realizar quaisquer atividades funcionais 


\section{Desafio Diagnóstico/Terapêutico (CB2) (Estado Atual)}

Explicação:

0 - Diagnósticos claros e/ou tratamento descomplicado

1 - Diagnósticos diferenciais claros e/ou diagnóstico esperado com tratamentos claros

2 - Dificuldade de diagnosticar e tratar, causa/origem física e tratamento esperado

3 - Dificuldade de diagnosticar ou tratar, outros problemas além de causas físicas interferindo no diagnóstico e no processo terapêutico

\section{Complicações e Ameaça à Vida (VB) (Vulnerabilidades)}

Explicação:

$?$ - Desconhecidas

0 - Nenhum risco de limitações nas atividades da vida diária

1 - Risco leve de limitações nas atividades da vida diária

2 - Risco moderado de limitações permanentes e/ou significativas nas atividades da vida diária

3 - Risco grave de complicações físicas com déficits funcionais sérios permanentes e/ou morte

\section{PSICOLÓGICO}

\section{Barreiras para Enfrentamento (HP1) (Histórico)}

Explicação

0 - Capacidade de administrar o estresse, tal como pela procura de apoio ou hobbies

1 - Restritas habilidades para enfrentamento, tais como necessidade de controle, negação da doença, ou irritabilidade

2 - Insuficientes habilidades para enfrentamento, tais como reclamação não produtiva ou abuso de substâncias, porém sem sérios impactos na condição clínica, saúde mental, ou situação social

3 - Mínimas habilidades para enfrentamento, manifestadas por comportamentos destrutivos, tais como dependência de substâncias, doença psiquiátrica, automutilação, ou tentativa de suicídio

\section{Disfunção Psiquiátrica (HP2) (Histórico)}

Explicação

0 - Nenhuma disfunção psiquiátrica

1 - Disfunção psiquiátrica sem efeitos claros no funcionamento diário

2 - Disfunção psiquiátrica com efeitos claros no funcionamento diário

3 - Hospitalização(ões) psiquiátrica(s) e/ou efeitos permanentes no funcionamento diário

\section{Resistência ao Tratamento (CP1) (Estado Atual)}

Explicação

0 - Interessado em receber tratamento e disposto a cooperar ativamente

1 - Algum pensamento ambivalente apesar de disposto a cooperar com o tratamento

2 - Resistência considerável, tal como não adesão com hostilidade ou indiferença com relação aos profissionais de saúde e/ou tratamentos

3 - Resistência ativa ao cuidado médico

\section{Sintomas Psiquiátricos (CP2) (Estado Atual)}

\section{Explicação}

0 - Sem sintomas psiquiátricos

1 - Sintomas psiquiátricos leves, tais como dificuldade de concentração ou tensão 
2 - Sintomas psiquiátricos moderados, tais como ansiedade, depressão ou comprometimento cognitivo leve

3 - Sintomas psiquiátricos graves e/ou distúrbios comportamentais, tais como violência, dano de autopunição, delirium, psicose, ou mania

\section{Ameaça à Saúde Mental (VP) (Vulnerabilidades)}

Explicação

0 - Sem risco de transtorno psiquiátrico

1 - Risco leve de sintomas psiquiátricos, tais como estresse, ansiedade, tristeza, abuso de substância ou transtorno cognitivo; risco leve de resistência ao tratamento (ambivalência)

2 - Risco moderado de transtorno psiquiátrico necessitando de cuidado psiquiátrico; risco moderado de resistência ao tratamento

3 - Risco grave de transtorno psiquiátrico necessitando de visitas frequentes ao serviço de emergência e/ou admissões hospitalares; risco de recusa ao tratamento para transtornos psiquiátricos sérios

\section{SOCIAL}

\section{Problemas no Trabalho e no Lazer (HS1) (Histórico)}

Explicação

0 - Um trabalho (incluindo serviço doméstico, aposentadoria, estudos) e tendo atividades de lazer

1 - Um trabalho (incluindo serviço doméstico, aposentadoria, estudos) sem atividades de lazer

2 - Desempregado atualmente e durante pelo menos 6 meses com atividades de lazer

3 - Desempregado atualmente e durante pelo menos 6 meses sem atividades de lazer

\section{Disfunção Social (HS2) (Histórico)}

Explicação

0 - Sem ruptura social

1 - Disfunção social leve; problemas interpessoais

2 - Disfunção social moderada, tal como incapacidade de iniciar ou manter relações sociais

3 - Disfunção social grave, tal como envolvimento em relações sociais tumultuadas ou isolamento social

\section{Instabilidade Residencial (CS1) (Estado Atual)}

\section{Explicação}

0 - Moradia estável; totalmente capaz de viver independentemente

1 - Moradia estável com ajuda de outros, por ex. família, cuidado domiciliar, ou instituição

2 - Moradia instável, por ex. sem apoio em casa ou vivendo em um abrigo; mudança da situação de vida atual é necessária

3 - Sem moradia atual satisfatória, por ex. moradia transitória ou ambiente perigoso; mudança imediata é necessária 
Apoio Social Precário (CS2) (Estado Atual)

Explicação

0 - Assistência prontamente disponível de familiares, amigos, e/ou conhecidos, tais como colegas de trabalho, em todos os momentos

1 - Assistência disponível da família, amigos, e/ou conhecidos, tais como colegas de trabalho, porém com possíveis demoras

2 - Assistência prontamente disponível limitada da família, amigos, e/ou conhecidos, tais como colegas de trabalho

3 - Sem assistência prontamente disponível da família, amigos, e/ou conhecidos, tais como colegas de trabalho, em todos os momentos

\section{Vulnerabilidade Social (VS) (Vulnerabilidades)}

Explicações

0 - Sem risco de mudanças na situação de vida; apoio social e integração adequados

1 - Sem risco de mudanças na situação de vida, mas apoio social adicional e/ou maior integração são necessários, por ex., assistência domiciliária

2 - Risco de necessidade de admissão temporária ou permanente à instituição no futuro previsível

3 - Risco de necessidade de admissão temporária ou permanente à instituição agora

\section{SISTEMA DE SAÚDE}

\section{Acesso ao Cuidado (HHS1) (Histórico)}

Explicação

0 - Acesso adequado ao cuidado

1 - Alguma limitação no acesso ao cuidado devido a problemas de seguro, razões geográficas, linguagem, ou barreiras culturais

2 - Dificuldades no acesso ao cuidado devido a problemas de seguro, razões geográficas, linguagem, ou barreiras culturais

3 - Sem acesso adequado ao cuidado devido a problemas de seguro, razões geográficas, linguagem, ou barreiras culturais

\section{Experiência do Tratamento (HHS2) (Histórico)}

Explicação

0 - Sem problemas com profissionais de saúde

1 - Experiência negativa com profissionais de saúde (sua ou de parentes)

2 - Pedidos de segunda opinião ou mudança de médicos mais de uma vez; múltiplos prestadores; problema em manter profissional(is) estável(eis) e/ou de preferência

3 - Repetidos conflitos com médicos, visitas frequentes ao serviço de emergência, ou hospitalizações involuntárias; forçado a ficar com prestador indesejável devido a custo, opções de rede de prestadores, ou outras razões

\section{Organização do Cuidado (CHS1) (Estado Atual)}

Explicação

0 - Cuidado primário/clínico geral somente

1 - Serviços especializados no cuidado geral da saúde ou saúde mental/cuidado ao transtorno do uso de substâncias

2 - Ambos, cuidado geral da saúde e serviços de cuidado de saúde mental/transtorno do uso de substâncias

3 - Hospitalização ou transferência de um hospital de pacientes, que se qualificam em cuidado ambulatorial no Nível 2

\section{Coordenação do Cuidado (CHS2) (Estado Atual)}


Explicação

0 - Comunicação completa com o profissional e boa coordenação do cuidado

1 - Limitada comunicação com o profissional e coordenação do cuidado; médico do cuidado primário coordena os serviços médicos e de saúde mental/transtorno do uso de substâncias

2 - Precária comunicação e coordenação do cuidado entre os profissionais; sem médico do cuidado primário de rotina

3 - Nenhuma comunicação e coordenação do cuidado entre os profissionais; serviço de emergência utilizado para atender as necessidades de saúde não emergentes

\section{Impedimentos do Sistema de Saúde (VHS) (Vulnerabilidades)}

\section{Explicação}

? - Desconhecidos

0 - Sem risco de impedimentos para coordenar cuidado físico e de saúde mental/transtorno do uso de substâncias

1 - Risco leve de impedimentos ao cuidado, por ex. restrições do seguro, acesso distante ao serviço, limitada comunicação com os profissionais e/ou coordenação do cuidado

2 - Risco moderado de impedimentos ao cuidado, por ex. perda potencial do seguro, profissionais inconsistentes, barreiras de comunicação

3 - Risco grave de impedimentos ao cuidado, por ex. pouco ou nenhum seguro, resistência a comunicação e coordenação entre os profissionais

Isso leva à seguinte classificação:

\begin{tabular}{|c|c|c|c|}
\hline DOMÍNIOS & HISTÓRIA & ESTADO ATUAL & VULNERABILIDADE \\
\hline BIOLÓGICO & $\begin{array}{l}\text { Cronicidade } \\
\begin{array}{l}(0)(1)(2)(3) \quad(\mathrm{HB} 1) \\
\text { Dilema diagnóstico } \\
(0)(1)(2)(3) \quad(\mathrm{HB} 2)\end{array}\end{array}$ & \begin{tabular}{ll}
\multicolumn{2}{l}{ Severidade dos sintomas } \\
$\begin{array}{ll}(0)(1)(2)(3) & (\mathrm{CB} 1) \\
\text { Desafio diagnóstico } & \\
(0)(1)(2)(3) & (\mathrm{CB} 2)\end{array}$
\end{tabular} & $\begin{array}{l}\text { Complicações e ameaça } \\
\text { à vida } \\
(0)(1)(2)(3)(?) \quad(\text { VB) }\end{array}$ \\
\hline PSICOLÓGICO & $\begin{array}{l}\text { Restrições no } \\
\text { enfrentamento } \\
\text { (0) (1) (2) (3) } \quad \text { (HP1) } \\
\text { Disfunção psiquiátrica } \\
\begin{array}{ll}(0)(1)(2)(3) & \text { (HP2) }\end{array}\end{array}$ & $\begin{array}{l}\text { Resistência ao tratamento } \\
\text { (0) (1) (2) (3) (CP1) } \\
\text { Sintomas psiquiátricos } \\
(0)(1)(2)(3)\end{array}$ & $\begin{array}{l}\text { Ameaça à saúde mental } \\
(0)(1)(2)(3)\end{array}$ \\
\hline SOCIAL & $\begin{array}{ll}\text { Restrições em } & \\
\text { integração } & \\
\text { (0) (1) (2) (3) } & \text { (HS1) } \\
\text { Disfunção social } & \\
\text { (0) (1) (2) (3) } & \text { (HS2) }\end{array}$ & $\begin{array}{ll}\text { Instabilidade de residência } \\
\begin{array}{ll}(0)(1)(2)(3) & (C S 1) \\
\text { Restrições de rede } & \\
(0)(1)(2)(3) & (C S 2)\end{array}\end{array}$ & $\begin{array}{l}\text { Vulnerabilidade social } \\
\begin{array}{ll}(0)(1)(2)(3) & \text { (VS) }\end{array}\end{array}$ \\
\hline $\begin{array}{l}\text { SISTEMA DE } \\
\text { SAÚDE }\end{array}$ & $\begin{array}{ll}\text { Intensidade do } & \\
\text { tratamento } & \\
\text { (0) (1) (2) (3) } & (\mathrm{HHS} 1) \\
\text { Experiência de } & \\
\text { tratamento } & \\
(0)(1)(2)(3) & (\mathrm{HHS} 2)\end{array}$ & $\begin{array}{l}\text { Organização do cuidado } \\
(0)(1)(2)(3) \quad(\mathrm{CHS} 1) \\
\text { Coordenação do cuidado } \\
(0)(1)(2)(3)\end{array}$ & $\begin{array}{l}\text { Impedimentos do } \\
\text { sistema de saúde } \\
\text { (0) (1) (2) (3) (?) (VHS) }\end{array}$ \\
\hline SCO & & & \\
\hline
\end{tabular}


APÊNDICE 5

SUGESTÕES DOS JUÍZES E CONSENSO 


\section{SUGESTÕES DOS JUÍZES E CONSENSO}

\begin{tabular}{|c|c|c|}
\hline $\begin{array}{l}\text { PRIMEIRA VERSÃO } \\
\text { TRADUZIDA }\end{array}$ & $\begin{array}{l}\text { SUGESTÕES DOS } \\
\text { JUIIZES }\end{array}$ & $\begin{array}{c}\text { CONSENSO } \\
\text { SEGUNDA VERSÃO } \\
\text { TRADUZIDA }\end{array}$ \\
\hline $\begin{array}{l}\text { As variáveis e seus pontos } \\
\text { clínicos de Ancoragem }\end{array}$ & $\begin{array}{c}\text { - Apoio } \\
\text { - Fundamentação }\end{array}$ & $\begin{array}{c}\text { As variáveis e seus } \\
\text { pontos clínicos de apoio }\end{array}$ \\
\hline Dilema Diagnóstico & $\begin{array}{c}\text { - Avaliação da } \\
\text { complexidade diagnóstica } \\
\text { - Hipótese/ avaliação } \\
\text { diagnóstica }\end{array}$ & Dilema no Diagnóstico \\
\hline $\begin{array}{l}\text { Dilema diagnóstico } \\
\text { resolvido }\end{array}$ & $\begin{array}{l}\text { - Avaliação diagnóstica } \\
\text { resolvida } \\
\text { - Avaliação diagnóstica } \\
\text { concluída } \\
\end{array}$ & $\begin{array}{l}\text { Dilema no diagnóstico } \\
\text { resolvido }\end{array}$ \\
\hline $\begin{array}{l}\text { Com esforço diagnóstico } \\
\text { considerável }\end{array}$ & $\begin{array}{l}\text { - Com esforço } \\
\text { considerável para } \\
\text { diagnosticar } \\
\text { - Com esforço } \\
\text { considerável para o } \\
\text { diagnóstico } \\
\end{array}$ & $\begin{array}{c}\text { Com esforço considerável } \\
\text { para o diagnóstico }\end{array}$ \\
\hline $\begin{array}{c}\text { Dilema diagnóstico não } \\
\text { resolvido }\end{array}$ & $\begin{array}{l}\text { - Avaliação diagnóstica } \\
\text { não resolvida }\end{array}$ & $\begin{array}{c}\text { Dilema no diagnóstico } \\
\text { não resolvido }\end{array}$ \\
\hline $\begin{array}{l}\text { Apesar de esforços } \\
\text { diagnósticos consideráveis }\end{array}$ & $\begin{array}{c}\text { - Apesar de esforços } \\
\text { consideráveis para o } \\
\text { diagnóstico }\end{array}$ & $\begin{array}{c}\text { Apesar de esforços } \\
\text { consideráveis para o } \\
\text { diagnóstico }\end{array}$ \\
\hline $\begin{array}{l}\text { Sintomas moderados a } \\
\text { graves, que interferem no } \\
\text { funcionamento atual }\end{array}$ & $\begin{array}{c}\text { - Que interferem nas } \\
\text { atividades atuais } \\
\text { - Que interferem com as } \\
\text { funções atuais do } \\
\text { paciente } \\
\text { - Que interferem na } \\
\text { funcionalidade }\end{array}$ & $\begin{array}{l}\text { Sintomas moderados a } \\
\text { graves, que interferem na } \\
\text { funcionalidade atual }\end{array}$ \\
\hline $\begin{array}{l}\text { Diagnósticos claros e/ou } \\
\text { tratamento descomplicado }\end{array}$ & $\begin{array}{l}\text { - Simples } \\
\text { - Não complicado }\end{array}$ & Não complicado \\
\hline $\begin{array}{l}\text { Dificuldade de diagnosticar } \\
\text { e tratar, causa/origem } \\
\text { física e tratamento } \\
\text { esperado }\end{array}$ & $\begin{array}{l}\text { - Dificuldade para } \\
\text { diagnosticar a } \\
\text { causa/origem física e } \\
\text { tratá-la da forma } \\
\text { esperada }\end{array}$ & $\begin{array}{c}\text { Dificuldade para } \\
\text { diagnosticar a } \\
\text { causa/origem física e } \\
\text { tratá-la da forma } \\
\text { esperada }\end{array}$ \\
\hline $\begin{array}{c}\text { Risco grave* de } \\
\text { complicações físicas com } \\
\text { déficits funcionais sérios } \\
\text { permanentes e/ou morte** }\end{array}$ & $\begin{array}{c}{ }^{*} \text { Grande risco } \\
{ }^{* *} \text { Sérios déficits } \\
\text { funcionais permanentes } \\
\text { e/ou morte }\end{array}$ & $\begin{array}{l}\text { Risco elevado de } \\
\text { complicações físicas com } \\
\text { sérios déficits funcionais } \\
\text { permanentes e/ou morte }\end{array}$ \\
\hline $\begin{array}{l}\text { Barreiras para } \\
\text { enfrentamento }\end{array}$ & $\begin{array}{l}\text { Barreiras de } \\
\text { enfrentamento }\end{array}$ & $\begin{array}{c}\text { Barreiras de } \\
\text { enfrentamento }\end{array}$ \\
\hline
\end{tabular}




\begin{tabular}{|c|c|c|}
\hline $\begin{array}{c}\text { PRIMEIRA VERSÃO } \\
\text { TRADUZIDA }\end{array}$ & $\begin{array}{c}\text { SUGESTÕES DOS } \\
\text { JUIIZES }\end{array}$ & $\begin{array}{c}\text { CONSENSO } \\
\text { SEGUNDA VERSÃO } \\
\text { TRADUZIDA }\end{array}$ \\
\hline $\begin{array}{c}\text { Capacidade de administrar } \\
\text { o estresse, tal como pela } \\
\text { procura de apoio ou } \\
\text { hobbies* }\end{array}$ & $\begin{array}{c}{ }^{*} \text { Distração } \\
\text { - Capacidade de manejar } \\
\text { o estresse através da } \\
\text { busca de apoio ou } \\
\text { hobbies } \\
\text { - Capacidade de } \\
\text { administrar o estresse, } \\
\text { através da procura de } \\
\text { apoio ou passatempos }\end{array}$ & $\begin{array}{c}\text { Capacidade de manejar o } \\
\text { estresse, tal como pela } \\
\text { procura de apoio ou } \\
\text { passatempos }\end{array}$ \\
\hline $\begin{array}{c}\text { Restritas habilidades para } \\
\text { enfrentamento, tais como } \\
\text { necessidade de controle, } \\
\text { negação da doença, ou } \\
\text { irritabilidade }\end{array}$ & $\begin{array}{l}\text { Habilidades restritas de } \\
\text { enfrentamento }\end{array}$ & $\begin{array}{l}\text { Habilidades restritas de } \\
\text { enfrentamento }\end{array}$ \\
\hline $\begin{array}{l}\text { Insuficientes habilidades } \\
\text { para enfrentamento, tais } \\
\text { como reclamação não } \\
\text { produtiva ou abuso de } \\
\text { substâncias, porém sem } \\
\text { sérios impactos na } \\
\text { condição clínica, saúde } \\
\text { mental, ou situação social }\end{array}$ & $\begin{array}{l}\text { - Comprometimento das } \\
\text { habilidades de } \\
\text { enfrentamento, tais como } \\
\text { queixas não produtivas } \\
\text { - Prejuízo das habilidades } \\
\text { para o enfrentamento } \\
\text { - Habilidades } \\
\text { insuficientes para } \\
\text { enfrentamento }\end{array}$ & $\begin{array}{l}\text { Habilidades insuficientes } \\
\text { de enfrentamento, tais } \\
\text { como queixas não } \\
\text { pertinentes ou abuso de } \\
\text { substâncias, porém sem } \\
\text { sérios impactos na } \\
\text { condição clínica, saúde } \\
\text { mental, ou situação social }\end{array}$ \\
\hline $\begin{array}{c}\text { Mínimas habilidades para } \\
\text { enfrentamento, } \\
\text { manifestadas por } \\
\text { comportamentos } \\
\text { destrutivos, tais como } \\
\text { dependência de } \\
\text { substâncias, doença } \\
\text { psiquiátrica, automutilação, } \\
\text { ou tentativa de suicídio }\end{array}$ & Habilidades mínimas & $\begin{array}{l}\text { Habilidades mínimas de } \\
\text { enfrentamento }\end{array}$ \\
\hline $\begin{array}{c}\text { Disfunção psiquiátrica sem } \\
\text { efeitos claros no } \\
\text { funcionamento diário } \\
\\
\text { Hospitalização(ões) } \\
\text { psiquiátrica(s) e/ou efeitos } \\
\text { permanentes no } \\
\text { funcionamento diário }\end{array}$ & Funcionalidade & Funcionalidade \\
\hline $\begin{array}{c}\text { Algum pensamento } \\
\text { ambivalente apesar de } \\
\text { disposto a cooperar com o } \\
\text { tratamento }\end{array}$ & $\begin{array}{l}\text { - Algum pensamento } \\
\text { ambivalente embora } \\
\text { - Alguma/certa } \\
\text { ambivalência apesar de } \\
\text { estar disposto } \\
\text { - Alguma ambivalência, } \\
\text { embora disposto a } \\
\text { cooperar com o } \\
\text { tratamento }\end{array}$ & $\begin{array}{l}\text { Alguma ambivalência, } \\
\text { apesar de disposto a } \\
\text { cooperar com o } \\
\text { tratamento }\end{array}$ \\
\hline
\end{tabular}




\begin{tabular}{|c|c|c|}
\hline $\begin{array}{l}\text { PRIMEIRA VERSÃO } \\
\text { TRADUZIDA }\end{array}$ & $\begin{array}{c}\text { SUGESTÕES DOS } \\
\text { JUIIZES }\end{array}$ & $\begin{array}{c}\text { CONSENSO } \\
\text { SEGUNDA VERSÃO } \\
\text { TRADUZIDA }\end{array}$ \\
\hline $\begin{array}{l}\text { Sintomas psiquiátricos } \\
\text { graves e/ou distúrbios } \\
\text { comportamentais, tais } \\
\text { como violência, dano de } \\
\text { autopunição, delírio, } \\
\text { psicose, ou mania }\end{array}$ & $\begin{array}{c}\text { - Auto agressividade } \\
\text { - Autoflagelação } \\
\text { - Lesões auto infligidas }\end{array}$ & $\begin{array}{l}\text { Dano de auto } \\
\text { agressividade }\end{array}$ \\
\hline $\begin{array}{c}\text { Risco grave de transtorno } \\
\text { psiquiátrico necessitando } \\
\text { de visitas frequentes ao } \\
\text { serviço de emergência } \\
\text { e/ou admissões } \\
\text { hospitalares; risco de } \\
\text { recusa ao tratamento para } \\
\text { transtornos psiquiátricos } \\
\text { sérios }\end{array}$ & $\begin{array}{c}\text { Risco de recusa ao } \\
\text { tratamento devido a } \\
\text { transtornos psiquiátricos } \\
\text { sérios }\end{array}$ & $\begin{array}{c}\text { Risco de recusa ao } \\
\text { tratamento devido a } \\
\text { transtornos psiquiátricos } \\
\text { sérios }\end{array}$ \\
\hline $\begin{array}{c}\text { Desempregado atualmente } \\
\text { e durante pelo menos } 6 \\
\text { meses com atividades de } \\
\text { lazer } \\
\text { Desempregado atualmente } \\
\text { e durante pelo menos } 6 \\
\text { meses sem atividades de } \\
\text { lazer } \\
\end{array}$ & $\begin{array}{c}\text { Atualmente } \\
\text { desempregado }\end{array}$ & $\begin{array}{c}\text { Atualmente } \\
\text { desempregado e pelo } \\
\text { menos } 6 \text { meses com } \\
\text { atividades de lazer } \\
\text { Atualmente } \\
\text { desempregado e pelo } \\
\text { menos } 6 \text { meses sem } \\
\text { atividades de lazer }\end{array}$ \\
\hline $\begin{array}{c}\text { Moradia estável com ajuda } \\
\text { de outros, por ex. família, } \\
\text { cuidado domiciliar, ou } \\
\text { instituição }\end{array}$ & Ou institucional & Ou institucional \\
\hline $\begin{array}{c}\text { Sem moradia atual } \\
\text { satisfatória, por ex. } \\
\text { moradia transitória ou } \\
\text { ambiente perigoso; } \\
\text { mudança imediata é } \\
\text { necessária }\end{array}$ & $\begin{array}{c}\text { Mudança imediata se faz } \\
\text { necessária }\end{array}$ & $\begin{array}{c}\text { É necessária mudança } \\
\text { imediata }\end{array}$ \\
\hline $\begin{array}{l}\text { Assistência prontamente } \\
\text { disponível limitada da } \\
\text { família, amigos, e/ou } \\
\text { conhecidos, tais como } \\
\text { colegas de trabalho }\end{array}$ & $\begin{array}{l}\text { - Assistência limitada } \\
\text { prontamente disponível } \\
\text { pela família } \\
\text { - Assistência limitada, } \\
\text { mas prontamente } \\
\text { disponível da família }\end{array}$ & $\begin{array}{l}\text { Suporte limitado da } \\
\text { família, amigos, e/ou } \\
\text { conhecidos, tais como } \\
\text { colegas de trabalho }\end{array}$ \\
\hline $\begin{array}{l}\text { Sem risco de mudanças na } \\
\text { situação de vida, mas } \\
\text { apoio social adicional e/ou } \\
\text { maior integração são } \\
\text { necessários, por ex., } \\
\text { assistência domiciliária }\end{array}$ & $\begin{array}{l}\text { - Assistência domiciliar } \\
\text { - Assistência médica } \\
\text { domiciliar }\end{array}$ & Assistência domiciliária \\
\hline
\end{tabular}




\begin{tabular}{|c|c|c|}
\hline $\begin{array}{l}\text { PRIMEIRA VERSÃO } \\
\text { TRADUZIDA }\end{array}$ & $\begin{array}{c}\text { SUGESTÕES DOS } \\
\text { JUIIZES }\end{array}$ & $\begin{array}{c}\text { CONSENSO } \\
\text { SEGUNDA VERSÃO } \\
\text { TRADUZIDA }\end{array}$ \\
\hline $\begin{array}{l}\text { Risco de necessidade de } \\
\text { admissão* temporária ou } \\
\text { permanente à instituição } \\
\text { no futuro previsível }\end{array}$ & $\begin{array}{l}{ }^{*} \text { Hospitalização } \\
\text { - Risco de necessidade } \\
\text { de internação temporária } \\
\text { ou permanente em futuro } \\
\text { próximo }\end{array}$ & $\begin{array}{l}\text { Risco de admissão } \\
\text { temporária ou } \\
\text { permanente em } \\
\text { instituição/ } \\
\text { institucionalização no } \\
\text { futuro previsível }\end{array}$ \\
\hline $\begin{array}{c}\text { Risco de necessidade de } \\
\text { admissão temporária ou } \\
\text { permanente à instituição } \\
\text { agora }\end{array}$ & $\begin{array}{c}\text { - Risco de necessidade } \\
\text { de internação temporária } \\
\text { ou permanente em } \\
\text { instituição imediata } \\
\text { - Risco de necessidade } \\
\text { de admissão temporária } \\
\text { ou permanente / } \\
\text { institucionalização agora }\end{array}$ & $\begin{array}{c}\text { Necessidade imediata de } \\
\text { admissão temporária ou } \\
\text { permanente em } \\
\text { instituição agora }\end{array}$ \\
\hline $\begin{array}{c}\text { Alguma limitação no } \\
\text { acesso ao cuidado devido } \\
\text { a problemas de seguro*, } \\
\text { razões geográficas, } \\
\text { linguagem }{ }^{* *}, \text { ou barreiras } \\
\text { culturais }\end{array}$ & & $\begin{array}{c}\text { Alguma limitação no } \\
\text { acesso ao cuidado devido } \\
\text { a problemas do sistema } \\
\text { de saúde/ plano de } \\
\text { saúde, razões } \\
\text { geográficas, linguagem, } \\
\text { ou barreiras culturais }\end{array}$ \\
\hline $\begin{array}{c}\text { Dificuldades no acesso ao } \\
\text { cuidado devido a } \\
\text { problemas de seguro, } \\
\text { razões geográficas, } \\
\text { linguagem, ou barreiras } \\
\text { culturais }\end{array}$ & $\begin{array}{c}\text { * seguro-saúde } \\
\text { * convênio } \\
\text { * plano de saúde } \\
\text { * seguro/convênio } \\
\text { * plano/seguro-saúde } \\
\text { ** língua } \\
\text { ** idioma }\end{array}$ & $\begin{array}{c}\text { Dificuldades no acesso } \\
\text { ao cuidado devido a } \\
\text { problemas do sistema de } \\
\text { saúde/ plano de saúde, } \\
\text { razões geográficas, } \\
\text { linguagem, ou barreiras } \\
\text { culturais }\end{array}$ \\
\hline $\begin{array}{c}\text { Sem acesso adequado ao } \\
\text { cuidado devido a } \\
\text { problemas de seguro, } \\
\text { razões geográficas, } \\
\text { linguagem, ou barreiras } \\
\text { culturais }\end{array}$ & & $\begin{array}{c}\text { Sem acesso adequado } \\
\text { ao cuidado devido a } \\
\text { problemas do sistema de } \\
\text { saúde/ plano de saúde, } \\
\text { razões geográficas, } \\
\text { linguagem, ou barreiras } \\
\text { culturais }\end{array}$ \\
\hline $\begin{array}{l}\text { Pedidos de segunda } \\
\text { opinião ou mudança de } \\
\text { médicos mais de uma vez; } \\
\text { múltiplos prestadores; } \\
\text { problema em manter } \\
\text { profissional(is) estável(eis) } \\
\text { e/ou de preferência }\end{array}$ & $\begin{array}{c}\text { Problema em ter } \\
\text { consistência de manter } \\
\text { profissional estável e/ou } \\
\text { de preferência }\end{array}$ & $\begin{array}{c}\text { Pedidos de segunda } \\
\text { opinião ou mudança de } \\
\text { médicos mais de uma } \\
\text { vez; múltiplos } \\
\text { profissionais; problema } \\
\text { em manter profissional(is) } \\
\text { estável(eis) e/ou de } \\
\text { preferência }\end{array}$ \\
\hline
\end{tabular}




\begin{tabular}{|c|c|c|}
\hline $\begin{array}{l}\text { PRIMEIRA VERSÃO } \\
\text { TRADUZIDA }\end{array}$ & $\begin{array}{l}\text { SUGESTÕES DOS } \\
\text { JUÍZES }\end{array}$ & $\begin{array}{c}\text { CONSENSO } \\
\text { SEGUNDA VERSÃO } \\
\text { TRADUZIDA }\end{array}$ \\
\hline $\begin{array}{c}\text { Repetidos conflitos com } \\
\text { médicos, visitas frequentes } \\
\text { ao serviço de emergência, } \\
\text { ou hospitalizações } \\
\text { involuntárias; forçado a } \\
\text { ficar com prestador } \\
\text { indesejável devido a custo, } \\
\text { opções de rede de } \\
\text { prestadores, ou outras } \\
\text { razões }\end{array}$ & Profissional(is) & Profissional(is) \\
\hline $\begin{array}{c}\text { Cuidado primário/clínico } \\
\text { geral somente }\end{array}$ & $\begin{array}{c}\text { Somente cuidado } \\
\text { primário/clínico geral }\end{array}$ & $\begin{array}{l}\text { Somente atenção } \\
\text { primária em saúde }\end{array}$ \\
\hline $\begin{array}{l}\text { Hospitalização ou } \\
\text { transferência de um } \\
\text { hospital de pacientes, que } \\
\text { se qualificam em cuidado } \\
\text { ambulatorial no Nível } 2\end{array}$ & & $\begin{array}{c}\text { Hospitalização ou } \\
\text { transferência do paciente } \\
\text { que se qualifica em } \\
\text { cuidado ambulatorial no } \\
\text { Nível secundário }\end{array}$ \\
\hline $\begin{array}{l}\text { Limitada comunicação* } \\
\text { com o profissional e } \\
\text { coordenação do cuidado; } \\
\text { médico do cuidado } \\
\text { primário** coordena os } \\
\text { serviços médicos e de } \\
\text { saúde mental/transtorno do } \\
\text { uso de substâncias }\end{array}$ & $\begin{array}{l}\text { * Comunicação limitada } \\
\text { * Comunicação } \\
\text { insuficiente } \\
\\
{ }^{* *} \text { Atenção primária } \\
{ }^{* *} \text { Atenção básica }\end{array}$ & $\begin{array}{c}\text { Comunicação limitada } \\
\text { com o profissional e } \\
\text { coordenação do cuidado; } \\
\text { médico da atenção } \\
\text { primária coordena os } \\
\text { serviços médicos e de } \\
\text { saúde mental/ transtorno } \\
\text { do uso de substância }\end{array}$ \\
\hline $\begin{array}{c}\text { Precária comunicação e } \\
\text { coordenação do cuidado } \\
\text { entre os profissionais*; } \\
\text { sem médico do cuidado } \\
\text { primário de rotina** }\end{array}$ & $\begin{array}{l}\text { * Comunicação e } \\
\text { coordenação pobres } \\
\text { (precárias) do cuidado } \\
\text { entre os profissionais } \\
{ }^{* *} \text { Clínico geral } \\
{ }^{* *} \text { Médico de família }\end{array}$ & $\begin{array}{c}\text { Comunicação precária e } \\
\text { coordenação do cuidado } \\
\text { entre os profissionais; } \\
\text { sem médico da atenção } \\
\text { primária de rotina }\end{array}$ \\
\hline $\begin{array}{c}\text { Nenhuma comunicação e } \\
\text { coordenação do cuidado } \\
\text { entre os profissionais; } \\
\text { serviço de emergência } \\
\text { utilizado para atender as } \\
\text { necessidades de saúde } \\
\text { não emergentes }\end{array}$ & Não emergenciais & Não emergenciais \\
\hline $\begin{array}{c}\text { Risco leve de } \\
\text { impedimentos ao cuidado, } \\
\text { por ex. restrições do } \\
\text { seguro, acesso distante ao } \\
\text { serviço, limitada } \\
\text { comunicação com os } \\
\text { profissionais e/ou } \\
\text { coordenação do cuidado }\end{array}$ & $\begin{array}{l}\text { Comunicação limitada } \\
\text { com os profissionais }\end{array}$ & $\begin{array}{c}\text { Risco leve de } \\
\text { impedimentos ao } \\
\text { cuidado, por exemplo, } \\
\text { restrições do sistema de } \\
\text { saúde/ plano de saúde, } \\
\text { acesso distante ao } \\
\text { serviço, comunicação } \\
\text { limitada com os } \\
\text { profissionais e/ou } \\
\text { coordenação do cuidado }\end{array}$ \\
\hline
\end{tabular}




\begin{tabular}{|c|c|c|}
\hline $\begin{array}{l}\text { PRIMEIRA VERSÃO } \\
\text { TRADUZIDA }\end{array}$ & $\begin{array}{l}\text { SUGESTÕES DOS } \\
\text { JUIIZES }\end{array}$ & $\begin{array}{c}\text { CONSENSO } \\
\text { SEGUNDA VERSÃO } \\
\text { TRADUZIDA }\end{array}$ \\
\hline $\begin{array}{c}\text { Risco moderado de } \\
\text { impedimentos ao cuidado, } \\
\text { por ex. perda potencial do } \\
\text { seguro, profissionais } \\
\text { inconsistentes, barreiras de } \\
\text { comunicação } \\
\end{array}$ & $\begin{array}{l}\text { Potencial perda do } \\
\text { plano/seguro-saúde }\end{array}$ & $\begin{array}{c}\text { Potencial perda do } \\
\text { sistema de saúde/ plano } \\
\text { de saúde }\end{array}$ \\
\hline $\begin{array}{c}\text { Risco grave de } \\
\text { impedimentos ao cuidado*, } \\
\text { por ex. pouco ou nenhum } \\
\text { seguro**, resistência a } \\
\text { comunicação e } \\
\text { coordenação entre os } \\
\text { profissionais }\end{array}$ & $\begin{array}{l}\text { * Plano de saúde } \\
\text { insuficiente ou nenhum } \\
\text { plano de saúde } \\
\text { ** Grande risco de } \\
\text { impedimentos ao cuidado }\end{array}$ & $\begin{array}{c}\text { Risco elevado de } \\
\text { impedimentos ao } \\
\text { cuidado, por exemplo, } \\
\text { pouco ou nenhum acesso } \\
\text { ao sistema de saúde/ } \\
\text { plano de saúde, } \\
\text { resistência à } \\
\text { comunicação e } \\
\text { coordenação entre os } \\
\text { profissionais }\end{array}$ \\
\hline $\begin{array}{l}\text { Eu vou te contar o que eu } \\
\text { sei sobre a razão de seu } \\
\text { encaminhamento/admissão } \\
\text { e seu estado físico atual. } \\
\text { Você deve me corrigir } \\
\text { quando eu estiver errado. }\end{array}$ & Se eu estiver errado & $\begin{array}{l}\text { Eu vou lhe contar o que } \\
\text { eu sei sobre a razão de } \\
\text { seu encaminhamento/ } \\
\text { admissão e seu estado } \\
\text { físico atual. Você deve } \\
\text { me corrigir quando eu } \\
\text { estiver errado. }\end{array}$ \\
\hline $\begin{array}{l}\text { Agora eu gostaria de saber } \\
\text { como você se sente } \\
\text { fisicamente? Sua condição } \\
\text { física tem um impacto no } \\
\text { seu funcionamento físico? }\end{array}$ & $\begin{array}{c}\text { Na sua atividade de vida } \\
\text { diária }\end{array}$ & $\begin{array}{c}\text { Agora eu gostaria de } \\
\text { saber como você se } \\
\text { sente fisicamente. Sua } \\
\text { condição física tem um } \\
\text { impacto na sua atividade } \\
\text { de vida diária? }\end{array}$ \\
\hline $\begin{array}{l}\text { Os médicos tiveram } \\
\text { alguma dificuldade de } \\
\text { achar um diagnóstico com } \\
\text { as queixas/doenças que } \\
\text { você tinha nos últimos } 5 \\
\text { anos? Estas queixas não } \\
\text { foram solucionadas? } \\
\text { Atualmente, essas queixas } \\
\text { estão sendo investigadas? }\end{array}$ & $\begin{array}{l}\text { Esclarecer um } \\
\text { diagnóstico }\end{array}$ & $\begin{array}{c}\text { Os médicos tiveram } \\
\text { alguma dificuldade de } \\
\text { esclarecer um } \\
\text { diagnóstico com as } \\
\text { queixas/ doenças que } \\
\text { você teve nos últimos } 5 \\
\text { anos? Estas queixas não } \\
\text { foram solucionadas? } \\
\text { Atualmente, essas } \\
\text { queixas estão sendo } \\
\text { investigadas? }\end{array}$ \\
\hline $\begin{array}{c}\text { Quem tem sido os } \\
\text { profissionais - médicos, } \\
\text { psicólogos, enfermeiros ou } \\
\text { assistentes sociais - que } \\
\text { estão cuidando de você? } \\
\text { Eles trabalham todos na } \\
\text { mesma instituição e as } \\
\text { consultas são } \\
\text { coordenadas? }\end{array}$ & $\begin{array}{l}\text { - Há organização para as } \\
\text { consultas } \\
\text { - Os atendimentos são } \\
\text { coordenados }\end{array}$ & $\begin{array}{l}\text { Quem tem sido os } \\
\text { profissionais - médicos, } \\
\text { psicólogos, enfermeiros } \\
\text { ou assistentes sociais - } \\
\text { que estão cuidando de } \\
\text { você? Eles trabalham } \\
\text { todos na mesma } \\
\text { instituição e há } \\
\text { coordenação para os } \\
\text { atendimentos? }\end{array}$ \\
\hline
\end{tabular}




\begin{tabular}{|c|c|c|}
\hline $\begin{array}{l}\text { PRIMEIRA VERSÃO } \\
\text { TRADUZIDA }\end{array}$ & $\begin{array}{c}\text { SUGESTÕES DOS } \\
\text { JUÍZES }\end{array}$ & $\begin{array}{c}\text { CONSENSO } \\
\text { SEGUNDA VERSÃO } \\
\text { TRADUZIDA }\end{array}$ \\
\hline $\begin{array}{l}\text { Existe comunicação mútua } \\
\text { entre seus cuidadores para } \\
\text { discutir e ajustar seu } \\
\text { tratamento? }\end{array}$ & $\begin{array}{l}\text { Os profissionais que } \\
\text { cuidam de você }\end{array}$ & $\begin{array}{c}\text { Existe comunicação } \\
\text { mútua entre os } \\
\text { profissionais que cuidam } \\
\text { de você para discutir e } \\
\text { ajustar seu tratamento? }\end{array}$ \\
\hline $\begin{array}{l}\text { Agora, eu gostaria de } \\
\text { saber se você tem um bom } \\
\text { seguro-saúde? Você já } \\
\text { teve problemas com seu } \\
\text { seguro-saúde? A distância } \\
\text { das instituições onde você } \\
\text { é tratado é apropriada ou } \\
\text { você perdeu consultas } \\
\text { devido à distância? }\end{array}$ & $\begin{array}{l}\text { - Convênio } \\
\text { - Plano de saúde } \\
\text { - Seguro/convênio } \\
\text { - Plano/seguro-saúde }\end{array}$ & $\begin{array}{l}\text { Agora, eu gostaria de } \\
\text { saber se você tem um } \\
\text { bom sistema de saúde/ } \\
\text { plano de saúde. Você já } \\
\text { teve problemas com seu } \\
\text { sistema de saúde/ plano } \\
\text { de saúde? A distância } \\
\text { das instituições onde } \\
\text { você é tratado é } \\
\text { apropriada ou você } \\
\text { perdeu consultas devido } \\
\text { à distância? }\end{array}$ \\
\hline $\begin{array}{c}\text { Até onde é de meu } \\
\text { conhecimento você pode } \\
\text { ter uma formação cultural } \\
\text { diferente. Seus } \\
\text { prestadores levam isso em } \\
\text { consideração? (Há } \\
\text { problemas de comunicação } \\
\text { devido a problemas de } \\
\text { linguagem?) }\end{array}$ & $\begin{array}{l}\text { - Profissionais de saúde } \\
\text { - Os profissionais que } \\
\text { cuidam de você } \\
\text { - O senhor tem algum } \\
\text { costume/ hábito diferente } \\
\text { que é importante para o } \\
\text { senhor e que os } \\
\text { profissionais de saúde } \\
\text { não estão respeitando? }\end{array}$ & $\begin{array}{c}\text { Até onde é de meu } \\
\text { conhecimento você pode } \\
\text { ter uma formação cultural } \\
\text { diferente. Os profissionais } \\
\text { que cuidam de você } \\
\text { levam isso em } \\
\text { consideração? (O senhor } \\
\text { tem algum costume/ } \\
\text { hábito diferente que é } \\
\text { importante para o senhor } \\
\text { e que os profissionais de } \\
\text { saúde não estão } \\
\text { respeitando? Há } \\
\text { problemas de } \\
\text { comunicação devido a } \\
\text { problemas de } \\
\text { linguagem?) }\end{array}$ \\
\hline $\begin{array}{l}\text { Agora eu gostaria de } \\
\text { mudar de assunto e te } \\
\text { perguntar sobre o modo } \\
\text { em que você vive*. Você } \\
\text { tem um trabalho } \\
\text { atualmente? Qual nível de } \\
\text { instrução** você alcançou } \\
\text { e você conseguiu um } \\
\text { diploma***? }\end{array}$ & $\begin{array}{c}\text { * Perguntar sobre o seu } \\
\text { modo de vida } \\
\text { * Modo como você vive } \\
{ }^{* *} \text { Escolaridade } \\
\text { *** Você tem alguma } \\
\text { formação profissional } \\
\text { ** Se formou em alguma } \\
\text { profissão } \\
{ }^{* * *} \text { Qual a sua } \\
\text { graduação/cursos }\end{array}$ & $\begin{array}{c}\text { Agora eu gostaria de } \\
\text { mudar de assunto e lhe } \\
\text { perguntar sobre o modo } \\
\text { como você vive. Você } \\
\text { tem um trabalho } \\
\text { atualmente? Qual nível } \\
\text { de escolaridade você } \\
\text { alcançou e você se } \\
\text { formou }\end{array}$ \\
\hline $\begin{array}{c}\text { Você é uma pessoa que } \\
\text { consegue ter lazer? O que } \\
\text { você faz para ter alguma } \\
\text { distração? Você tem } \\
\text { hobbies? }\end{array}$ & Passatempos & Passatempos \\
\hline
\end{tabular}




\begin{tabular}{|c|c|c|}
\hline $\begin{array}{l}\text { PRIMEIRA VERSÃO } \\
\text { TRADUZIDA }\end{array}$ & $\begin{array}{c}\text { SUGESTÕES DOS } \\
\text { JUÍZES }\end{array}$ & $\begin{array}{c}\text { CONSENSO } \\
\text { SEGUNDA VERSÃO } \\
\text { TRADUZIDA }\end{array}$ \\
\hline $\begin{array}{c}\text { Agora eu gostaria de saber } \\
\text { que tipo de pessoa você é. } \\
\text { No geral, você é uma } \\
\text { pessoa calma e estável? } \\
\text { Você é alguém que } \\
\text { consegue ter um bom } \\
\text { relacionamento com outras } \\
\text { pessoas ou há conflitos às } \\
\text { vezes? }\end{array}$ & Como você é & $\begin{array}{l}\text { Agora eu gostaria de } \\
\text { saber como você é. No } \\
\text { geral, você é uma pessoa } \\
\text { calma e estável? Você é } \\
\text { alguém que consegue ter } \\
\text { um bom relacionamento } \\
\text { com outras pessoas ou } \\
\text { há conflitos às vezes? }\end{array}$ \\
\hline $\begin{array}{l}\text { Eu gostaria de te perguntar } \\
\text { sobre seus hábitos de } \\
\text { fumo e bebida e a relação } \\
\text { destes com os seus } \\
\text { problemas atuais? Você } \\
\text { usa analgésico? Você às } \\
\text { vezes se preocupa que } \\
\text { você possa usá-los em } \\
\text { excesso? }\end{array}$ & Usá-los demais & $\begin{array}{c}\text { Eu gostaria de lhe } \\
\text { perguntar sobre sua } \\
\text { dependência de tabaco e } \\
\text { bebida e a relação destes } \\
\text { com os seus problemas } \\
\text { atuais? Você usa } \\
\text { analgésico? Você às } \\
\text { vezes se preocupa que } \\
\text { você possa usá-los em } \\
\text { excesso? }\end{array}$ \\
\hline $\begin{array}{c}\text { Como você lida com } \\
\text { situações difíceis? Esta } \\
\text { seria uma razão* para usar } \\
\text { álcool, tabaco** ou drogas? } \\
\text { Você é propenso a adiar } \\
\text { decisões } \\
\text { a falar demais ou ficar em } \\
\text { silêncio? }\end{array}$ & $\begin{array}{c}\text { * Enfrentar situações } \\
\text { difíceis seria uma razão } \\
{ }^{* *} \text { Cigarro } \\
{ }^{* * *} \text { Costuma ser indeciso } \\
{ }^{* * *} \text { Costuma adiar }\end{array}$ & $\begin{array}{c}\text { Como você lida com } \\
\text { situações difíceis? Estas } \\
\text { seriam uma razão para } \\
\text { usar álcool, tabaco ou } \\
\text { drogas? Você é propenso } \\
\text { a adiar decisões? Isso o } \\
\text { levaria a falar demais ou } \\
\text { ficar em silêncio? }\end{array}$ \\
\hline $\begin{array}{l}\text { Finalmente, eu gostaria de } \\
\text { saber como você segue as } \\
\text { recomendações do seu } \\
\text { médico. Você é uma } \\
\text { pessoa que é no geral } \\
\text { propensa a fazer o que os } \\
\text { médicos recomendam? }\end{array}$ & $\begin{array}{c}\text { - Faz } \\
\text { - Geralmente faz }\end{array}$ & $\begin{array}{l}\text { Finalmente, eu gostaria } \\
\text { de saber como você } \\
\text { segue as recomendações } \\
\text { do seu médico. Você é } \\
\text { uma pessoa que } \\
\text { geralmente faz o que os } \\
\text { médicos recomendam? }\end{array}$ \\
\hline
\end{tabular}


APÊNDICE 6 VERSÃO FINAL TRADUZIDA PARA O PORTUGUÊS DO MÉTODO INTERMED 


\section{As questões direcionadoras [1-17] do INTERMED - entrevista}

\section{Introdução}

Conforme combinado, nós teremos esta entrevista visando entender melhor o que suas queixas atuais ou doença significam para você e o que é necessário para melhor controlar sua situação. Agora que nós sabemos sobre sua situação clínica, eu gostaria de ter uma idéia melhor de que tipo de pessoa você é e como você está lidando com seus problemas clínicos; estas informações ajudarão a organizar o cuidado, adaptado às suas necessidades individuais específicas. Durante a entrevista vários tópicos serão abordados. Pode ser que haja certas questões, as quais você realmente gostaria de refletir um pouco mais. Para poder elaborar um plano de tratamento apropriado, é necessário na nossa primeira conversa ter/criar uma visão geral dos problemas. Quando necessário, nós podemos focar nestas questões na próxima fase. Você entende e concorda ou você tem alguma dúvida?

Bom.

Considere se o paciente é capaz de ser entrevistado.

1. Eu vou the contar o que eu sei sobre a razão de seu encaminhamento/ admissão e seu estado físico atual. Você deve me corrigir quando eu estiver errado. [Gravidade dos Sintomas/ Comprometimento; Desafio diagnóstico/ Terapêutico; Cronicidade]

2. Agora eu gostaria de saber como você se sente fisicamente. Sua condição física tem um impacto na sua atividade de vida diária? [Gravidade dos Sintomas/ Comprometimento]

3. Agora que você me informou como você se sente fisicamente, eu gostaria de ter mais alguma informação a respeito de suas doenças físicas e tratamentos nos últimos cinco anos. [Cronicidade]

4. Os médicos tiveram alguma dificuldade de esclarecer um diagnóstico com as queixas/ doenças que você teve nos últimos 5 anos? Estas queixas não foram solucionadas? Atualmente, essas queixas estão sendo investigadas? [Dilema no Diagnóstico]

5. Quem tem sido os profissionais - médicos, psicólogos, enfermeiros ou assistentes sociais - que estão cuidando de você? Eles trabalham todos na mesma instituição e há coordenação para os atendimentos? [Organização do Cuidado]

6. Existe comunicação mútua entre os profissionais que cuidam de você para discutir e ajustar seu tratamento? [Coordenação do Cuidado]

7. Houve conflitos com médicos durante os últimos cinco anos, os quais te causaram uma má impressão, que podem interferir na sua confiança em médicos? [Experiência do Tratamento]

8. Agora, eu gostaria de saber se você tem um bom sistema de saúde/ plano de saúde. Você já teve problemas com seu sistema de saúde/ plano de saúde? A distância das instituições onde você é tratado é apropriada ou você perdeu consultas devido à distância?

1. Até onde é de meu conhecimento você pode ter uma formação cultural diferente. Os profissionais que cuidam de você levam isso em consideração? (O senhor tem algum costume/ hábito diferente que é importante para o senhor e que os profissionais de saúde não estão respeitando? Há problemas de comunicação devido a problemas de linguagem?) [Acesso ao Cuidado] 
9. Agora eu gostaria de mudar de assunto e lhe perguntar sobre o modo como você vive. Você tem um trabalho atualmente? Qual nível de escolaridade você alcançou e você se formou? [Problemas Relacionados ao Trabalho e Lazer]

10. Você é uma pessoa que consegue ter lazer? O que você faz para ter alguma distração? Você tem passatempos? [Problemas Relacionados ao Trabalho e Lazer]

11. Você pode me contar como você vive atualmente? E no caso de doença ou deficiência, há alguém com quem você possa contar? [Condições no Domicílio; Rede de Apoio Social Precária]

12. Agora eu gostaria de saber como você é. No geral, você é uma pessoa calma e estável? Você é alguém que consegue ter um bom relacionamento com outras pessoas ou há conflitos às vezes? [Situação social; Barreiras de Enfrentamento]

13. Eu gostaria de Ihe perguntar sobre sua dependência de tabaco e bebida e a relação destes com os seus problemas atuais? Você usa analgésico? Você às vezes se preocupa que você possa usá-los em excesso? [Barreiras de Enfrentamento]

14. Como você lida com situações difíceis? Estas seriam uma razão para usar álcool, tabaco ou drogas? Você é propenso a adiar decisões? Isso o levaria a falar demais ou ficar em silêncio? [Barreiras de Enfrentamento]

15. Agora eu gostaria de saber como você se sentiu emocionalmente durante a última semana. Eu quero dizer, tenso, ansioso, desanimado ou esquecido? [Sintomas Psiquiátricos]

16. Você já consultou um psiquiatra alguma vez na sua vida ou houve períodos em que você esteve ansioso, deprimido ou confuso? [Disfunção Psiquiátrica]

17. Finalmente, eu gostaria de saber como você segue as recomendações do seu médico. Você é uma pessoa que geralmente faz o que os médicos recomendam? [Resistência ao Tratamento]

Agora, chegando ao final da entrevista, eu gostaria de enfatizar que você forneceu informações muito úteis. Vou elaborá-las e discuti-las com a equipe. Nós podemos discuti-las durante nossa próxima consulta.

Eu finalmente gostaria de saber como você se sentiu nesta entrevista? Você acha que estas informações serão úteis para te tratar bem ou há informações importantes que faltaram? Você acha que não foi adequado fazer essas perguntas a você?

Obrigada por sua paciência e disposição em fornecer informações. Se você quiser eu resumirei os principais pontos levantados. 


\title{
As variáveis e seus pontos clínicos de apoio
}

\author{
BIOLÓGICO \\ Cronicidade (HB1) (Histórico) \\ Explicação \\ 0 - Menos que 3 meses de disfunção física \\ 1 - Mais que 3 meses de disfunção física ou vários períodos de menos de 3 meses \\ 2 - Uma doença crônica \\ 3 - Várias doenças crônicas
}

\section{Dilema no Diagnóstico (HB2) (Histórico)}

Explicação

0 - Sem períodos de complexidade diagnóstica

1 - Diagnóstico e etiologia foram rapidamente esclarecidos

2 - Dilema no diagnóstico resolvido, mas somente com esforço considerável para o diagnóstico

3 - Dilema no diagnóstico não resolvido, apesar de esforços consideráveis para o diagnóstico

\section{Gravidade dos Sintomas/ Comprometimento (CB1) (Estado Atual)}

Explicação

0 - Sem sintomas ou sintomas reversíveis sem esforços médicos intensivos

1 - Sintomas leves, mas significativos, que não interferem na funcionalidade atual

2 - Sintomas moderados a graves, que interferem na funcionalidade atual

3 - Sintomas graves que levam à incapacidade de realizar quaisquer atividades funcionais

\section{Desafio Diagnóstico/ Terapêutico (CB2) (Estado Atual)}

Explicação

0 - Diagnósticos claros e/ou tratamento não complicado

1 - Diagnósticos diferenciais claros e/ou diagnóstico esperado com tratamentos definidos

2 - Dificuldade para diagnosticar a causa/origem física e tratá-la da forma esperada

3 - Dificuldade de diagnosticar ou tratar, outros problemas além de causas físicas interferindo no diagnóstico e no processo terapêutico

\section{Complicações e Ameaça à Vida (VB) (Vulnerabilidades)}

Explicação

? - Desconhecidas

0 - Nenhum risco de limitações nas atividades da vida diária

1 - Risco leve de limitações nas atividades da vida diária

2 - Risco moderado de limitações permanentes e/ou significativas nas atividades da vida diária

3 - Risco elevado de complicações físicas com sérios déficits funcionais permanentes e/ou morte

\section{PSICOLÓGICO}

\section{Barreiras de Enfrentamento (HP1) (Histórico)}

Explicação

0 - Capacidade de manejar o estresse, tal como pela procura de apoio ou passatempos

1 - Habilidades restritas de enfrentamento, tais como necessidade de controle, negação da doença, ou irritabilidade

2 - Habilidades insuficientes de enfrentamento, tais como queixas não pertinentes 
ou abuso de substâncias, porém sem sérios impactos na condição clínica, saúde mental, ou situação social

3 - Habilidades mínimas de enfrentamento, manifestadas por comportamentos destrutivos, tais como dependência de substâncias, doença psiquiátrica, automutilação, ou tentativa de suicídio

\section{Disfunção Psiquiátrica (HP2) (Histórico)}

Explicação

0 - Nenhuma disfunção psiquiátrica

1 - Disfunção psiquiátrica sem efeitos claros na funcionalidade diária

2 - Disfunção psiquiátrica com efeitos claros na funcionalidade diária

3 - Hospitalização(ões) psiquiátrica(s) e/ou efeitos permanentes na funcionalidade diária

\section{Resistência ao Tratamento (CP1) (Estado Atual)}

Explicação

0 - Interessado em receber tratamento e disposto a cooperar ativamente

1 - Alguma ambivalência, apesar de disposto a cooperar com o tratamento

2 - Resistência considerável, tal como não adesão com hostilidade ou indiferença com relação aos profissionais de saúde e/ou tratamentos

3 - Resistência ativa ao cuidado médico

\section{Sintomas Psiquiátricos (CP2) (Estado Atual)}

Explicação

0 - Sem sintomas psiquiátricos

1 - Sintomas psiquiátricos leves, tais como dificuldade de concentração ou tensão

2 - Sintomas psiquiátricos moderados, tais como ansiedade, depressão ou comprometimento cognitivo leve

3 - Sintomas psiquiátricos graves e/ou distúrbios comportamentais, tais como violência, dano de auto agressividade, delirium, psicose, ou mania

\section{Ameaça à Saúde Mental (VP) (Vulnerabilidades)}

Explicação

0 - Sem risco de transtorno psiquiátrico

1 - Risco leve de sintomas psiquiátricos, tais como estresse, ansiedade, tristeza, abuso de substância ou transtorno cognitivo; risco leve de resistência ao tratamento (ambivalência)

2 - Risco moderado de transtorno psiquiátrico, necessitando de cuidado psiquiátrico; risco moderado de resistência ao tratamento

3 - Risco grave de transtorno psiquiátrico, necessitando de visitas frequentes ao serviço de emergência e/ou admissões hospitalares; risco de recusa ao tratamento devido a transtornos psiquiátricos sérios

\section{SOCIAL}

\section{Problemas relacionados ao Trabalho e Lazer (HS1) (Histórico)}

Explicação

0 - Trabalho/ ocupação (incluindo serviço doméstico, aposentadoria, estudos) e tem atividades de lazer

1 - Trabalho/ ocupação (incluindo serviço doméstico, aposentadoria, estudos) e sem atividades de lazer

2 - Atualmente desempregado e pelo menos 6 meses com atividades de lazer

3 - Atualmente desempregado e pelo menos 6 meses sem atividades de lazer

Situação Social (HS2) (Histórico)

\section{Explicação}


0 - Sem ruptura social

1 - Dificuldade de interação social leve

2 - Dificuldade de interação social moderada, tal como incapacidade de iniciar ou manter relações sociais

3 - Dificuldade de interação social grave, tal como envolvimento em relações sociais conflitivas ou isolamento social

\section{Condições no Domicílio (CS1) (Estado Atual)}

Explicação

0 - Domicílio estável; totalmente capaz de viver independentemente

1 - Domicílio estável com ajuda de outros, por exemplo, família, cuidador domiciliar, ou institucional

2 - Domicílio instável, por exemplo, sem apoio em casa ou vivendo em um abrigo; é necessária mudança da situação de vida atual

3 - Sem domicílio atual satisfatório, por exemplo, moradia transitória ou ambiente perigoso; é necessária mudança imediata

\section{Rede de Apoio Social Precária (CS2) (Estado Atual)}

Explicação

0 - Suporte prontamente disponível de familiares, amigos, e/ou conhecidos, tais como colegas de trabalho, em todos os momentos

1 - Suporte disponível da família, amigos, e/ou conhecidos, tais como colegas de trabalho, porém inconstante

2 - Suporte limitado da família, amigos, e/ou conhecidos, tais como colegas de trabalho

3 - Sem nenhum suporte da família, amigos, e/ou conhecidos, tais como colegas de trabalho

\section{Vulnerabilidade Social (VS) (Vulnerabilidades)}

Explicações

0 - Sem risco de mudanças na situação de vida; suporte social e integração adequados

1 - Sem risco de mudanças na situação de vida, mas são necessários maior suporte social e integração, por exemplo, assistência domiciliária

2 - Risco de admissão temporária ou permanente em instituição/ institucionalização no futuro previsível

3 - Necessidade imediata de admissão temporária ou permanente em instituição agora

\section{SISTEMA DE SAÚDE}

\section{Acesso ao Cuidado (HHS1) (Histórico)}

\section{Explicação}

0 - Acesso adequado ao cuidado

1 - Alguma limitação no acesso ao cuidado devido a problemas do sistema de saúde/ plano de saúde, razões geográficas, linguagem, ou barreiras culturais

2 - Dificuldades no acesso ao cuidado devido a problemas do sistema de saúde/ plano de saúde, razões geográficas, linguagem, ou barreiras culturais

3 - Sem acesso adequado ao cuidado devido a problemas do sistema de saúde/ plano de saúde, razões geográficas, linguagem, ou barreiras culturais 


\section{Experiência do Tratamento (HHS2) (Histórico)}

Explicação

0 - Sem problemas com profissionais de saúde

1 - Experiência negativa com profissionais de saúde (sua ou de parentes)

2 - Pedidos de segunda opinião ou mudança de médicos mais de uma vez; múltiplos profissionais; problema em manter profissional(is) estável(eis) e/ou de preferência

3 - Repetidos conflitos com médicos, visitas frequentes ao serviço de emergência, ou hospitalizações involuntárias; forçado a ficar com profissional indesejável devido a custo, opções de rede de profissionais, ou outras razões

\section{Organização do Cuidado (CHS1) (Estado Atual)}

\section{Explicação}

0 - Somente atenção primária em saúde

1 - Serviços especializados no cuidado geral da saúde ou saúde mental/ cuidado ao transtorno do uso de substâncias

2 - Ambos, cuidado geral da saúde e serviços de cuidado de saúde mental/ transtorno do uso de substâncias

3 - Hospitalização ou transferência do paciente, que se qualifica em cuidado ambulatorial no Nível secundário

\section{Coordenação do Cuidado (CHS2) (Estado Atual)}

Explicação

0 - Comunicação completa com o profissional e boa coordenação do cuidado

1 - Comunicação limitada com o profissional e coordenação do cuidado; médico da atenção primária coordena os serviços médicos e de saúde mental/ transtorno do uso de substâncias

2 - Comunicação precária e coordenação do cuidado entre os profissionais; sem médico da atenção primária de rotina

3 - Nenhuma comunicação e coordenação do cuidado entre os profissionais; serviço de emergência utilizado para atender as necessidades de saúde não emergenciais

Impedimentos do Sistema de Saúde/ Plano de Saúde (VHS) (Vulnerabilidades) Explicação

? - Desconhecidos

0 - Sem risco de impedimentos para coordenar cuidado físico e de saúde mental/ transtorno do uso de substâncias

1 - Risco leve de impedimentos ao cuidado, por exemplo, restrições do sistema de saúde/ plano de saúde, acesso distante ao serviço, comunicação limitada com os profissionais e/ou coordenação do cuidado

2 - Risco moderado de impedimentos ao cuidado, por exemplo, potencial perda do sistema de saúde/ plano de saúde, profissionais inconsistentes, barreiras de comunicação

3 - Risco elevado de impedimentos ao cuidado, por exemplo, pouco ou nenhum acesso ao sistema de saúde/ plano de saúde, resistência à comunicação e coordenação entre os profissionais 
Isso leva à seguinte Classificação de Avaliação da Complexidade:

\begin{tabular}{|c|c|c|c|}
\hline DOMÍNIOS & HISTÓRIA & ESTADO ATUAL & VULNERABILIDADE \\
\hline BIOLÓGICO & $\begin{array}{l}\text { Cronicidade } \\
\text { (0) (1) (2) (3) (HB1) } \\
\text { Dilema diagnóstico } \\
\begin{array}{ll}(0)(1)(2)(3) \quad(\mathrm{HB} 2)\end{array}\end{array}$ & $\begin{array}{l}\text { Gravidade sintomas } \\
(0)(1)(2)(3) \\
\text { Desafio } \\
\text { diagnóstico/Terapêutico } \\
(0)(1)(2)(3) \quad(C B 2)\end{array}$ & $\begin{array}{l}\text { Complicações e ameaça } \\
\text { à vida } \\
\begin{array}{ll}(0)(1)(2)(3)(?) \quad(V B)\end{array}\end{array}$ \\
\hline PSICOLÓGICO & $\begin{array}{l}\text { Barreiras de } \\
\text { enfrentamento } \\
\text { (0) (1) (2) (3) (HP1) } \\
\text { Disfunção psiquiátrica } \\
\text { (0) (1) (2) (3) (HP2) }\end{array}$ & $\begin{array}{l}\text { Resistência ao tratamento } \\
\text { (0) (1) (2) (3) } \\
\text { Sintomas psiquiátricos } \\
(0)(1)(2)(3) \quad(C P 2)\end{array}$ & $\begin{array}{l}\text { Ameaça à saúde mental } \\
(0)(1)(2)(3)\end{array}$ \\
\hline SOCIAL & $\begin{array}{l}\text { Problemas trabalho e } \\
\text { lazer } \\
\begin{array}{ll}(0)(1)(2)(3) & (\mathrm{HS} 1) \\
\text { Situação social } & \\
(0)(1)(2)(3) & (\mathrm{HS} 2)\end{array}\end{array}$ & \begin{tabular}{ll}
\multicolumn{3}{l}{ Condições no domicílio } \\
$(0)(1)(2)(3)$ & $(C S 1)$ \\
Rede de apoio social & \\
precária & \\
$(0)(1)(2)(3)$ & $(\mathrm{CS} 2)$
\end{tabular} & $\begin{array}{l}\text { Vulnerabilidade social } \\
\text { (0) (1) (2) (3) (VS) }\end{array}$ \\
\hline $\begin{array}{l}\text { SISTEMA DE } \\
\text { SAÚDE }\end{array}$ & $\begin{array}{l}\text { Acesso ao cuidado } \\
(0)(1)(2)(3) \quad(H H S 1) \\
\text { Experiência do } \\
\text { tratamento } \\
(0)(1)(2)(3) \quad(H H S 2)\end{array}$ & $\begin{array}{l}\text { Organização do cuidado } \\
(0)(1)(2)(3) \\
\text { Coordenação do cuidado } \\
\text { (0) (1) (2) (3) } \quad \text { (CHS2) }\end{array}$ & $\begin{array}{l}\text { Impedimentos do } \\
\text { sistema de saúde/ Plano } \\
\text { de saúde } \\
(0)(1)(2)(3)(?) \quad(\mathrm{VHS})\end{array}$ \\
\hline & & & \\
\hline
\end{tabular}


Annescos 
ANEXOS

\author{
ANEXO 1 \\ VERSÃO ORIGINAL DO MÉTODO INTERMED
}




\section{The leading questions [1-17] of the INTERMED - interview}

\section{Introduction}

As agreed, we will have this interview in order to better understand what your current complaints or illness mean for you and what is needed to better control your situation. Now that we know about your medical situation, I would like to get a better idea what kind of person you are and how are you dealing with your medical problems; this information will help to organize medical care, tailored to your specific individual needs. During the interview several topics will pass. It could well be that there are certain issues, which you really would like to elaborate on. In order to be able to formulate an appropriate treatment plan, it is necessary in our first conversation to have/create an overview of the problems. When needed, we can focus on such issues in the next phase. Do you understand and agree or do you have questions?

Consider whether the patient is capable of being interviewed

Good.

1. I will tell you what I know about the reason for your referral/admission and your current physical state. You should correct me when I am wrong. [Symptom severity/Impairment; Diagnostic challenge; Chronicity]

2. Now I would like to know how you feel physically? Does you physical condition have an impact on your physical functioning? [Symptom severity]

3. Now you have informed me how you physically feel, I would like to have some more information concerning physical illnesses and treatments in the past five years. [Chronicity]

4. Did doctors have any difficulties to find a diagnosis with the complaints/illnesses you had in the past 5 years? Have certain complaints not been resolved. Are currently diagnostic investigations in process for these complaints? [Diagnostic dilemma]

5. Who have been the caretaker -doctors, psychologists, nurses or social workers who are taking care for you? Do they all work in the same institution and are appointments coordinated? [Organization of Care]

6. Is there mutual communication between your caretakers to discuss and adjust your treatment? [Coordination of care]

7. Had there been conflicts with doctors during the past five years, which gave you a bad feeling, which might interfere with your trust in doctors? [Treatment experience]

8. Now, I would like to know if you are well insured? Have you ever had problems with your insurance? Is the distance to the institutions where you are treated appropriate or did you miss appointments due to the distance?

1. As far as I can see you might have a different cultural background. Do your providers take this into account? (Are there communicational problems due to impeded understanding of your language?) [Access]

9. Now I would like to change the subject and ask about the way you live. Do you have a job currently? What level of education did you achieve and did you get a diploma? [Job and leisure problems]

10. Are you a person who is able to leisure? What do you do to find some distraction? Do you have hobbies? [Job and leisure problems]

11. Can you tell me how you currently live? And in case of illness or handicap, is there anyone you can count on? [Residential stability; Poor social support] 
12. Now I would like to know what kind of person you are. Generally speaking, are you an easygoing and stable person? Are you someone who can get along well with other persons or are there sometimes conflicts? [Social dysfunction; Barriers to coping]

13. I would like to ask you about your smoking and drinking habits and their relation to the current problems? Do you use painkiller? Are you sometimes concerned that you might over-use these? [Barriers to coping]

14. How do you handle difficult situations? Is that a reason to use alcohol, tobacco or drugs? Are you inclined to postpone decisions? Would it lead to become talkative or silent? [Barriers to coping]

15. Now I would like to know how you felt emotionally during the last week? I mean tense, anxious, low or forgetful? [Psychiatric symptoms]

16. Have you ever seen a psychiatrist in your life or have there been periods that you have been anxious, depressed or confused? [Psychiatric dysfunction]

17. Finally, I would like to know how you follow your doctor's recommendations. Are you a person who is generally speaking inclined to do what doctors say? [Resistance to treatment]

Now, coming to the end of the interview, I would like to emphasize that you have provided most useful information. I will elaborate it and discuss it with the team. We can discuss it during our next appointment.

I finally want to know how you have experienced this interview? Do you think that this will be helpful information to treat you well or is there important information we miss? Did you think it was inappropriate to ask you this? Thanks for your patients and your willingness to provide information. If you want to I will summarize the main points raised.

The variables and their clinical anchor points

BIOLOGICAL

Chronicity (HB1) (History)

Explanation

0 - Less than 3 months of physical dysfunction

1 - More than 3 months of physical dysfunction or several periods of less than 3 months

2 - A chronic disease

3 - Several chronic diseases

\section{Diagnostic Dilemma (HB2) (History)}

Explanation

0 - No periods of diagnostic complexity

1 - Diagnosis and etiology was clarified quickly

2 - Diagnostic dilemma solved but only with considerable diagnostic effort

3 - Diagnostic dilemma not solved despite considerable diagnostic efforts

\section{Symptom Severity/Impairment (CB1) (Current State)}

Explanation

0 - No symptoms or symptoms reversible without intensive medical efforts

1 - Mild but notable symptoms, which do not interfere with current functioning

2 - Moderate to severe symptoms, which interfere with current functioning

3 - Severe symptoms leading to inability to perform any functional activities 
Diagnostic/Therapeutic Challenge (CB2) (Current State)

Explanation

0 - Clear diagnoses and/or uncomplicated treatment

1 - Clear differential diagnoses and/or diagnosis expected with clear treatments

2 - Difficult to diagnose and treat, physical cause/origin and treatment expected

3 - Difficult to diagnose or treat, other issues than physical causes interfering with the diagnostic and therapeutic process

\section{Complications and Life Threat (VB) (Vulnerabilities)}

Explanation

? - Unknown

0 - No risk of limitations in activities of daily living

1 - Mild risk of limitations in activities of daily living

2 - Moderate risk of permanent and/or substantial limitations of activities in daily living

3 - Severe risk of physical complications with serious permanent functional deficits and/or dying

\section{PSYCHOLOGICAL}

\section{Barriers to Coping (HP1) (History)}

Explanation

0 - Ability to manage stress, such as through support seeking or hobbies

1 - Restricted coping skills, such as need of control, illness denial, or irritability

2 - Impaired coping skills, such as non-productive complaining or substance abuse but without serious impact on medical condition, mental health, or social situation

3 - Minimal coping skills, manifest by destructive behaviors, such as substance dependence, psychiatric illness, self-mutilation, or attempted suicide

\section{Psychiatric Dysfunction (HP2) (History)}

Explanation

0 - No psychiatric dysfunction

1 - Psychiatric dysfunction without clear effects on daily function

2 - Psychiatric dysfunction with clear effects on daily function

3 - Psychiatric admission(s) and/or permanent effects on daily function

\section{Resistance to Treatment (CP1) (Current State)}

Explanation

0 - Interested in receiving treatment and willing to cooperate actively

1 - Some ambivalence though willing to cooperate with treatment

2 - Considerable resistance, such as non-adherence with hostility or indifference towards health care professionals and/or treatments

3 - Active resistance to medical care

\section{Psychiatric Symptoms (CP2) (Current State)}

Explanation

0 - No psychiatric symptoms

1 - Mild psychiatric symptoms, such as problems with concentration or feeling tense

2 - Moderate psychiatric symptoms, such as anxiety, depression or mild cognitive impairment

3 - Severe psychiatric symptoms and/or behavioral disturbances, such as violence, self-inflicted harm, delirium, psychosis, or mania 
Mental Health Threat (VP) (Vulnerabilities)

Explanation

0 - No risk of psychiatric disorder

1 - Mild risk of psychiatric symptoms, such as stress, anxiety, feeling blue, substance abuse or cognitive disturbance; mild risk of treatment resistance (ambivalence)

2 - Moderate risk of psychiatric disorder requiring psychiatric care; moderate risk of treatment resistance

3 - Severe risk of psychiatric disorder requiring frequent ER-visits and/or hospital admissions; risk of refusal of treatment for serious psychiatric disorder

\section{SOCIAL}

\section{Job and Leisure Problems (HS1) (History)}

\section{Explanation}

0 - A job (including housekeeping, retirement, studying) and having leisure activities

1 - A job (including housekeeping, retirement, studying) without leisure activities

2 - Unemployed now and for at least 6 month with leisure activities

3 - Unemployed now and for at least 6 month without leisure activities

\section{Social Dysfunction (HS2) (History)}

Explanation

0 - No social disruption

1 - Mild social dysfunction; interpersonal problems

2 - Moderate social dysfunction, such as inability to initiate or maintain social relations

3 - Severe social dysfunction, such as involvement in disruptive social relations or social isolation

\section{Residential Instability (CS1) (Current State)}

Explanation

0 - Stable housing; fully capable of independent living

1 - Stable housing with support of others, e.g. family, home care, or an institutional setting

2 - Unstable housing, e.g. no support at home or living in a shelter; change of current living situation is required

3 - No current satisfactory housing, e.g. transient housing or dangerous environment; immediate change is necessary

\section{Poor Social Support (CS2) (Current State)}

\section{Explanation}

0 - Assistance readily available from family, friends, and/or acquaintances, such as work colleagues, at all times

1 - Assistance available from family, friends, and/or acquaintances, such as work colleagues, but possible delays

2 - Limited assistance readily available from family, friends, and/or acquaintances, such as work colleagues

3 - No assistance readily available from family, friends, and/or acquaintances, such as work colleagues, at all times 
Social Vulnerability (VS) (Vulnerabilities)

Explanation

0 - No risk of changes in the living situation; adequate social support and integration

1 - No risk of changes in the living situation but additional social support and/or increased integration is needed, e.g. home health care

2 - Risk of need for temporary or permanent admission to facility/institution in the foreseeable future

3 - Risk of need for temporary or permanent admission to facility/institution now

\section{HEALTH SYSTEM}

\section{Access to Care (HHS1) (History)}

Explanation

0 - Adequate access to care

1 - Some limitation in access to care due to insurance problems, geographical reasons, language, or cultural barriers

2 - Difficulties in access to care due to insurance problems, geographical reasons, language, or cultural barriers

3 - No adequate access to care due to insurance problems, geographical reasons, language, or cultural barriers

\section{Treatment Experience (HHS2) (History)}

Explanation

0 - No problems with healthcare professionals

1 - Negative experience with healthcare professionals (self or relatives)

2 - Requests for second opinions or changing doctors more than once; multiple providers; trouble keeping consistent and/or preferred provider(s)

3 - Repeated conflicts with doctors, frequent ER-visits, or involuntary admissions; forced to stay with undesirable provider due to cost, provider network options, or other reasons

\section{Organization of Care (CHS1) (Current State)}

Explanation

0 - Primary care/General practitioner only

1 - Specialist services either in the general health care or mental health/SUD care

2 - Both general health care and MH/SUD care services

3 - Hospitalization or transfer from a hospital of patients, who qualify in ambulatory care on Level 2

\section{Coordination of Care (CHS2) (Current State)}

\section{Explanation}

0 - Complete practitioner communication and good coordination of care

1 - Limited practitioner communication and coordination of care; primary care physician coordinates medical and MH/SUD services

2 - Poor communication and coordination of care among practitioners; no routine primary care physician

3 - No communication and coordination of care among practitioners; primary ER use to meet non-emergent health needs 
Health System Impediments (VHS) (Vulnerabilities)

Explanation

? - Unknown

0 - No risk of impediments to coordinated physical and MH/SUD care

1 - Mild risk of impediments to care, e.g. insurance restrictions, distant service access, limited provider communication and/or care coordination

2 - Moderate risk of impediments to care, e.g. potential insurance loss, inconsistent practitioners, communication barriers

3 - Severe risk of impediments to care, e.g. little or no insurance, resistance to communication and coordination among providers

It leads to the following grid:

\section{History}

Chronicity

Diagnostic Dilemma

回

]
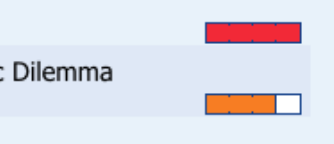

Symptom Severity/Impairment

Diagnostic/Therapeutic Challenge

re

Complications and Life Threat

a

Vulnerabilities

a.

Resistance to Treatment

Psychiatric Symptoms

$\square$

Mental Health Threat

Psychiatric Dysfunction

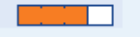

Residential Instability

Job and Leisure Problems

Social Dysfunction
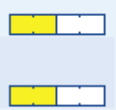

Poor Social Support

(6.

Organization of Care

Access to Care

Treatment Experience

단.

Coordination of Care

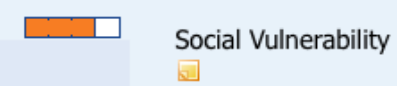

a

Health System Impediments

(a) 
ANEXO 2

AUTORIZAÇÃO DOS AUTORES DO INTERMED 


\section{AUTORIZAÇÃO DOS AUTORES DO INTERMED}

\section{Re: Solicitud de INTERMED}

Quinta-feira, 27 de Maio de 2010 10:17

De: "Elena Lobo Escolar"<elobo@unizar.es>

Para: Beatriz Gutierrez" <biagutierrez@yahoo.com.br>, biagutierrez@usp.br

Cc: fhuyse@mac.com, info@intermedfoundation.org

Dear Beatriz,

Referring your mails, I think you already know the INTERMED Foundation (IMF) webpage (http://www.intermedfoundation.org) where you can find and download for free the English version of the INTERMED ("Description of INTERMED method including the Complexity Assessment Grid v6"). I'll forward you next week the Spanish version. As you want to translate it into Portuguese you can use either of them, considering that the English version is the gold standard.

Although I (and Frits) will be assisting you in case of doubts, Frits has informed me about a Brazilian colleague who works in Canada as a consultant and who could be of help in the forward and backward translation of the instrument. We could consider the possibility ofcontacting her.

The INTERMED is for free use, and the proper references to be cited in the project/publications/etc are listed in the webpage.

Referring your last mail question about INTERMED as a management decision tool in Hospital management and the acceptance by hospital administrators, here in Spain we still have only used the INTERMED for research purposes. Frits Huyse can tell you of first-hand, his experience with the implementation of INTERMED into clinical practice in the Netherlands, as well as he knows the USA experience. Both can illustrate better the interest of health care administrators in the instrument.

Recently, the IMF has signed a contract with a North American Health Care Company and has trained case managers to use the INTERMED on a large scale.

I hope this can orient a bit more your plans with the INTERMED.

We keep in touch.

Best regards,

Elena

Elena Lobo Escolar

Dpto. Medicina Preventiva y Salud PúblicaUniversidad de Zaragoza

976-761000(Ext.1761)elobo@unizar.es

Sexta-feira, 28 de Maio de 2010 11:02

De: "INTERMED Foundation" <info@intermedfoundation.org>

Para: "Beatriz Gutierrez" <biagutierrez@yahoo.com.br>

Cc: "Elena Lobo" <elenle@ hotmail.com>

Dear Beatriz

Good to hear of your interest and enthousiasm!

I will follow the actions decided upon with Elena Lobo and assist when needed.

Sincerely

Frits Huyse 
ANEXO 3

PARECER DO COMITÊ DE ÉTICA EM PESQUISA DO HOSPITAL DO CORAÇÃO 


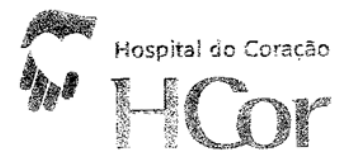

Asscrctacăe die Saratório sirie

CORITE DE ÉTICA EM PESQUISA DO HOSPITAL DO CORAÇ̧̃̃O

CEP/HCOr - 169/2011

\section{APROVAÇÃo}

O Comitê de Ética em Pesquisa - CEP/HCor, em sua reunião de 19/04/2011, APROVOU os documentos abaixo mencionados referentes ao protocolo de pesquisa $n^{\circ} 169 / 2011$ intitulado "Adaptação transcultural e validação do método INTERMED: avaliação biopsicossocial e de recursos de saúde visando o uso racional da estrutura hospitalar", sob responsabilidade de execução da pesquisadora Bernardete Weber.

Protocolo de Pesquisa: "Adaptação transcultural e validação do método INTERMED: avaliação biopsicossocial e de recursos de saúde visando o uso racional da estrutura hospitalar"

Termo de Consentimento Livre e Esclarecido (versão 1.0 de Abril de 2011)

o Comitê de Ética em Pesquisa do Hospital do Coração recomenda que seja consultado o médico referenciador do paciente e que este dê anuência por escrito para que o seu paciente seja recrutado para a pesquisa aprovada. É importante salientar que esta recomendação é válida tanto para médicos do corpo clínico como para médicos externos e não pertencentes ao corpo clínico do HCor.

Cabe ao pesquisador executante elaborar e apresentar ao Comitê de Ética em Pesquisa do Hospital do Coração - CEP/HCor, os relatórios parcial e final sobre a pesquisa, Resolução do Conselho Nacional de Saúde no 196, de 10.10.1996, inciso IX. 2, letra "c", nas seguintes datas: 19/10/2011, 19/04/2012 e a cada seis meses até o término no estudo.

CEP/HCor, 19 de abril de 2011

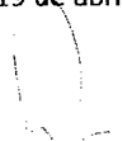

Prof. Dr. Alberto Duarte

Coordenador

Comitê de Ética em Pesquisa - CEP/HCor

CEP/Hcor - Comitê de Ética em Pesquisa do Hospital do Coração - Associação do Sanatório Sirio Rua Abilio Soares , $250-11^{\circ}$ andar - Paraiso, CEP 04005-000, Sáo Paulo. SP

Tel: (11)3886-4688 Fax: 3886-4689

e-mail: etica.pesquisa@hcor.com.br 


\begin{abstract}
ANEXO 4
PARECER DO COMITÊ DE ÉTICA EM PESQUISA DO HOSPITAL UNIVERSITÁRIO DA UNIVERSIDADE DE SÃO

PAULO
\end{abstract}


São Paulo, 28 de agosto de 2010.

$I l^{m o(a)} \cdot S^{r(a)}$

Dra. Beatriz Aparecida Ozello Gutierrez

Escola de Artes, Ciências e Humanidades - EACH

UNIVERSIDADE DE SÃO PAULO

REFERENTE: Projeto de Pesquisa "Gerenciamento de leitos em hospital de ensino" - Pesquisador(a) Responsável: Dra. Beatriz Aparecida Ozello Gutierrez - Registro CEP-HU/USP: 973/10 - SISNEP CAAE: 0102.0.000.198-10.

Prezado(a) Senhor(a)

O Comitê de Ética em Pesquisa do Hospital Universitário da Universidade de São Paulo, em reunião ordinária realizada no dia 27 de agosto de 2010, analisou o Projeto de Pesquisa acima citado, considerando-o como APROVADO, bem como o seu Termo de Consentimento Livre e Esclarecido.

Lembramos que cabe ao pesquisador elaborar e apresentar a este Comitê, relatórios anuais (parciais ou final, em função da duração da pesquisa), de acordo com a Resolução n 196/96 do Conselho Nacional de Saúde, inciso IX.2, letra "c".

O primeiro relatório está previsto para 27 de agosto de 2011.

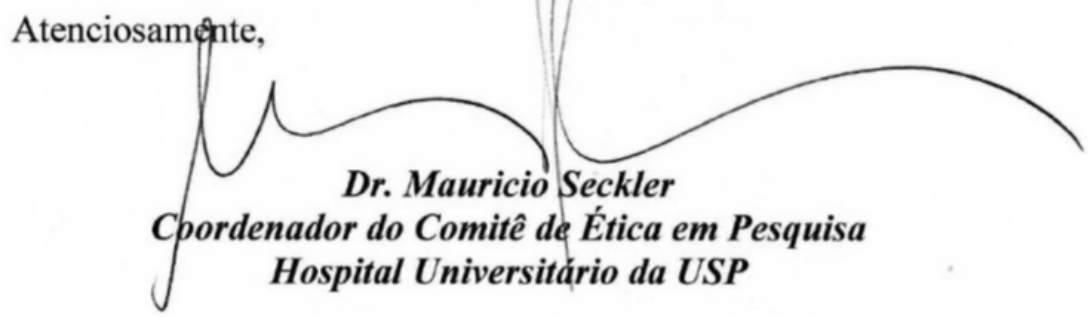


ANEXO 5

PARECER DO COMITÊ DE ÉTICA EM PESQUISA DO HOSPITAL MUNICIPAL DR. MOYSÉS DEUTSCH 
ALBERT EINSTEIN

INSTITUTO ISRAELITA DE ENSINO E PESQUISA

São Paulo, 19 de outubro de 2011.

Processo CEP/Einstein $n^{\circ}$. 11/1671

Projeto de Grupo III

Título: "Adaptação transcultural e validação do método INTERMED: avaliaçăo biopsicossocial e de recursos humanos de saúde visando o uso racional da estrutura hospitalar." Protocolo versåo 2 de abril de 2011; Termo de Consentimento Livre e Esclarecido versăo 1 de abril de 2011.

Pesquisadora Responsável: Ana Cristina Rosseti

Instituiçăo proponente: Hospital do Coraçăo - HCOR

Instituições co-participantes: HU da USP e Hospital Municipal Moysés Deutsch

Patrocinador: HCor e Programa de Apoio ao Desenvolvimento Institucional do SUS do Ministério da Saúde.

\section{PARECER CEP/EINSTEIN Nº 319/2011}

O Comitê de Ética em Pesquisa do Hospital Israelita Albert Einstein no cumprimento de suas atribuiçరes, analisou e aprovou o projeto de pesquisa supracitado, bem como o Termo de Consentimento Livre e Esclarecido.

Aproveitamos a oportunidade para orientar a pesquisadora sobre os seguintes itens:

- O pesquisador deve desenvolver a pesquisa conforme delineada no protocolo aprovado $\theta$ descontinuar o estudo somente após análise das razóes da descontinuidade pelo CEP que o aprovou (Res. CNS 196 Item III. 3.z)

- De acordo com a Carta Circular $n^{\circ}$ 003/2011 CONEP/CNS de 21 de março de 2011, o sujeito de pesquisa ou seu representante, quando for o caso, deverá rubricar todas as folhas do Termo de Consentimento Livre e Esclarecido apondo sua assinatura na última página do referido termo. O pesquisador responsável deverá da mesma forma, rubricar todas as folhas do Termo de Consentimento Livre e Esclarecido apondo sua assinatura na última página do referido termo.

- O CEP deve ser informado de todos os fatos relevantes que alterem o curso normal do estudo (Res. CNS 96 item V.4).

- Eventuals modificaçठos ou emendas ao protocolo devem ser apresentadas ao CEP de forma clara e sucinta, identificando a parte do protocolo a ser modificada e suas justificativas.

- Ao pesquisador cabe elaborar e apresentar ao CEP/Einstein os relatórios semestrais o o relatório final (Res. CNS 198, IX.2.C), inicialmente em 19 de abril de 2012, conforme o modelo padronizado disponivel em http://apps.einstein.br/forms/pesquisa/form-padr.htm/ 